\title{
Understanding the durability of advanced fibre-reinforced polymer (FRP) composites for structural applications
}

K. BENZARTI, Université Paris-Est/IFSTTAR, France and

X. COLIN, Arts et Métiers ParisTech, France

\begin{abstract}
Fibre-reinforced polymer (FRP) composites are increasingly being used in the field of civil engineering, either for the rehabilitation/retrofitting of existing infrastructures or for the construction of new structural elements. However, such applications are still recent and there are still unresolved questions regarding the long-term durability of FRP reinforcements or structural elements under service conditions, and their behaviour under accidental fire events as well. In this chapter, it is proposed to highlight the basic mechanisms involved in the environmental degradation of FRP composites, with a large emphasis on ageing mechanisms of the polymer matrix and their consequences on the mechanical properties. The last section is specifically devoted to the fire behaviour of polymer composites and also recalls existing fire-proofing solutions.
\end{abstract}

Key words: FRP composites, matrix, reinforcing fibres, interphase, ageing mechanisms, degradation, mechanical properties, fire behaviour.

\subsection{Introduction}

Composite materials have been used successfully for many decades in various industrial sectors (aerospace, automotive, rail, defence, telecommunication, sport and leisure, etc.). Their outstanding properties combined with decreasing production costs continue to drive a growing demand for their use in place of traditional materials such as metal. Key advantages of composites over metal alloys include low density, high specific stiffness and strength, good fatigue life, excellent corrosion resistance, good thermal insulation and low thermal expansion. There has been extensive research to adapt raw materials and manufacturing processes to meet the durability requirements for these industrial applications.

The use of FRP composites in civil engineering and construction is more recent. When faced with increasing problems of ageing concrete infrastructure and traffic growth, civil engineers realized the potential of composite materials for strengthening structural components and started to develop practical applications in the 1980s. Good mechanical performance, resistance to 
corrosion, light weight and ease of installation have made these materials very attractive. Some of these applications (e.g. strengthening of concrete structures by externally bonded FRP systems) are now used routinely around the world and their effectiveness is well recognized. However, the long-term behaviour of FRP composites under service conditions still remains a crucial issue.

FRP materials used in civil infrastructure have a number of specific features compared with composites designed for other sectors:

- They may differ in terms of manufacturing process (manual operations are often necessary for on-site implementation) and in terms of constitutive materials (cold-curing thermoset matrices/adhesives are often used during on-site implementation). These factors can affect the overall quality of the FRP material and hence its durability.

- They can be exposed to various and complex environments during service life, such as harsh and changing weather conditions or contact with alkaline media, with possible additional sustained mechanical loads. Such environments play a key role in the mechanisms and kinetics of ageing and consequently in changes in material properties.

- The lifespan of FRPs is ideally expected to match the usual design life of civil infrastructure, typically in the range 50-100 years or more. However, predicting durability over such long periods of time is a difficult challenge, and traditional methods based on accelerated ageing tests may not be representative of actual environmental ageing conditions.

- There is still a lack of well-developed standard testing methods and experimental procedures for FRP materials used in construction.

These specific features may explain why only limited information can be found on the durability of FRP composites in civil engineering and, when available, data from different studies can be contradictory. As a result, concern about durability remains a barrier to the widespread acceptance of FRP materials in construction. Another critical concern is the behaviour of FRP materials or structures in the case of fire. These materials are very vulnerable to fire and their combustion may produce large amounts of toxic gases which are a direct threat to life. Civil engineers should take this issue into account when choosing materials used in FRP composites, and should implement adequate fireproofing solutions.

This chapter begins by briefly describing the multiphase structure of FRP composites. The main applications of these composites in civil engineering are outlined in order to identify environmental factors which may induce physical/chemical changes in materials under normal service conditions. The following sections describe in more detail the various ageing mechanisms involved in the environmental degradation of FRP constituents (with a special focus on the polymer matrix), and the consequences of these degradation 
mechanisms on mechanical properties. Finally, the fire behaviour of polymer composites is discussed in a separate section at the end of the chapter.

\subsection{Structure and processing of fibre-reinforced polymer (FRP) composites}

Advanced polymer composites are heterogeneous materials resulting from the combination of different constituents, including high-performance fibres, a polymer matrix and various fillers and additives. Due to synergistic effects, polymer composites are expected to perform better at the macroscopic scale than the individual constituents taken separately. The reinforcing elements (fibres) determine the mechanical properties of the FRP composite (elastic modulus, strength, etc.) whereas the polymer matrix is the continuous phase that binds the fibres together, transfers loads to the fibres and protects them from abrasion and environmental degradation. The role of the interfaces between the different phases is also of paramount importance and a good level of adhesion is usually required to ensure both optimal load transfer and durability. Fillers and additives are also used to reduce the cost and confer specific properties (for instance toughness, flame resistance, etc.) to the FRP composite. When investigating the durability of a composite structure, it is usually necessary to take into account this multiphase structure as well as the manufacturing process used to combine the raw materials.

\subsubsection{Fibres}

Fibres are the dominant constituents of composite systems as they control the mechanical performance of the material (stiffness and strength) as well as other physical properties such as thermal and electrical conductivity. Key parameters are the fibre content (usually in the range 30-70 vol\%, depending on the manufacturing process) and the arrangement of the fibre network within the composite. The orientation of fibres (unidirectional, multidirectional or multiple configurations) is usually adapted for optimizing the load-carrying capacity of the composite structure.

FRP composites used in construction are mainly based on glass, carbon and aramid fibres. The suitability of these fibres for a specific application depends on the required mechanical performance, the cost and the required durability. Glass fibres are inexpensive, exhibit high tensile and compressive strength and present both good compatibility with conventional polymer matrices and good processability. However, their drawback is a low elastic modulus which restricts the range of applications, and their high sensitivity to hydrolysis when exposed to alkaline environments (in a concrete medium, for instance). Carbon fibres are more expensive, but also much stiffer and lighter than glass fibres. They are appropriate for applications requiring a 
high performance-to-weight ratio and are very popular in strengthening systems for civil infrastructure. They also show a very good resistance to environmental attack (e.g. UV radiation and moisture) and exhibit a good thermal stability up to $450^{\circ} \mathrm{C}$. Aramid fibres are less used than the previous types of reinforcements and show intermediate properties between glass and carbon fibres. Their main advantages are their low density (even lower than carbon) and excellent toughness. However, they are known to be sensitive to $\mathrm{UV}$ radiation and moisture.

\subsubsection{Polymer matrices}

Polymer matrices used in composite materials are either thermosetting systems or thermoplastics. Thermoset polymers are usually formulated from a resin, a curing agent and a catalyst or initiator. A solvent is also introduced to lower viscosity and improve fibre impregnation. The polymerization process involves irreversible chemical cross-linking reactions and produces a three-dimensional network of macromolecular chains which cannot be reversibly softened and has high temperature resistance. Physical and mechanical properties of thermoset networks are generally dependent upon the achieved cross-link density. In contrast, thermoplastic matrices are composed of long molecular chains that are only bonded together by weak van der Waals interactions. They can be processed in the melted state at elevated temperature, and become solid and retain their shape as they are cooled to room temperature.

Polymer matrices used in civil engineering are almost exclusively based on thermosetting systems, due to their good thermal stability, chemical resistance, low creep and relaxation properties and their better ability to impregnate the fibre reinforcements in comparison with thermoplastic matrices. Depending on the type of application and the aggressiveness of the surrounding environment, either unsaturated polyesters, vinylesters or epoxies are selected for the thermosetting matrix. Polyester resins are traditionally used with glass fibres to yield low-cost structural composite elements. These resins consist of low molecular weight unsaturated polyester chains dissolved in styrene. Polymerization of styrene forms cross-links across unsaturated sites of the polyester chains. These reactions are highly exothermic and the excessive heat generated may damage the final laminate. Other major drawbacks of unsaturated polyesters are substantial shrinkage, production of toxic vapours (styrene), and sensitivity to hydrolysis when exposed to alkaline environments (for instance in contact with concrete).

Vinylester resins differ from polyesters in that the unsaturation is located at the end of the molecule and not along the chain. They exhibit a much better resistance to hydrolysis and are stable in aqueous environments. They are thus preferred to unsaturated polyesters for specific applications requiring alkali resistance, and are commonly used in the composition of FRP reinforcing bars 
for concrete structures. In epoxy systems, cross-linking reactions generally involve polycondensation between a prepolymer containing reactive oxirane functions (diglycidyl ether of bisphenol-A is the most common) and a polyamine hardener. Due to their good wetting ability and adhesion to most building materials, epoxies are often used as adhesives for the bonding of external FRP reinforcements. In this case, cold-curing epoxies are usually chosen for the sake of practicality. Durability characteristics may be affected by the low glass transition temperature or an incomplete curing of these systems (Mays and Hutchinson, 1992; Benzarti et al., 2011). For specific cases requiring composites with high thermal or fire resistance, advanced thermosetting matrices are also available on the market, such as phenolic resins manufactured from phenol and formaldehyde or bismaleimide resins prepared by reaction of maleic anhydride with primary amines. However, these materials are characterized by their brittleness and low toughness.

Thermoplastic matrices (mainly polypropylene, polyethylene, polyethylene teraphthalate) have sometimes been used with short-length glass fibres to produce FRPelements for civil structures. The attractiveness of these materials is due to the possibility of joining elements by heat welding, and theoretically, the possibility of recycling at the end of their service life. However, they are difficult to process and show lower strength and stiffness than thermoset composites, although they are tougher and more ductile (Bank, 2006).

\subsubsection{Interfacial areas}

Interfacial areas between the bulk matrix and the reinforcing fibres can be characterized by a gradient of physical and mechanical properties (Theocaris, 1987; Thomason, 1990; Vasquez et al., 1998). In this region, which is often called the interphase or mesophase, the structure and properties of the polymer network differ from those of the bulk matrix, due to several possible phenomena such as:

- diffusion of the fibre sizing (using silane coupling agents, lubricant agents like fatty acids or esters, etc.) into the polymer, that may induce a local plasticization of the matrix in the vicinity of the fibres,

- influence of the fibres on the polymerization kinetics of the matrix, due either to the presence of humidity at the fibre surface or to an alteration in thermal properties, and leading to a local variation of the cross-link density of the thermoset network (Amdouni, 1989),

- effects of residual thermal stresses due to the curing cycle (Theocaris, 1987).

The interphase has a significant effect on the mechanical properties and the failure mode of FRP composites (Benzarti et al., 2001). It may also affect long-term behaviour by controlling resistance to hydrothermal degradations, 
for instance (Chateauminois et al., 1994). An optimization of the fibre sizing composition may thus help to increase composite durability.

\subsubsection{Manufacturing processes}

There are various techniques for manufacturing polymer composites used in civil engineering. Each method involves a specific curing cycle (for instance, cure at ambient temperature or at elevated temperature, or a possible additional post-curing period) and a particular level of compaction. These parameters influence both the cross-link density of the polymer matrix and the structure of the composite material (distribution and alignment of the reinforcing fibres, volume fraction of voids, etc.), which can impact the long- term performances of FRP elements under service conditions. Manufacturing processes are of three types (Hollaway, 2001):

- Manual processes, such as the wet lay-up (fabricated in the factory or on site) and the pressure bag method. In these methods, the matrix is usually cold cured (at ambient temperature).

- Semi-automated processes, like resin injection and moulding of preimpregnated sheets (cured under pressure at elevated temperature).

- Fully automated methods, such as pultrusion (hot curing cycle), filament winding (cold or hot cured), injection moulding, etc.

Amongst these methods, pultrusion produces a broad range of thermoset FRP products (pipes, profiles, rods, plates, panels, box girders) with high fibre contents (up to $80 \mathrm{wt} \%$ ) and which can be directly used as structural elements or reinforcements in civil infrastructure. These products have a more consistent quality and compaction compared to FRP composites prepared by manual techniques, and are thus expected to behave better in the long term under normal or severe service conditions.

\subsection{Applications of FRP composites in civil engineering}

Structural applications of composite materials in civil engineering can be sorted into three main categories (Hollaway, 2010):

- Repair/strengthening of existing infrastructures with externally bonded FRP composites

- Internal reinforcement of concrete structures using FRP bars in replacement of steel gratings

- $\quad$ All-FRP structural members and all-FRP infrastructures. 


\subsubsection{External FRP strengthening systems}

The rehabilitation or upgrading of concrete infrastructures by externally bonded FRP composites is a well-established technique developed in the 1990s. It is considered to be an efficient and inexpensive alternative to the replacement of damaged or structurally deficient RC elements. This method covers several specific applications:

- Flexural or shear strengthening of concrete elements (beams) can be performed using the wet lay-up process, in which fabrics or sheets are saturated with a cold-curing epoxy resin and applied directly to the concrete surfaces, or using an epoxy adhesive or putty to bond a prefabricated FRP laminate (Fig. 12.1(a)). In the wet lay-up process, the dry fabric or sheet is impregnated on-site and the epoxy resin serves both as matrix for FRP laminate and as adhesive joint. Carbon fibres are most often chosen as they provide high stiffness and strength to the reinforcing laminates. This method of flexural and shear strengthening is also applicable for metal, timber or masonry structures.

- An alternative or complementary technique based on 'near surface mounted' reinforcements and called NSM consists in inserting FRP rods with an epoxy adhesive or cement grout into grooves cut in the concrete member (De Lorenzis and Teng, 2007).

- A specific technique for the seismic retrofit of concrete columns consists in wrapping these elements by resin-impregnated fabrics or sheets (Fig. 12.1(b)). Installation of composite jackets or rigid shells can also be used for the rehabilitation of severely corroded or degraded concrete piles, as they both restore the integrity of the structure and act as a protective barrier against further penetration of deleterious species (chloride, moisture, etc.).

For external strengthening applications, the durability of the adhesive bond between the FRP composite and the infrastructure member is a crucial issue, as any degradation of the bond properties may affect severely the effectiveness of the FRP reinforcement (Benzarti et al., 2011). Several guidelines for the design of externally bonded FRP reinforcements have been published worldwide, in particular ACI 440.2R-08 (2008) in the United States, JSCE recommendations (2001) in Japan, Italian and French guidelines in Europe (CNR, 2004; AFGC, 2011), etc.

\subsubsection{Internal reinforcement of concrete structures}

Passive FRP bars are increasingly being used as internal reinforcement for concrete structures (beams, slabs, columns, decks), especially in Canada and in the United States where the weather conditions can be very harsh. 


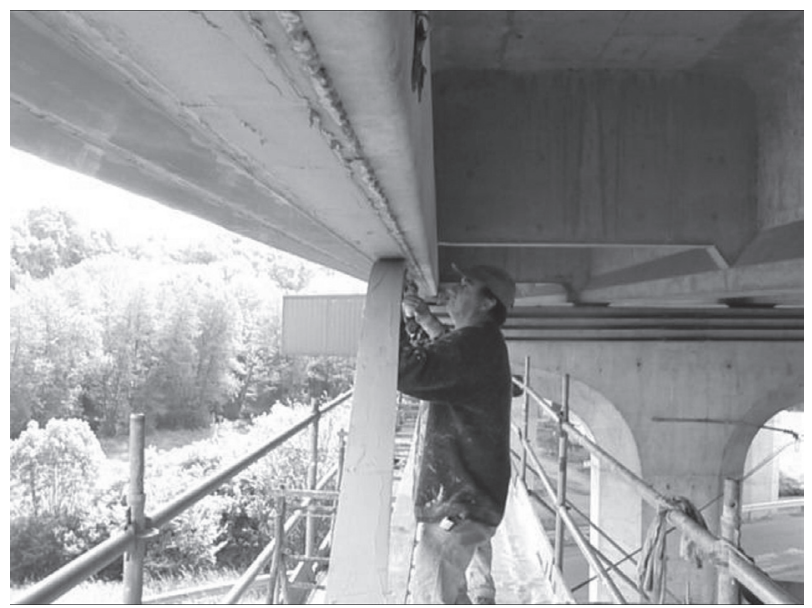

(a)

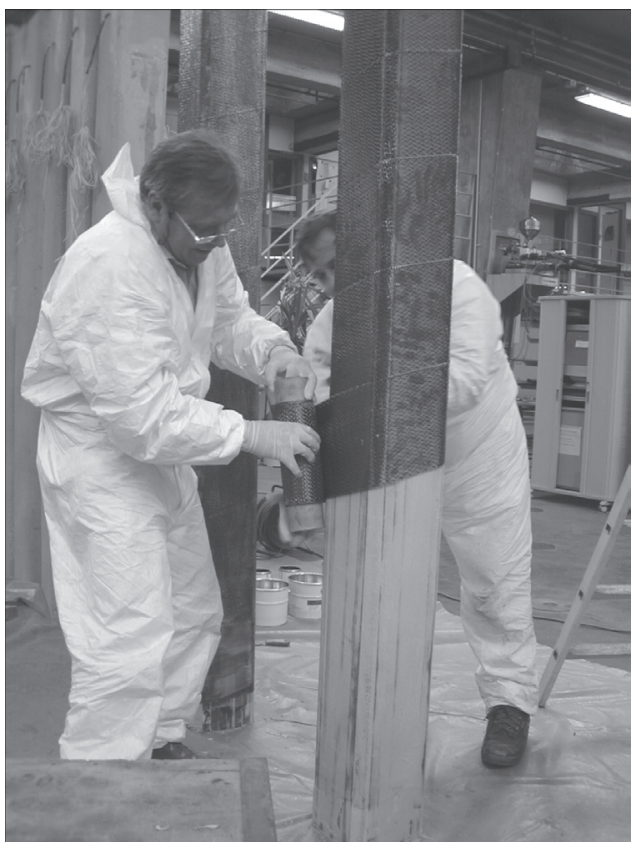

(b)

12.1 FRP external strengthening of concrete structures: (a) flexural strengthening of a concrete beam using carbon FRP laminates; (b) wrapping of a concrete column with resin-impregnated carbon fabrics.

A major advantage of these materials over traditional steel bars is that they are not subject to electrochemical corrosion, and the reinforced elements require very limited maintenance. Most FRP rebars used in civil engineering 
are based on vinylester/glass fibre composites, as these materials are less expensive than other high-performance FRPs and vinylester matrices show relatively good resistance to hydrothermal ageing and alkaline environments (Robert et al., 2009). However, their low stiffness compared to steel and their brittle behaviour must be taken into account in the design of the reinforced structures. Some of the main related guidelines are ACI Committee 440.1R06 (2006) in the United States, and the Canadian (CSA, 2002) and Japanese (JSCE, 1997) guidelines. Pre- or post-tensioned FRP tendons have also been used as effective reinforcements of concrete structural elements. In this case, there are still unresolved problems due to creep/relaxation phenomena which induce loss of pre-stress and limit the wide diffusion of this technique.

\subsubsection{All structural members}

The production of high-quality profiles at a competitive cost by the pultrusion process has opened new horizons for the development of all-FRP members, and even full composite infrastructures. Composite materials have been used, for instance, to construct various types of structural elements, such as cables for cable-stayed bridges (epoxy/carbon fibres), box girders and bridge deck panel systems (usually based on polyester/glass fibre composites), all-FRP piles, modular building systems, etc. As regards full composite structures, the first realizations were initially restricted to relatively small-scale structures and demonstrators like pedestrian bridges (cf. the Aberfeldy bridge in Scotland) and short-span FRP bridges, but larger projects are currently under study. A major issue is related to the connection of FRP structural members: the current practice of bolting generally leads to a large oversizing of the structural elements and requires very conservative design, whereas adhesive bonding would be more appropriate (it favours more uniform load transfer and lowers the stress concentrations) and may widen the design possibilities (Keller, 2006). However, in the latter case, the durability characteristics of the adhesive bond under combined mechanical and environmental loads become a critical issue.

\subsubsection{Durability concerns}

In the above-mentioned civil engineering applications, FRP materials and adhesive joints are exposed to weathering conditions and may also be in contact with alkaline concrete medium, whilst being simultaneously subjected to sustained load or fatigue cycles due to the infrastructure dead load or to traffic. In this context, durability of FRP composites has been defined by Karbhari et al. (2003) as "the ability of these materials to resist cracking, oxidation, chemical degradation, delamination, wear and/or the effects of foreign object damage for a specified period of time, under the appropriate 
load conditions, under specified environmental conditions'. Although FRP materials are not susceptible to electrochemical corrosion like steel, they may indeed deteriorate under the combined action of environmental factors related to outdoor exposure and physical factors, such as:

- Moisture diffusion from the surrounding medium (concrete pore solution, wet environment)

- Effect of an alkaline environment, if embedded in concrete (FRP rebars) or in contact with cementitious materials (FRP external strengthening)

- Effects of temperature variations during the manufacturing process or the installation procedure or under service conditions

- Impact of ultraviolet radiation (photo-oxidation)

- Effect of fire

- Influence of sustained mechanical loads (creep/relaxation) and fatigue cycles.

These factors may affect the properties of the polymer matrix, the fibres and the interfacial areas to differing degrees, depending on the chemical nature and volume fraction of these components in the FRP material, and on the manufacturing process of the composite as well (cf. Section 12.2.1). It is usually recognized that the matrix-related properties of the FRP composite are affected more than fibre-related characteristics. Information on ageing kinetics and changes in properties are commonly obtained from field testing or from laboratory-accelerated ageing tests (Karbhari, 2007; Hollaway, 2010). Significant data have been collected during the two last decades. These are sometimes contradictory due to the broad range of FRP products tested and the various ageing procedures and characterization methods involved.

To account for the material evolutions, guidelines dedicated to the external or internal reinforcements of concrete structures using FRP composites usually introduce substantial durability parameters (reduction factors on FRP tensile properties and on shear characteristics of FRP/concrete bonded interfaces, creep stress levels and fatigue limits); see, for instance, ACI 440.2R-08 (2008) and ACI 440.1R-06 (2006). However, further research is still needed to refine the design codes and better calibrate the durability reduction factors taking into account synergistic effects between various environmental factors.

The next sections do not review the various durability studies available in the literature, since there are recent reviews by Karbhari (2007) and Benmokrane et al. (2006). Instead they assess the main environmental ageing mechanisms involved in the degradation of FRP components (especially polymer matrices, but also reinforcing fibres) under normal service conditions, as well as their consequences on the mechanical properties of the overall composite. The influence of creep and fatigue loading will not be discussed in this chapter. 


\subsection{Physical ageing: mechanisms and stabilization techniques}

Physical ageing can result from the spatial reorganization of polymer chains or segments (relaxation of enthalpy, volume, orientation or stress; crystallization; etc.), transport phenomena (penetration of a solvent, migration of additives) and superficial phenomena (e.g. cracking in a tension-active medium).

\subsubsection{Structural reorganization}

Transition from liquid to glass and crystallization are both phenomena responsible for polymer solidification at the end of a processing operation. Since they are kinetic phenomena, they lead to an out-of-equilibrium thermodynamic state: glassy polymers present an excess of unstable conformations and free volume; semi-crystalline polymers are not totally crystallized, their melting point being largely lower (usually some dozens of degrees) than the equilibrium value.

If, in their use conditions, polymers are subjected to a residual molecular mobility ( $\beta$ motions in glassy polymers, $\alpha$ motions in the rubbery amorphous phase of semi-crystalline polymers), they will undergo a molecular reorganization towards the thermodynamic equilibrium, characterized by:

- a compaction of polymer chains or segments, and a loss in enthalpy;

- an increase in yield stress;

- a decrease in creep compliance.

The variation against time of creep compliance, $J(t)$, has been the subject of significant research, in particular in the case of organic glasses (Struik, 1978). As an example, the general shape of creep curves of samples aged for three different durations: $t_{\mathrm{a}}, 10 \times t_{\mathrm{a}}$ and $100 \times t_{\mathrm{a}}$, is presented in Fig. 12.2.

The shift factor of creep curves along the logarithmic scale of time, defined by $a_{\mathrm{c}}=\log \left(t_{1 \mathrm{c}} / t_{2 \mathrm{c}}\right)$, and corresponding to a variation $a_{\mathrm{a}}=\log \left(t_{1 \mathrm{a}} / t_{2 \mathrm{a}}\right)$ in ageing time, is such that $a_{\mathrm{a}} / a_{\mathrm{c}} \approx 1$. In other words, one decade increase in ageing time leads to about one decade increase in the creep characteristic time. This is a general trend of the physical ageing by structural relaxation observed for polymers or molecular organic materials (glucose), as well as for granular solids like sand, or emulsions.

The decrease in creep compliance (i.e. increase in Young's modulus), as well as the increase in yield stress, can be viewed as advantages for many industrial applications. Unfortunately, these changes are counterbalanced by a catastrophic decrease in ductility/toughness, as schematized in Fig. 12.3. Thus, the consequence of structural relaxation can be understood as an increase in the polymer brittleness.

The increase in yield stress (typically, up to $30 \%$ of its initial value 


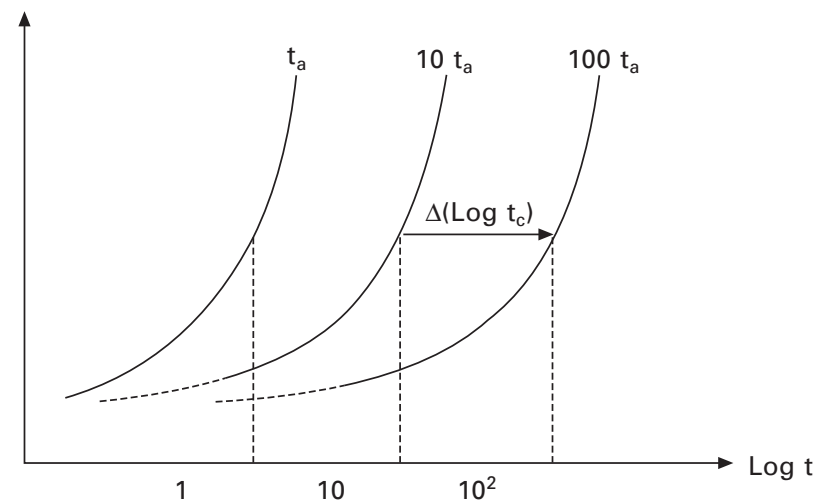

12.2 Creep curves (in a log-log scale) of samples aged in their glassy state during $t_{\mathrm{a}}, 10 \times t_{\mathrm{a}}$ and $100 \times t_{\mathrm{a}}$.

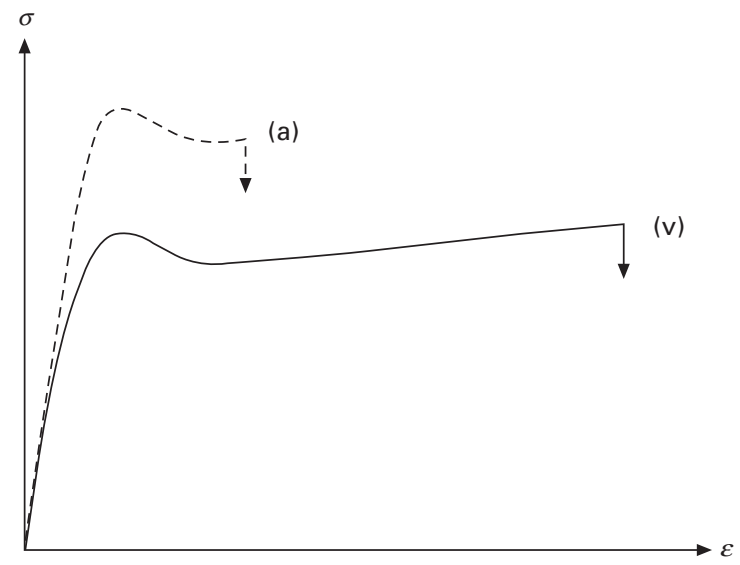

12.3 Shape of stress $(\sigma)$ vs. strain $(\varepsilon)$ curves before (v) and after (a) structural relaxation. Vertical arrows symbolize sample failure.

for a polycarbonate (PC)), the loss in ductility without any variation of the molecular weight distribution, plus the appearance of an endothermic peak close to the glass transition temperature $\left(T_{\mathrm{g}}\right)$ (Fig. 12.4) in differential scanning calorimetry (DSC) thermograms allow one to unambiguously identify the structural relaxation from any other type of physical ageing in amorphous glassy polymers. Another direct effect of the decrease in free volume induced by structural relaxation is about one decade decrease in the diffusion coefficient of gases in amorphous polymers (Tiemblo et al., 2001). 


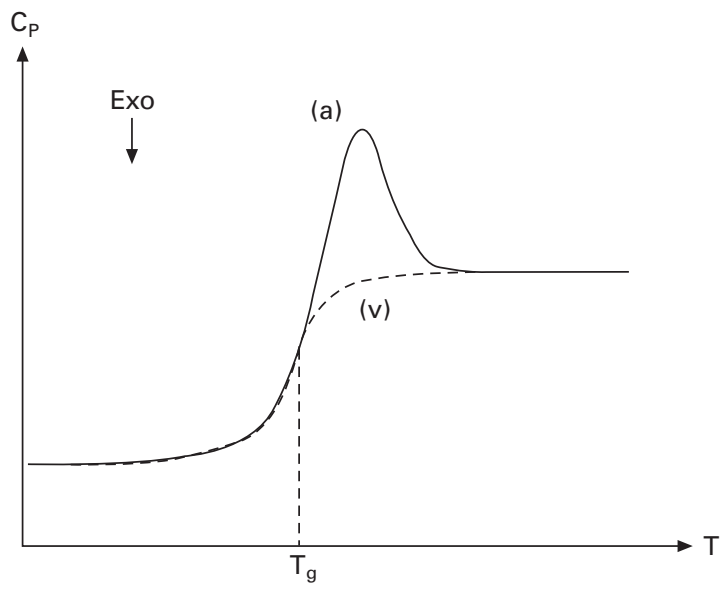

12.4 Shape of DSC thermograms around the glass transition temperature $\left(T_{\mathrm{g}}\right)$ before $(\mathrm{v})$ and after $(\mathrm{a})$ structural relaxation.

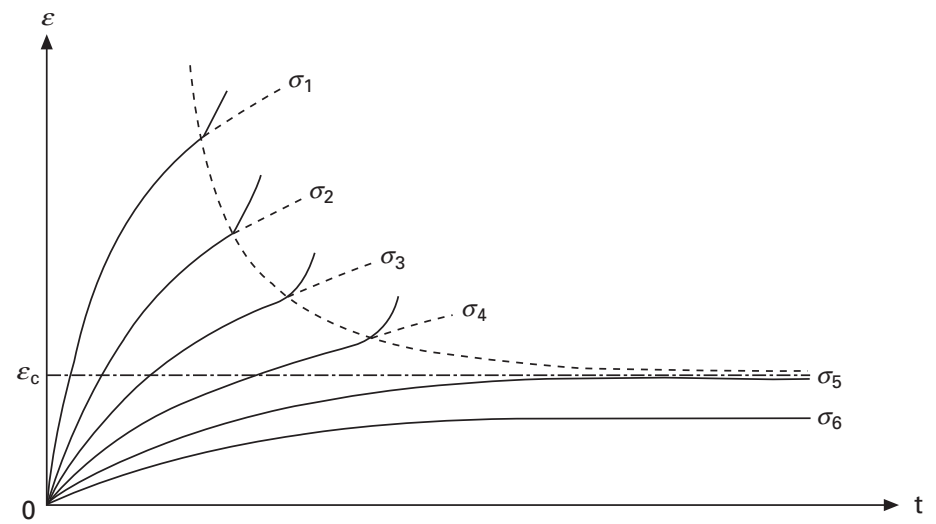

12.5 Shape of creep curves (time variation of strain) for different stress levels $\left(\sigma_{1}>\sigma_{2}>\sigma_{3}\right.$, etc.) in the presence of a solvent. Black points indicate the appearance of damage. Their envelope follows a horizontal asymptote for $\varepsilon=\varepsilon_{\mathrm{C}}$.

\subsubsection{Solvent absorption}

Solvents plasticize polymers and thus lead to a decrease in $T_{\mathrm{g}}$ and yield stress (if the polymer is initially ductile). However, the most significant effects, in practice, are observed when the polymer is subjected to a mechanical loading. In this case, plasticization favours damage, in particular by crazing. As an example, let us consider a creep test during which damage is detected by an optical technique. The resulting behaviour can be schematized by Fig. 12.5 . 
One can see that there is a critical strain $\varepsilon_{\mathrm{C}}$ below which the material does not damage. The value of $\varepsilon_{\mathrm{C}}$ is a function of the polymer-solvent couple. In simplest cases, for moderately polar polymers such as poly $(2,6-$ dimethyl oxyphenylene) (PPO) (Bernier and Kambour, 1968), $\varepsilon_{\mathrm{C}}$ depends on the solvent solubility parameter as shown in Fig. 12.6. The dashed zone corresponds to values of $\varepsilon_{\mathrm{C}}$ determined in air. In the case of polar polymers, e.g. poly(methyl methacrylate) (PMMA), the behaviour can be more complex: the curve $\varepsilon_{\mathrm{C}}=f\left(\delta_{\mathrm{S}}\right)$ can exhibit several minima.

Let us remember that some peculiar vapours and gases (e.g. water and carbon dioxide) can play an important role in physical ageing. Moreover, plasticizers can migrate from one polymer to another and induce damage under mechanical loading. In components of complex geometries using FRP composites, solvent vapours can create residual stresses by generating localized damage.

The penetration of solvents into a polymer leads to swelling, but also to stress gradients induced by hindered swelling during the transient regime of diffusion. Numerous problems of damage of FRP structures induced by water diffusion have been reported in the literature of the past half-century, in particular in aeronautics (McKague et al., 1975; Shen and Springer, 1976; Whitney and Browning, 1978).

\subsubsection{Loss of additives}

Most technical polymers contain additives like antioxidants, plasticizers or processing agents that do not form chemical bonds with macromolecules.

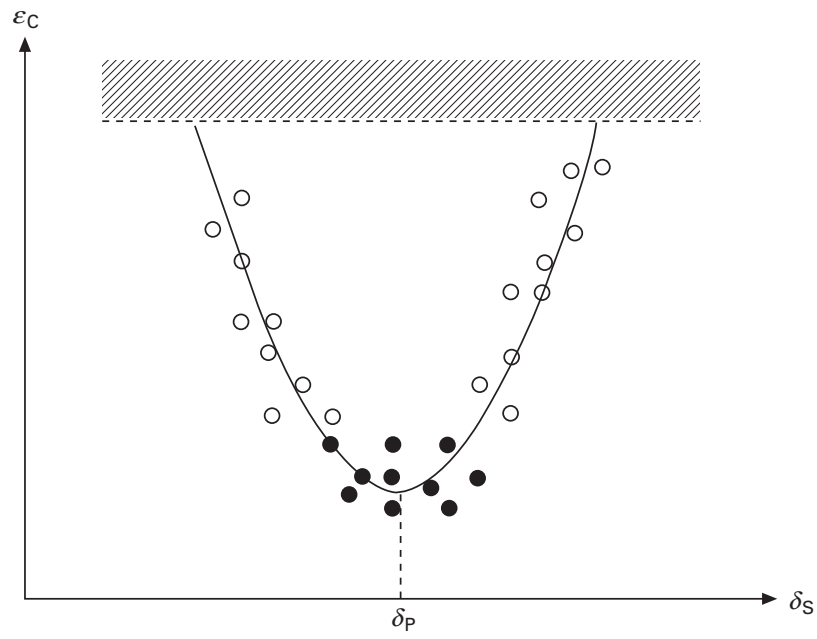

12.6 Shape of the variation, against a parameter of solvent solubility $\left(\delta_{\mathrm{S}}\right)$, of critical strain $\left(\varepsilon_{\mathrm{C}}\right)$ for PPO (Bernier and Kambour, 1968).

Minimum of curve corresponds to $\delta_{\mathrm{S}}=\delta_{\mathrm{P}}, \delta_{\mathrm{P}}$ being the parameter of polymer solubility. Legend: (०) crazes; $(\bullet)$ open cracks. 
These molecules can migrate within the host polymer with a rate depending on their size, their solubility and diffusivity among other parameters. The following discussion reviews the limiting steps in additive migration.

A polymer-additive mixture is out of thermodynamic equilibrium. Since the additive concentration in the environment is equal to zero, there is no equality between its chemical potentials in the environment and in the polymer. Additive molecules tend to migrate outside the polymer in order to reach an equilibrium. This migration is composed of two elementary steps (see Fig. 12.7):

1. The first step corresponds to the passing of some additive molecules into a medium of molecules close to the polymer surface, that is to say the crossing of the polymer-external medium interface. It is an additive evaporation in the case of an external gaseous medium (e.g. atmosphere), or an additive dissolution in the case of an external liquid medium (e.g. water),

2. The additive molecule exchange between the polymer and the external medium leads to a gradient of concentration in a region adjacent to the material surface. This latter is the 'driving force' for the diffusion of additive molecules from the core towards the sample surface. If diffusion obeys the second Fick's law, the diffusion distance $(\ell)$ is proportional to the square root of time $\left(t_{\mathrm{d}}\right)$ :

$$
t_{\mathrm{d}}=\frac{\ell^{2}}{D}
$$

where $D$ is the coefficient of additive diffusion into the polymer.

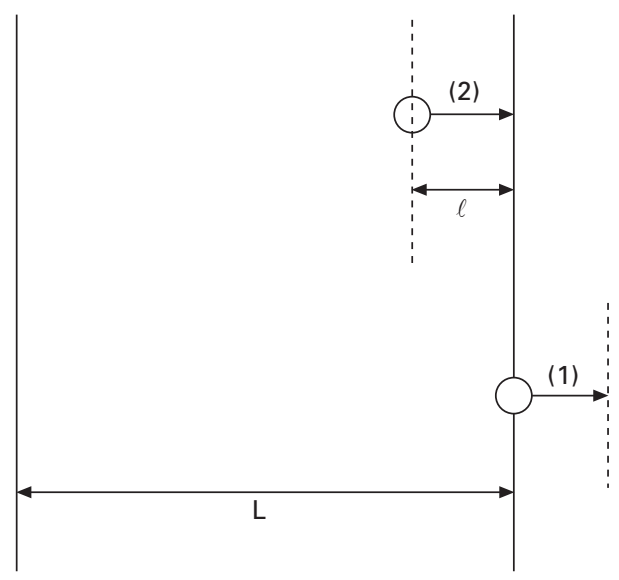

12.7 Schematization of a two-step migration of molecular species outside the polymer. $L$ is the sample thickness. 
For the sake of simplicity, we only consider here the Fickian diffusion process which may occur in the glassy state far from $T_{\mathrm{g}}$. But there are exceptions to this process and we invite the reader to refer to extensive literature reviews for the treatment of other transport modes of small molecules into polymers (Müller-Plathe, 1994; Masaro and Zhu, 1999; George and Thomas, 2001).

One can see from Equation [12.1] that $t_{\mathrm{d}}$ is an increasing function of the sample thickness $L$. As a result, one can distinguish two distinct kinetic regimes, depending on the relative predominance of the previous steps:

1. Regime 1: Evaporation (or dissolution)-controlled kinetics. In the case of thin samples (fibres, films, coatings) and high additive diffusivity, additive evaporation (step 1 in Fig. 12.7) is the slowest step and thus controls the global migration kinetics. Its concentration $C$ (into the polymer) decreases proportionally with time (see Fig. 12.8(a)):
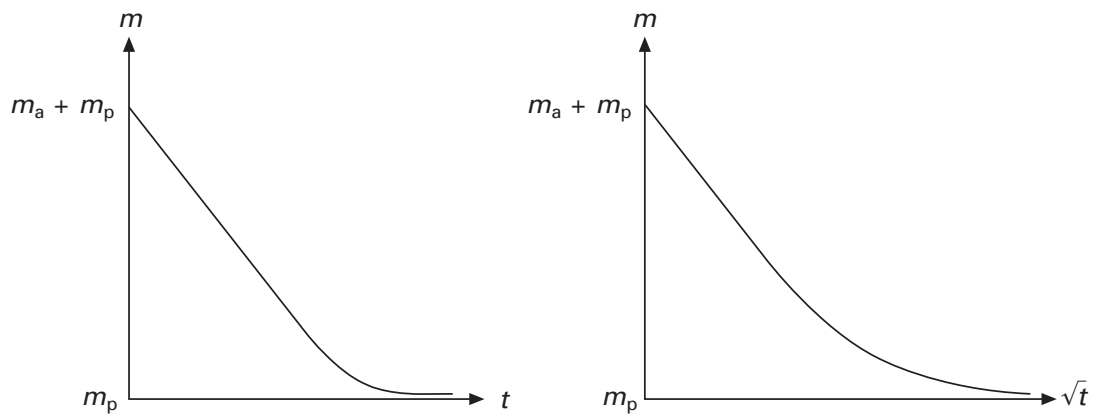

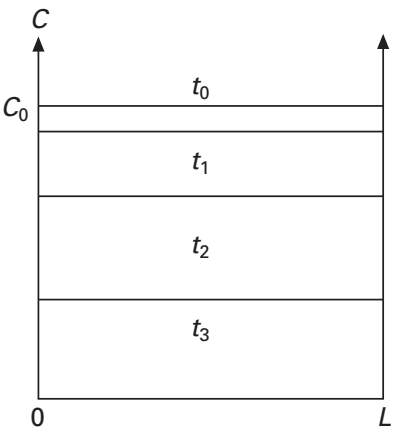

(a)

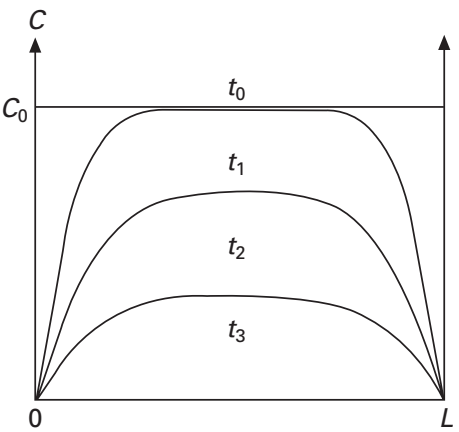

(b)

12.8 Additive migration governed by (a) evaporation and (b) diffusion. Top: shape of weight changes as a function of time. Sample weight $(m)$ corresponds to polymer weight $\left(m_{\mathrm{p}}\right)$ plus additive weight $\left(m_{\mathrm{a}}\right)$. Bottom: distribution, in the sample thickness, of additive concentration $(C)$ for different times of exposure: $t_{0}<t_{1}<t_{2}<t_{3}$. The initial concentration is $C=C_{0}$ (at $t=t_{0}$ ). 


$$
\frac{\mathrm{d} C}{\mathrm{~d} t}=-H
$$

The evaporation rate $H$ is a decreasing function of the additive molar mass and the cohesive energy density.

2. Regime 2: Diffusion-controlled kinetics. In the case of relatively thick samples (typically a few millimetres) and low additive diffusivity, diffusion in the bulk (step 2 in Fig. 12.7) controls the global migration kinetics. In the simplest case, the second Fick's law can be successfully applied. It is found that, in the early period of exposure, the sample weight $\mathrm{m}$ decreases proportionally with the square root of time (see Fig. 12.8(b)):

$$
\frac{\partial m}{\partial t}=D \frac{\partial^{2} m}{\partial z^{2}}
$$

where $z$ is the spatial coordinate in the sample thickness.

Thus, a gradient of the additive concentration appears in the sample thickness. Figure 12.8 shows the shape of the time variation of sample mass and concentration profile in the cases of evaporation- and diffusion-controlled additive migration.

If the additive molar mass is relatively high, its evaporation (or, more generally speaking, its crossing of the polymer-medium interface) is slow. Then, its concentration at the sample surface takes an intermediate value between $C_{0}$ and zero. It is thus necessary to take into account this variation in the boundary conditions for solving Equation [12.3]. If the additive concentration is high (in the case of plasticizers), it modifies the polymer properties. Then, its diffusivity becomes concentration dependent (an increasing function of the plasticizer concentration). Complications appear when a phase transition takes place during the additive migration. As an example, in case of diffusion of plasticizers in PVC, a dramatic increase in $T_{\mathrm{g}}$ occurs in regions of low plasticizer concentration. The resulting $T_{\mathrm{g}}$ profile can have the shape illustrated in Fig. 12.9.

One can see that, in the sample bulk, the polymer remains in a rubbery state. On the contrary, in the superficial layer of thickness $\ell_{\mathrm{a}}$, the polymer vitrifies and thus becomes brittle. Since the coefficient of plasticizer diffusion varies by at least one order of magnitude on both sides of the glass transition, the real gradient will display rather the shape of Fig. 12.10. In such cases, the diffusion 'front' is very abrupt and the sample weight decreases proportionally with time.

From the mechanical point of view, the loss in additives leads to a loss in the specific properties targeted by the introduction of these additives: long-term durability in the case of antioxidants, flexibility in the case of plasticizers, etc. If the additive concentration is high (in the case of plasticizers), their 


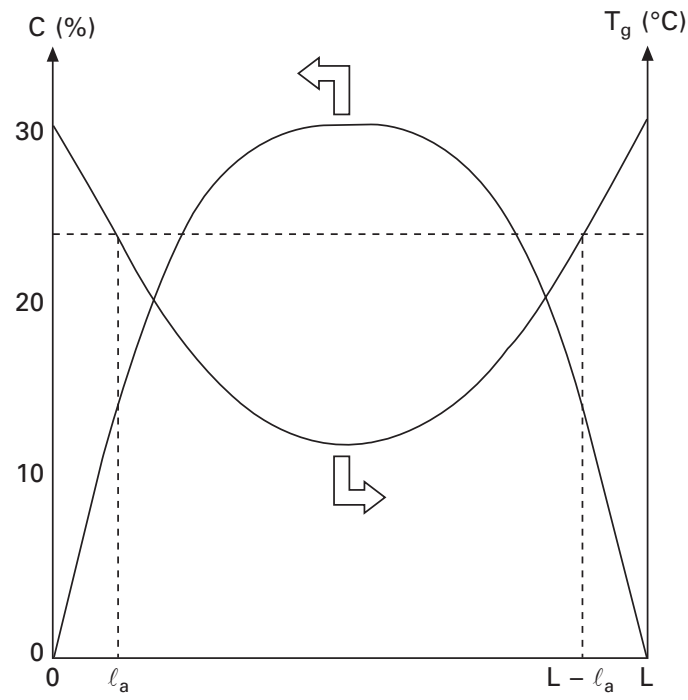

12.9 Shape of distribution, in the sample thickness, of plasticizer concentration ( $C$ expressed in weight fraction) and resulting local glass transition temperature $\left(T_{\mathrm{g}}\right)$ for a plasticized PVC aged at room temperature (Wypych, 2004).

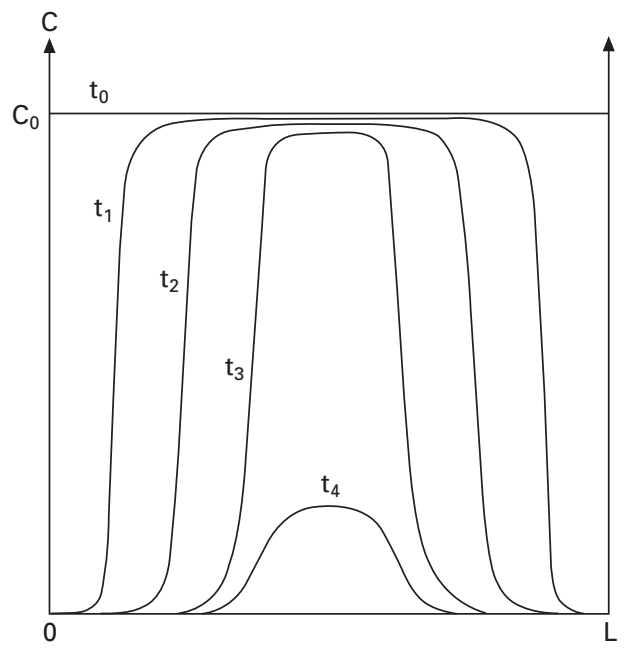

12.10 Correction of the hypothetical curve (right) presented in Fig. 12.8. Real shape of the distribution, in the sample thickness, of plasticizer concentration $(C)$ for different times of exposure: $t_{0}<t_{1}<t_{2}<t_{3}<t_{4}$.

loss induces a volume shrinkage (of the same order of magnitude than the weight loss, but slightly lower). This shrinkage can generate local stresses and thus lead to crack initiation in the brittle superficial layer. 


\subsubsection{Stabilization against physical ageing}

One can envisage ways of stabilizing polymer matrices against at least two types of physical ageing:

- After processing, annealing at a temperature below $T_{\mathrm{g}}$ for glassy polymers, or between $T_{\mathrm{g}}$ and $T_{\mathrm{m}}$ for semi-crystalline polymers, can be made to allow the polymer chains and segments to reorganize in a relatively short duration. However, such post-processing operation can be difficult to achieve in some industries, in particular in civil engineering, for which composite materials are generally processed directly on site.

- Increasing the molar mass of additives, such as plasticizers and stabilizers, by grafting a long aliphatic chain on the active function allows one to increase their compatibility with weakly polar polymers and reduce significantly their loss rate by diffusion and evaporation (or dissolution by a solvent).

\subsection{Mechanisms of chemical ageing: introduction}

This section focuses on two main types of chemical ageing processes covering the great majority of deterioration problems encountered in civil engineering: 'hydrolytic ageing' and 'oxidative ageing'. Both processes result from the chemical interaction between the polymer matrix and the environmental reagents, especially water, oxygen and alkalis. Moreover, they have two important common characteristics. First, they induce random chain scission, which is the cause of deep embrittlement at low conversion of the chemical ageing process. Second, they are diffusion-controlled, affecting a more or less thick superficial layer and inducing gradients of degradation.

This part of the chapter will be divided into four main sections. This first section will be devoted to common aspects of chemical ageing processes. The second section will be devoted to reaction-diffusion coupling, and the last two will focus on hydrolytic and oxidative ageing respectively. Durability problems will be considered essentially from the 'material science' point of view rather than the 'chemical mechanism' point of view. Emphasis will be put on the consequences of chemical ageing on mechanical properties.

Structural changes induced by chemical ageing can be ranged into four categories depending on the affected structural scale (see Table 12.1). The 'target' of water, oxygen or alkali attack is always the molecular scale, i.e. a region of sub-nanometric dimension. Some examples of chemical transformations at this scale are presented in Fig. 12.11. One can distinguish two categories of chemical events: those which do not affect the structure at the macromolecular scale and those (chain scissions, cross-linking) which do affect the structure at this scale. This distinction is based on a simple rule: only the structural changes at the macromolecular scale can induce 
Table 12.1 The four scales of structure and the corresponding tools of investigation

\begin{tabular}{llll}
\hline Structural scale & Entity & Main analytical tools & Theoretical tools \\
\hline Molecular & Group of atoms & IR and NMR & Organic \\
& Monomer unit & spectrometry & chemistry \\
Macromolecular & Chain & Viscosimetry & $\begin{array}{l}\text { Macromolecular } \\
\text { physico-chemistry }\end{array}$ \\
& Network strand & SEC & \\
& Cross-link & Sol-gel analysis & \\
Morphological & Crystalline lamellae & SAXS, WAXS, DSC & Materials science \\
& Spherulite & SEM, TEM, AFM & \\
Macroscopic & Skin-core structure & Visible microscopy & Materials science \\
& & Modulus profiling & \\
& & Nano- and macro- & \\
& & indentation & \\
\hline
\end{tabular}

dramatic consequences on the polymer mechanical properties at reasonably low conversions of the chemical ageing process.

Hydrolysis without chain scission occurs only in acrylic and vinylic polymers with ester side groups. These polymers are not frequently used as composite matrices. Oxidation leads to a predominating chain scission process in the majority of cases, and to a predominating cross-linking in few cases such as polybutadiene (Coquillat et al., 2007). An important quantity is the yield of chain scission or cross-linking expressed as the number of broken chains or cross-links formed per oxygen molecule absorbed. There is, to our knowledge, no case of industrial polymer for which this quantity is null.

\subsubsection{Changes of side-groups}

As previously seen, a change of side-groups, e.g. the replacement of an ester by an acid (case A in Fig. 12.11), or the replacement of a methylene by a ketone or an alcohol (case C in Fig. 12.11), has no effect on mechanical properties. However, it can affect other physical properties, for instance:

- Colour, if the new group is a chromophore. In general, hydrolysis does not affect colour, but oxidation induces yellowing in most aromatic polymers, because it can transform some aromatic nuclei into quinonic structures absorbing in the violet-blue part of the visible spectrum.

- Replacement of a non-polar group by a polar group, e.g. an ester by an acid (case A in Fig. 12.11) or a methylene by an alcohol (case $\mathrm{C}$ in Fig. 12.11). Such modifications are expected to have the following consequences: increase in dielectric permittivity; increase in the refractive index; growth of dielectric absorption bands; and increase in hydrophilicity and wettability. 
Case A: Hydrolysis of an acrylic polymer

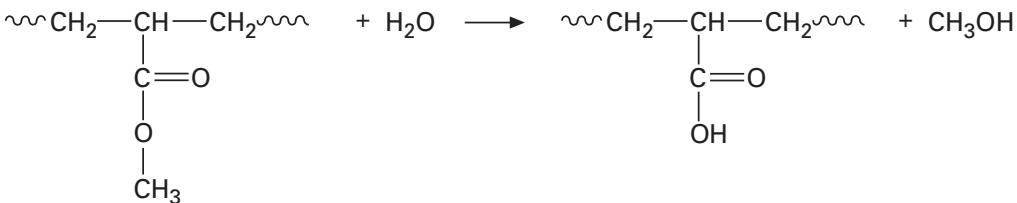

Case B: Hydrolysis of PET

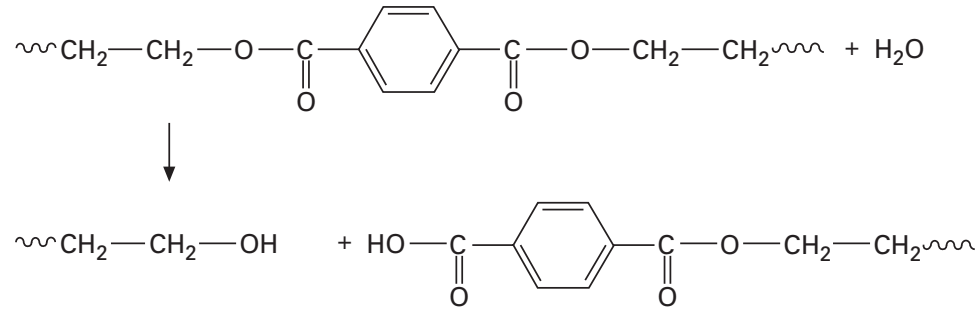

Case C: Oxidation of a polymer containing an aliphatic segment

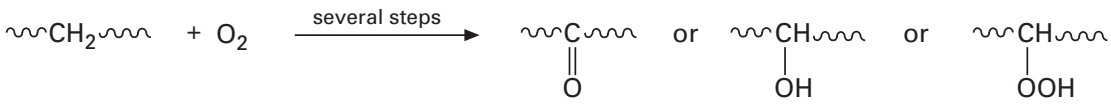

Case D: Oxidation of a polymer containing an aliphatic segment (case B)

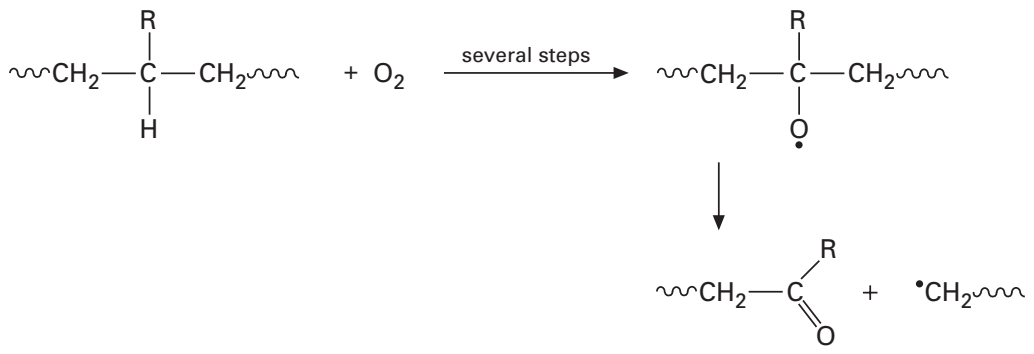

12.11 Examples of hydrolysis (A, B) or oxidation (C, D) processes leading $(B, D)$ or not $(A, C)$ to a chain scission.

However, these chemical changes are rarely decisive in the case of composites.

\subsubsection{Random versus selective chain scissions}

Chain scissions can occur at peculiar sites of high reactivity (selective chain scissions). They may also be randomly distributed if all the repeat units are equi-reactive (random chain scissions). Both types of scissions are schematized in Fig. 12.12. For composite matrices, in the context of long-term hydrolytic 
Random chain scission in a linear polymer

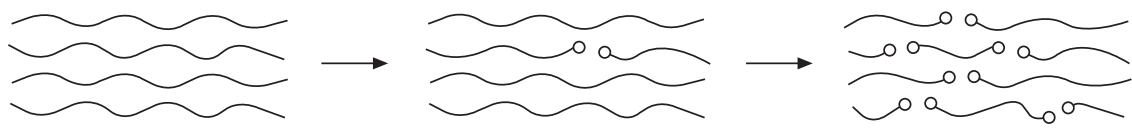

Selective chain scission in a linear polymer (depolymerization)

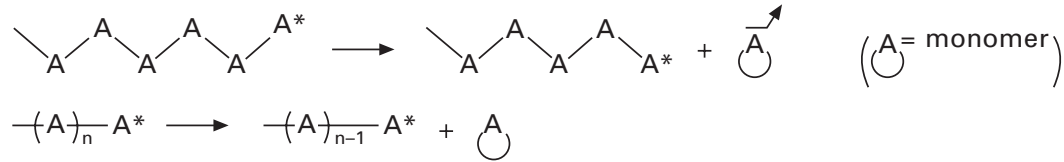

Random chain scission in a network

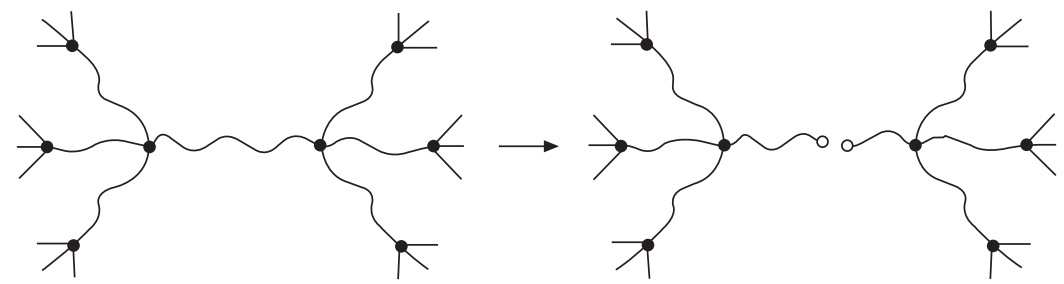

Selective chain scission in a network

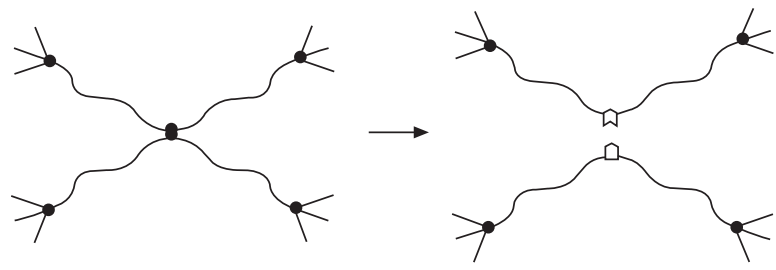

12.12 Random and selective chain scissions in linear and tridimensional polymers.

or oxidative ageing, random chain scissions predominate over all the other processes in the great majority of cases.

Depolymerization (or reversion) occurs essentially at high temperatures, only in linear polymers having weak monomer-monomer bonds, or in tridimensional polymers having weak cross-link junctions (see Table 12.2). These are linear polymers containing the weakest aliphatic $\mathrm{C}-\mathrm{C}$ bonds, i.e. involving tetrasubstituted carbon atoms, e.g. polyisobutylene (PIB), poly(methyl methacrylate) (PMMA), poly( $\alpha$-methyl styrene) (P $\alpha$ MS), etc. These are also linear polymers containing heteroatoms, e.g. poly(oxy methylene) (POM), poly(ethylene terephthalate) (PET), poly(vinyl chloride) (PVC), etc., but also sulphur vulcanized elastomers. Cross-linking predominates mainly in unsaturated linear polymers, i.e. essentially polybutadiene and its 
polymer chemical bonds

\begin{tabular}{llll}
\hline Chemical bond & $E_{\mathrm{D}}\left(\mathrm{kJ} . \mathrm{mol}^{-1}\right)$ & Chemical bond & $E_{\mathrm{D}}\left(\mathrm{kJ}^{\mathrm{m}} \mathrm{mol}^{-1}\right)$ \\
\hline Aromatic C-C & 510 & $\mathrm{C}-\mathrm{Cl}$ & 320 \\
C-F & 470 & $\mathrm{C}-\mathrm{Si}$ & 300 \\
Aromatic C-H & 465 & $\mathrm{C}-\mathrm{N}$ & 290 \\
Aliphatic C-H & $325-425$ & $\mathrm{C}-\mathrm{S}$ & 275 \\
Aliphatic C-C & $300-380$ & $\mathrm{~S}-\mathrm{S}$ & 260 \\
C-O & 340 & $\mathrm{O}-\mathrm{O}$ & 150 \\
\hline
\end{tabular}

copolymers (Coquillat et al., 2007), and in poorly cross-linked elastomers and thermosets. Some exceptions are known for composite matrices, and will be examined in a later short paragraph.

\subsubsection{Random chain scissions in linear polymers}

The random character results from the fact that all the reactive groups of the macromolecules have an equal probability to react. This means that the probability for a chain to react is an increasing function of its length. The number $\left(M_{\mathrm{n}}\right)$ and weight $\left(M_{\mathrm{W}}\right)$ average molar masses are linked to the number $S$ of chain scissions per mass unit by the following relationships (Saito, 1958a, 1958b):

$$
\begin{aligned}
& \frac{1}{M_{\mathrm{n}}}-\frac{1}{M_{\mathrm{n} 0}}=S \\
& \frac{1}{M_{\mathrm{w}}}-\frac{1}{M_{\mathrm{w} 0}}=\frac{S}{2}
\end{aligned}
$$

The polydispersity index PI varies as follows:

$$
\mathrm{PI}=\mathrm{PI}_{0} \frac{1+S M_{\mathrm{n} 0}}{1+\frac{\mathrm{PI}_{0}}{2} S M_{\mathrm{n} 0}}
$$

One sees that PI increases when $\mathrm{PI}_{0}<2$, decreases when $\mathrm{PI}_{0}>2$, but in all cases tends towards 2 when $S$ increases (Fig. 12.13). This characteristic is generally used to recognize a random chain scission.

Steric exclusion chromatography (SEC) can be used to determine the molar mass distribution and the average values $M_{\mathrm{n}}$ and $M_{\mathrm{W}} \cdot M_{\mathrm{W}}$ can also be determined by viscosimetry using a power law:

$$
\eta=K M_{\mathrm{w}}^{a}
$$

In the case of dilute polymer solution, $\eta$ is the intrinsic viscosity: $a \approx 0.7$ and $K$ depends on temperature and solvent nature. In contrast, in the case 


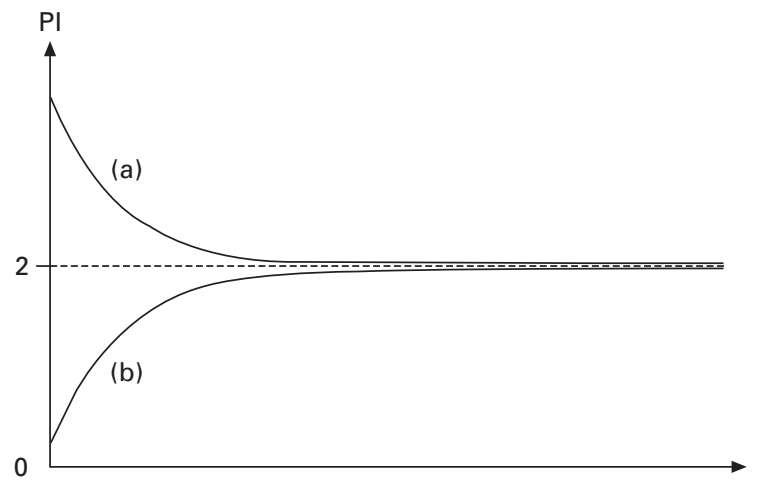

12.13 Shape of the variation of polydispersity index (PI) as a function of ageing time for a linear polymer undergoing a random chain scission: (a) $\mathrm{PI}_{0}>2$; (b) $\mathrm{PI}_{0}<2$.

of molten polymer, $\eta$ is the Newtonian viscosity: $a=3.4$ and $K$ depends on temperature and polymer chemical structure.

According to Fox and Flory (1954), in linear polymers, the glass transition temperature $T_{\mathrm{g}}$ is a decreasing function of the number of chain ends:

$$
T_{\mathrm{g}}=T_{\mathrm{g} \infty}-\frac{K_{\mathrm{FF}}}{M_{\mathrm{n}}}
$$

where $K_{\mathrm{FF}}$ and $T_{\mathrm{g} \infty}$ are parameters depending on the polymer chemical structure.

Both parameters are increasing functions of the chain stiffness. According to Richaud et al. (2010), they would be closely related:

$$
K_{\mathrm{FF}} \propto T_{\mathrm{g} \infty}^{2}
$$

From Equations [12.4] and [12.8], one obtains:

$$
T_{\mathrm{g} 0}-T_{\mathrm{g}}=K_{\mathrm{FF}} S
$$

One can see that $T_{\mathrm{g}}$ is a decreasing function of the number of chain scissions $S$. The effect of these latter is an increasing function of the chain stiffness. Indeed, in flexible polymers having typically $T_{\mathrm{g}}$ values lower than $100^{\circ} \mathrm{C}, T_{\mathrm{g}}$ changes are negligible. In contrast, they can be measured in stiff polymers, especially in those having aromatic groups in their macromolecular chain.

In semi-crystalline polymers, chemical ageing is accompanied by morphological changes (see below) and it is not easy to separate the (small) effects of molecular mass decrease from the effects of morphological changes. To summarize, chemical ageing induces only small variations of melting point and the sense of this variation can vary from one polymer to another. Melting point measurement is thus not an adequate method to monitor random chain scissions. 
At conversions of practical interest, random chain scissions have no significant effect on elastic properties of linear polymers. The effect of molar mass on toughness of linear polymers is schematized in Fig. 12.14. Let us notice that the same type of curve can be obtained for the ultimate elongation. For all the polymers, one can distinguish two regimes separated by a relatively sharp transition at a critical molar mass $M_{\mathrm{F}}$. At molar masses lower than $M_{\mathrm{F}}$, polymers are extremely brittle, their toughness being due only to van der Waals interactions. Polymers behave like a wax or an eggshell, depending on their stiffness. They cannot be used in mechanical applications owing to their extremely high brittleness. On the contrary, at molar masses higher than $M_{\mathrm{F}}$, polymers often have toughness in the range of $10^{3}-10^{4} \mathrm{~J}_{\mathrm{m}} \mathrm{m}^{-2}$, i.e. almost independent of the molar mass.

In amorphous polymers, $M_{\mathrm{F}}$ is mainly linked to the entanglement density. Indeed, plastic deformations, responsible for the high toughness, are linked to chain drawing and this latter is only possible if the chains participate in a network, here the entanglement (topological) network. In contrast, in semicrystalline polymers, the critical quantity is the interlamellar spacing $l_{\mathrm{a}}$. As an example, PE is brittle when $l_{\mathrm{a}} \leq 6 \mathrm{~nm}$ (Kennedy et al., 1994). Since $l_{\mathrm{a}}$ is sharply linked to molar mass, it can be considered, for these polymers also, that there is a critical molar mass $M_{\mathrm{F}}$ separating the brittle from the ductile domains (Fayolle et al., 2008).

It can be interesting to establish a relationship between $M_{\mathrm{F}}$ and the entanglement molar mass $M_{\mathrm{E}}$, this latter being sharply linked to the chemical structure (Fetters et al., 1999). It appears that:

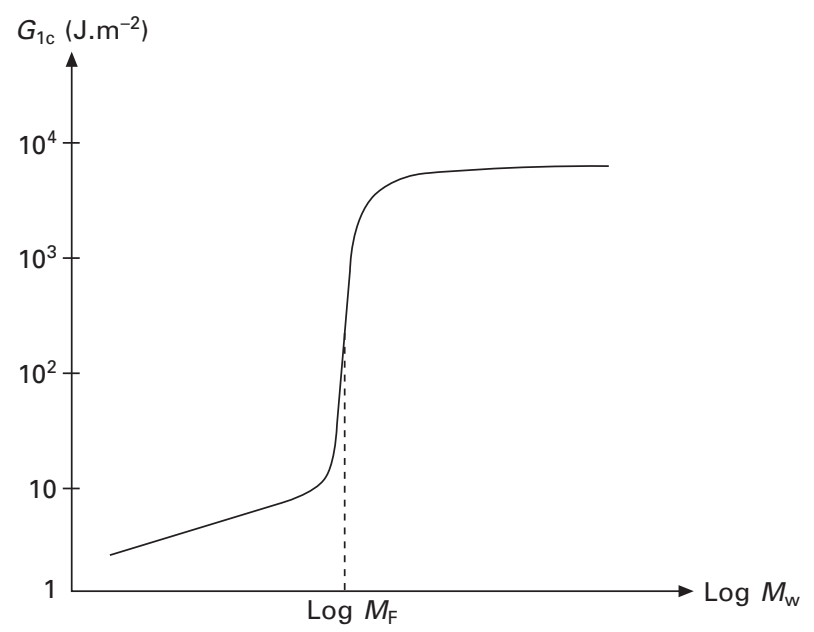

12.14 Shape of the variation of toughness $\left(G_{1 C}\right)$ for a linear polymer as a function of its weight average molar mass $\left(M_{\mathrm{W}}\right)$ (according to Greco and Ragosta, 1987). 
- For amorphous polymers (e.g. PC, PS and PMMA) and semi-crystalline polymers having initially their amorphous phase in the glassy state (e.g. PA11 and PA6-6) (Kausch et al., 2001):

$$
\frac{M_{\mathrm{F}}}{M_{\mathrm{E}}} \approx 2 \text { to } 5
$$

- For semi-crystalline polymers having their amorphous phase in the rubbery state (e.g. PE, PP and PET) (Fayolle et al., 2008):

$$
\frac{M_{\mathrm{F}}}{M_{\mathrm{E}}} \approx 50
$$

According to the shape of Fig. 12.14, the effect of random chain scissions on fracture properties must display three characteristics:

1. If the initial molar mass is high enough, chain scissions are expected to have no effect on fracture properties in the initial period of exposure, before molar mass reaches the critical value $M_{\mathrm{F}}$.

2. Toughness must decay abruptly by one to three decades when molar mass reaches $M_{\mathrm{F}}$.

3. Beyond the ductile-brittle transition, the toughness decreases continuously but very slowly.

Let us consider a chain scission process occurring at a constant rate: $r=\mathrm{d} S / \mathrm{d} t$. Assuming that $\mathrm{PI} \approx \mathrm{PI}_{0} \approx 2$, Equation [12.6] can be rewritten as:

$$
M_{\mathrm{w}}=\frac{2 M_{\mathrm{w} 0}}{2+r_{\mathrm{r}} M_{\mathrm{w} 0} t}
$$

The changes in molar mass $M_{\mathrm{W}}$ and ultimate elongation $\varepsilon_{\mathrm{R}}$ with time are schematized in Fig. 12.15. One can see that, although $S$ is a linear function of time, $M_{\mathrm{W}}$ is a hyperbolic function of time. As expected, $\varepsilon_{\mathrm{R}}$ falls abruptly when $M_{\mathrm{W}}=M_{\mathrm{F}}$.

The critical number of chain scissions $S_{\mathrm{F}}$ for embrittlement is given by:

$$
S_{\mathrm{F}}=2\left(\frac{1}{M_{\mathrm{F}}}-\frac{1}{M_{\mathrm{w} 0}}\right)
$$

In any case $M_{\mathrm{F}}>10 \mathrm{~kg} \cdot \mathrm{mol}^{-1}$, so that:

$$
S_{\mathrm{F}} \leq \frac{2}{M_{\mathrm{F}}} \approx 0.2 \mathrm{~mol} . \mathrm{kg}^{-1}
$$

In common industrial linear polymers, the monomer concentration $[m]$ is such that:

$$
[m]>2 \text { mol. } \mathrm{kg}^{-1}
$$




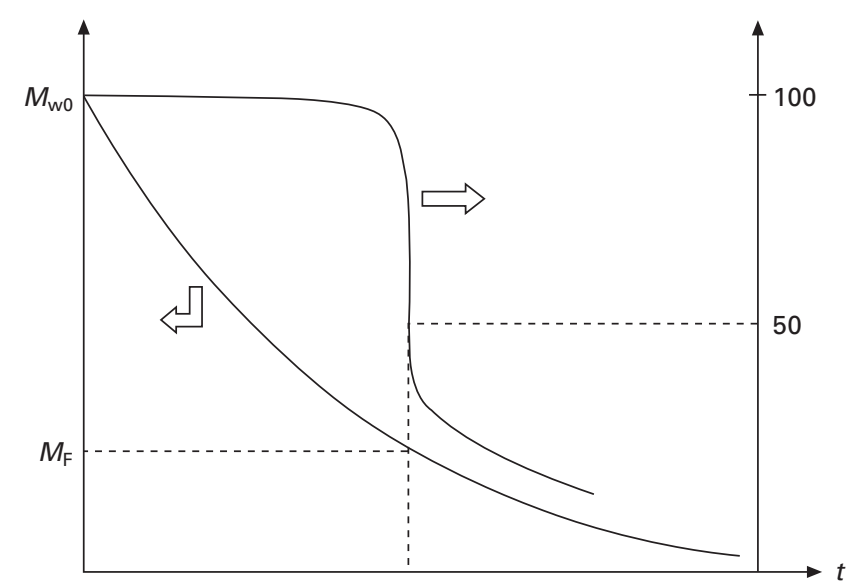

12.15 Shape of the changes with ageing time of weight average molar mass $\left(M_{W}\right)$ and ultimate elongation $\left(\varepsilon_{R}\right)$ for a linear polymer subjected to a random chain scission process.

It appears that embrittlement occurs always at a small conversion degree of the chain scission process. In certain cases, e.g. PP (Fayolle et al., 2002), embrittlement occurs while no structural change is observable by spectrophotometry IRTF.

\subsubsection{Random chain scissions in networks}

Let us consider an ideal network in which every chain is connected to crosslink nodes at both extremities. Such chains are called 'elastically active chains' (EACs). Their concentration $v_{0}$ is linked to the concentration $x_{0}$ of nodes by:

$$
v_{0}=\frac{f}{2} x_{0}
$$

where $f$ is the node functionality, i.e. the number of EACs connected to a node.

If the network undergoes a small number of random chain scissions such that $S<<v_{0}$, each chain scission occurs in an EAC, so that new cross-link density is given by (Pascault et al., 2002):

$$
v=v_{0}-j S
$$

with $j=3$ for $f=3$, and $j=1$ for $f>3$ (see Fig. 12.16).

Each chain scission creates two dangling chains. Indeed, chain scissions transform an ideal network into a non-ideal one, and the probability of 

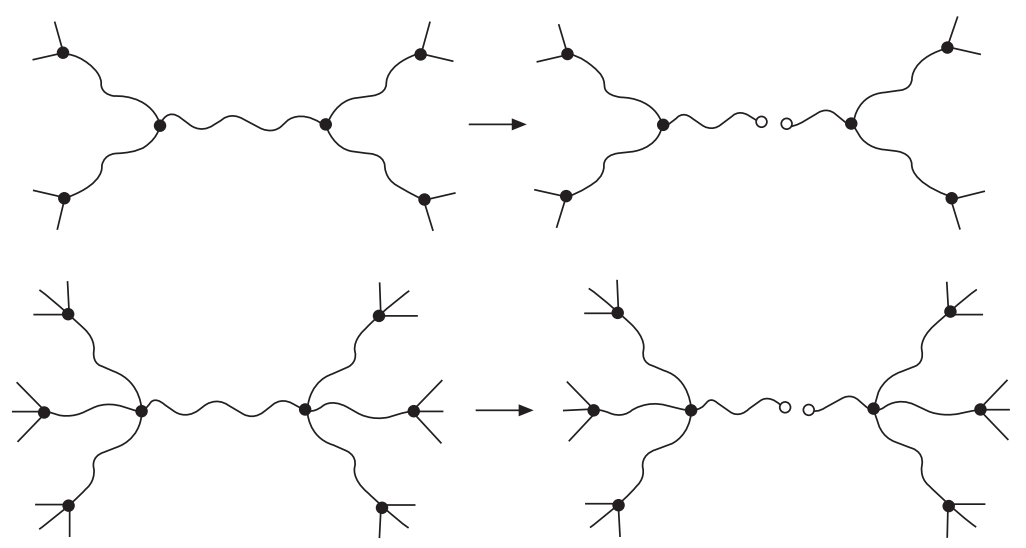

12.16 Schematization of a random chain scission in a network with trifunctional (above) and tetrafunctional (below) nodes.

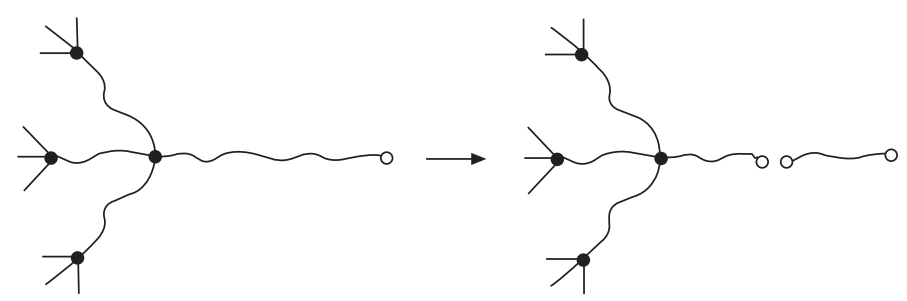

12.17 Schematization of a chain scission in a dangling chain.

having a chain scission in a dangling chain increases with the number of chain scissions (see Fig. 12.17).

At a given state of degradation, the mass fraction $w_{\mathrm{e}}$ of EAC is:

$$
w_{\mathrm{e}}=v M_{\mathrm{e}}
$$

Let us consider a chain scission process at a constant rate: $r=\mathrm{d} S / \mathrm{d} t$, e.g. in a network having nodes of functionality $f>3$. The probability of breaking an EAC is expected to be proportional to the EAC mass fraction, so that:

$$
\frac{\mathrm{d} v}{\mathrm{~d} t}=-r w_{\mathrm{e}}=-r M_{\mathrm{e}} v
$$

It follows that:

$$
v=v_{0} \exp \left(-r M_{\mathrm{e}} t\right)
$$

One can see that, although chain scission is an apparent zero-order process, the cross-link density decreases in an apparent first-order process. In practice, the mechanical behaviour is strongly altered at relatively low conversions of the chemical ageing process, before the probability of having a scission in 
a dangling chain has reached a significant value. It is noteworthy that chain scissions on dangling chains create free chains. The amount of the latter corresponds to the extractable fraction in solvents.

Analytical methods for the determination of the number of chain scissions $S$ per mass unit are scarce. When elastic properties in the rubbery state are measurable, one can use the theory of rubber elasticity (Flory, 1953), according to which:

$$
\frac{\mathrm{d} G}{\mathrm{~d} S}=\frac{\mathrm{d} G}{\mathrm{~d} v} \frac{\mathrm{d} v}{\mathrm{~d} S}=-j R T \rho
$$

where $G$ is the shear modulus at $T>T_{\mathrm{g}}$ and $\rho$ is the specific weight $\left(\mathrm{kg} \cdot \mathrm{m}^{-3}\right)$ of the polymer.

The glass transition temperature $T_{\mathrm{g}}$ is also dependent on cross-link density. According to Di Marzio (1964):

$$
T_{\mathrm{g}}=\frac{T_{\mathrm{gl}}}{1-K_{\mathrm{DM}} F v}
$$

where $T_{\mathrm{gl}}$ and $F$ are parameters depending on chain stiffness, and $K_{\mathrm{DM}}$ is a universal constant $\left(\mathrm{K}_{\mathrm{DM}} \approx 3\right)$.

$$
\frac{\mathrm{d} T_{\mathrm{g}}}{\mathrm{d} S}=-j \frac{T_{\mathrm{g}}}{\mathrm{d} v}=\frac{j K_{\mathrm{DM}} F T_{\mathrm{gl}}}{\left(1-K_{\mathrm{DM}} F v\right)^{2}}=j K_{\mathrm{DM}} F \frac{T_{\mathrm{g}}^{2}}{T_{\mathrm{gl}}}
$$

The effect of chain scissions is thus an increasing function of $T_{\mathrm{g}}$. Let us consider, for instance, an epoxy network based on the triglycidyl derivative of $p$-aminophenol (TGAP) cross-linked by diaminodiphenylmethane (DDM) in stoichiometric proportion. The characteristics are (Pascault et al., 2002) $T_{\mathrm{g}}$ $=494 \mathrm{~K}, F=23 \mathrm{~g} \cdot \mathrm{mol}^{-1}, T_{\mathrm{gl}}=293 \mathrm{~K}$ and $j=3$ (trifunctional cross-links). Then, it follows that:

$$
\frac{\mathrm{d} T_{\mathrm{g}}}{\mathrm{d} S}=172 \mathrm{~K} \cdot \mathrm{kg} \cdot \mathrm{mol}^{-1}
$$

Effects of random chain scissions on elastic properties depend on the amplitude of the dissipation peak related to the $\beta$ relaxation. For polymers having a weak $\beta$ transition, e.g. styrene cross-linked polyesters or vinylesters, chain scissions have a minor effect on elastic properties in the glassy state. In contrast, for polymers having a strong $\beta$ transition, e.g. diamine-cross-linked epoxies, chain scissions lead to an increase in the modulus plateau between the $\beta$ transition and the glass transition (Fig. 12.18). This phenomenon is called 'internal antiplasticization' (Rasoldier et al., 2008). It can be evidenced through nano- or micro-indentation profiles that characterize degradation gradients in the sample thickness (Olivier et al., 2009). Chain scissions induce a decrease in fracture toughness (or ultimate elongation). 


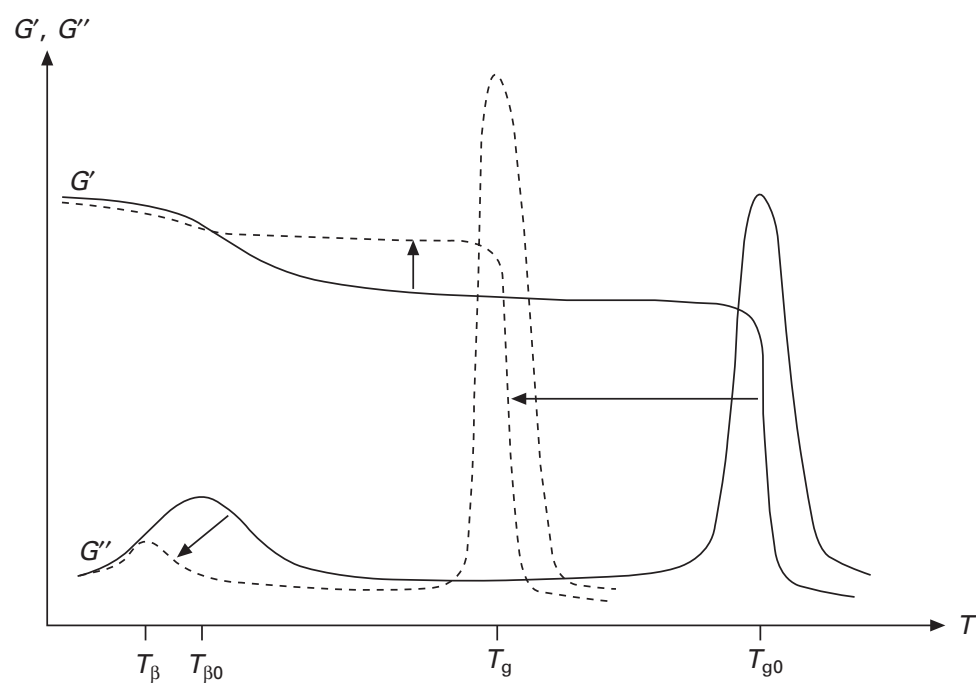

12.18 Storage $\left(G^{\prime}\right)$ and dissipation $\left(G^{\prime \prime}\right)$ modulus against temperature for a network having a strong $\beta$ transition before (full line) and after (dashed line) a chain scission process.

From this point of view, degraded networks differ from ideal networks in which fracture properties are generally a decreasing function of cross-link density (Crawford and Lesser, 1999; Pascault et al., 2002). Little is known on the quantitative relationships between chain scission and embrittlement in networks.

\subsubsection{Simultaneous random chain scissions and cross- linking}

In linear polymers, Saito's equations become (Saito, 1958a, 1958b):

$$
\begin{aligned}
& \frac{1}{M_{\mathrm{n}}}-\frac{1}{M_{\mathrm{n} 0}}=S-X \\
& \frac{1}{M_{\mathrm{W}}}-\frac{1}{M_{\mathrm{W} 0}}=\frac{S}{2}-2 X
\end{aligned}
$$

where $X$ is the number of cross-links and $S$ the number of chain scissions.

There is an 'equilibrium' corresponding to the constancy of $M_{\mathrm{W}}$ for:

$$
S=4 X
$$

For $X>S / 4$, cross-linking predominates over chain scissions. Polymer gelation occurs when $M_{\mathrm{W}} \rightarrow 0$, i.e. when: 


$$
\frac{S}{2}-2 X=-\frac{1}{M_{\mathrm{W} 0}}
$$

i.e. in the absence of chain scission for:

$$
X_{\mathrm{g}}=-\frac{1}{2 M_{\mathrm{W} 0}}
$$

Beyond the gel point, an insoluble fraction appears. According to Charlesby and Pinner (1959), the soluble fraction $w_{S}$ is related to the number of chain scissions and cross-links by:

$$
w_{\mathrm{s}}+w_{\mathrm{s}}^{1 / 2}=\frac{S}{2 X}+\frac{1}{M_{\mathrm{w} 0} X}
$$

In linear polymers, cross-linking affects mainly rheological properties in the molten state. Indeed, long branching is responsible for the disappearance of the Newtonian plateau (Fig. 12.19).

Cross-linking induces an increase in the glass transition temperature. In the case of simultaneous chain scission and cross-linking, it can be written, in a first approach, that:

$$
T_{\mathrm{g}}=T_{\mathrm{g} 0}+k_{\mathrm{S}} S+k_{\mathrm{X}} X
$$

$k_{\mathrm{S}}$ is significantly higher than $k_{\mathrm{X}}$. As an example, in bisphenol-A polysulphone, $k_{\mathrm{S}} / k_{\mathrm{X}} \approx 2.1$ (Richaud et al., 2010). In other words, cross-linking has less influence than chain scissions on $T_{\mathrm{g}}$.

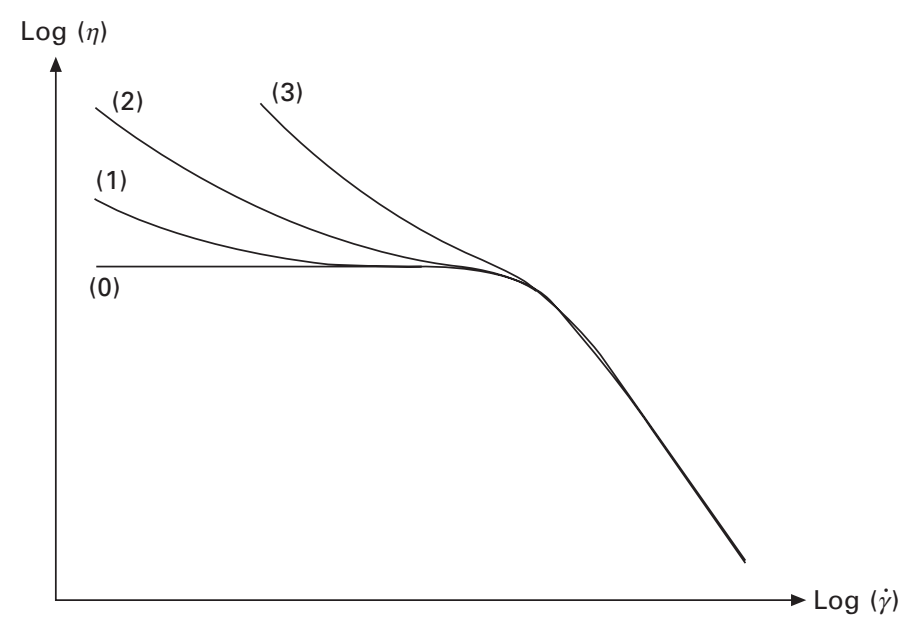

12.19 Shape of the curve of log(viscosity) versus log(shear rate) for a linear polymer before $(0)$ and after ageing leading to an increase in degree of branching $(0<1<2<3)$. 
The effects of cross-linking on fracture properties are not well known. In most cases, cross-linking is expected to induce embrittlement according to the following causal chains:

1. Cross-linking $\rightarrow$ Increase in $T_{\mathrm{g}} \rightarrow$ Increase in yield stress $\rightarrow$ Ductile (plastic) deformation less and less competitive with brittle deformation.

2. Cross-linking $\rightarrow$ Shortening of EAC $\rightarrow$ Decrease in drawability of EAC $\rightarrow$ Reduction in plastic zone at crack tip $\rightarrow$ Decrease in toughness.

\subsubsection{Effects of post-curing}

In most industrial thermosets and especially for cold-cured systems used in construction, cure is not complete and reactive groups remain trapped at the end of processing operations. In ageing conditions, they can recover enough mobility to react, because they are heated at temperatures close to $T_{\mathrm{g}}$ or the polymer is plasticized by a solvent, e.g. water. Cure reactions are then reactivated; the cross-link density increases in an auto-retardated way and stops when all the available reactive groups have been consumed. Except for scarce cases, e.g. epoxides cross-linked by unsaturated anhydrides (Le Huy et al., 1993), oxidative ageing is dominated by chain scission, so that, for thermosets, cross-link density variations during thermal ageing have the shape of Fig. 12.20.

These curves can be decomposed into two components, i.e. post-cure and degradation (see Fig. 12.21). In the simplest cases, there is no interaction between both processes, so that their effects on cross-link density are additive.

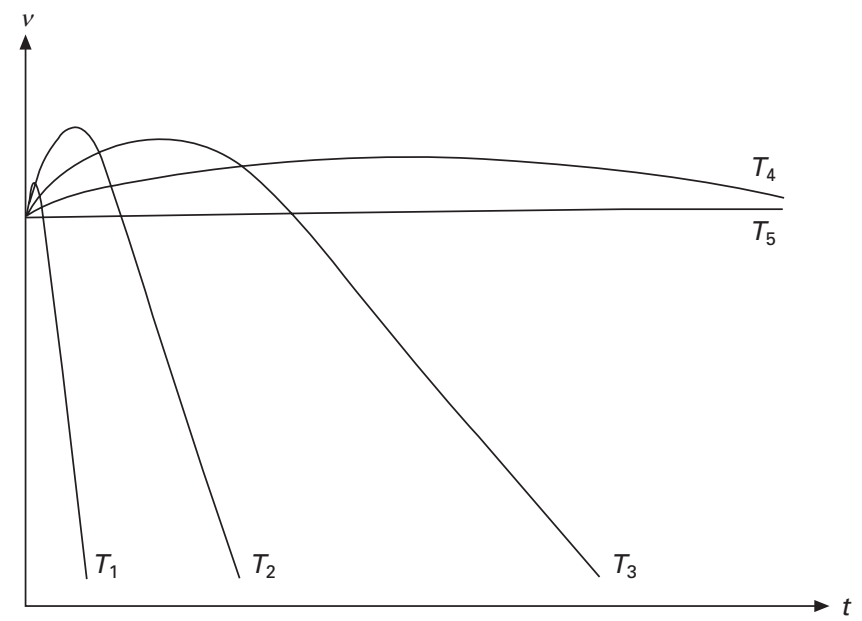

12.20 Shape of kinetic curves of cross-link density variations during the thermal ageing (in air) of a thermoset at various temperatures: $T_{1}$ $>T_{2}>T_{3}>T_{4}>T_{5}$. 


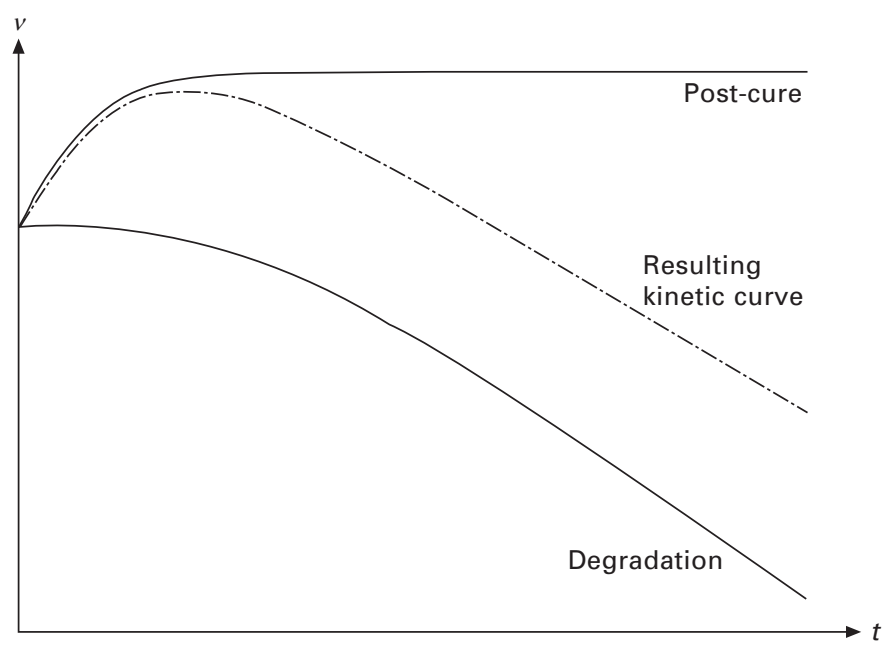

12.21 Schematization of combined effects of post-cure and degradation.

In other cases, however, oxygen or water can inhibit post-cure and a more complex behaviour can be expected.

\subsection{Mechanisms of chemical ageing: reaction- diffusion coupling}

In both oxidation and hydrolysis, the polymer matrix reacts with a small molecule coming from the environment (oxygen or water, for instance). In a thin elementary layer at a distance $z$ from the sample surface, the reactant concentration balance can be ascribed as follows: reactant concentration change $=$ rate of reactant supply by diffusion - rate of reactant consumption by reaction.

In the case of unidirectional diffusion, far from the sample edges, this balance equation can be written:

$$
\left(\frac{\partial C}{\partial t}\right)_{z}=D \frac{\partial^{2} C}{\partial z^{2}}-r(C)
$$

where $C$ is the reactant concentration, $D$ is the coefficient of reactant diffusion in the polymer matrix and $r(C)$ is the rate of reactant consumption expressed as a function of the reactant concentration.

Resolution of Equation [12.33] requires the knowledge of two physical quantities: the equilibrium concentration $C_{\mathrm{S}}$ of the reactant and its coefficient of diffusion $D$ in the polymer matrix; and one item of chemical data: the concentration dependence of the reactant chemical consumption $r(C)$. 
There are various works (Crank and Park, 1968; Hopfenberg, 1974; Bicerano, 2002; Van Krevelen and Te Nijenhuis, 2009) devoted to transport properties of gases and vapours in polymer matrices and their relationships with polymer structure. The main differences between oxygen and water properties can be summarized as follows: oxygen solubility in polymers is always low, typically $\leq 10^{-3}$ mol. $1^{-1}$, and practically insensitive to small structural changes. The coefficient of oxygen diffusion is of the order of $10^{-11}$ ${ }^{ \pm 2} \mathrm{~m}^{2} \cdot \mathrm{s}^{-1}$ at ambient temperature and its apparent activation energy is located in the $30-60 \mathrm{~kJ} \cdot \mathrm{mol}^{-1}$ interval. Oxygen transport properties are practically always determined from permeability measurements. It can be reasonably assumed that, during an ageing experiment at a constant temperature, $D$ is independent of $C$ and reaction conversion at reasonably low conversions of the oxidation process, e.g. before and just after embrittlement. In contrast, relationships between polymer structure and water transport characteristics are obviously more complicated, as illustrated by Table 12.3.

The main trends of structure-property relationships can be briefly summarized as follows:

- Three main types of groups can be distinguished:

- G1: Hydrocarbon and halogenated groups of which the contribution to hydrophilicity is negligible. Polymers containing only these groups (polyethylene, polypropylene, polystyrene, elastomers, etc.) absorb less than $0.5 \mathrm{wt} \%$ water.

Table 12.3 Molar mass of the constitutive repeat unit, water mass fraction at equilibrium at $50^{\circ} \mathrm{C}$ and $50 \% \mathrm{RH}$, coefficient of water diffusion in the same conditions, and number of moles of water per constitutive repeat unit

\begin{tabular}{llllll}
\hline Polymer & Code & $\begin{array}{l}M \\
\left(\mathrm{~g} \cdot \mathrm{mol}^{-1}\right)\end{array}$ & $\begin{array}{l}m_{\text {equ }} \\
(\%)\end{array}$ & $\begin{array}{l}D \times 10^{12} \\
\left(\mathrm{~m}^{2} \cdot \mathrm{s}^{-1}\right)\end{array}$ & $\begin{array}{l}n \\
\left(\mathrm{~mol}^{\mathrm{mol}} \mathrm{mo}^{-1}\right)\end{array}$ \\
\hline Poly(methyl methacrylate) & PMMA & 100 & 1.28 & 0.36 & 0.071 \\
Poly(ethylene terephthalate) $)$ & PET & 192 & 0.55 & 0.54 & 0.059 \\
Polycarbonate & PC & 254 & 0.25 & 5.4 & 0.035 \\
Polyamide 11 & PA11 & 183 & 1.5 & 0.13 & 0.153 \\
Poly(bisphenol-A) sulphone & PSU & 442 & 0.52 & 8.97 & 0.128 \\
Polyethersulphone & PES & 232 & 1.8 & 2.79 & 0.232 \\
Polyetherimide & PEI & 592 & 1.4 & 0.97 & 0.460 \\
Polypyromellitimide & PPI & 382 & 5.0 & 0.1 & 1.061 \\
Polyimide & IP960 & 486 & 4.2 & 0.83 & 1.134 \\
Epoxy & DGEBA-Etha & 858 & 2.0 & 1.03 & 0.953 \\
Epoxy & DGEBD-Etha & 578 & 6.8 & 0.11 & 2.183 \\
Unsaturated polyester & UP & 334 & 0.83 & 0.88 & 0.154 \\
Vinylester & VE(D) & 980 & 1.7 & 0.6 & 0.926 \\
Vinylester & VE(C) & 550 & 0.5 & 0.5 & 0.153 \\
\hline
\end{tabular}

Source: data compiled from Bellenger et al. (1994), Tcharkhtchi et al. (2000) and Gaudichet-Maurin et al. (2008). 
- G2: Groups of relatively low polarity (ethers, ketones, esters, etc.). Polymers containing only these groups (with hydrocarbon ones) absorb generally less than 2 wt $\%$ water. Physical effects of water absorption (plasticization, swelling) are generally negligible. Polymers containing ester groups (polyalkylene terephthalates, unsaturated polyesters, anhydride crosslinked epoxies, etc.) are, however, susceptible to hydrolysis (see below). Polymers containing methacrylic esters (polymethyl methacrylate, vinylesters, etc.) are generally resistant to hydrolysis.

- G3: Highly polar groups able to establish strong hydrogen bonds with water (sulphones, alcohols, amides, acids, etc.). These polymers can absorb up to $5 \mathrm{wt} \%$ water, which can induce considerable physical changes, e.g. $T_{\mathrm{g}}$ decreases by about $10 \mathrm{~K}$ per percent of water absorbed, and swelling and damage by swelling stresses occur during the sorption or desorption transients.

- In each polymer family containing one type of hydrophilic group, e.g. polyamides, polysulphones, polyimides, epoxies, etc., the equilibrium water concentration increases non-linearly with the concentration of polar groups. A theory based on the hypothesis that water is doubly bonded was proposed to explain this trend (Tcharkhtchi et al., 2000; Gaudichet-Maurin et al., 2008).

- The relationships between diffusion coefficient and polymer structure are not fully understood, but it is clear that in a given family, $D$ is a decreasing function of the water equilibrium concentration (Thominette et al., 2006). Such dependence indicates that water-polymer hydrogen bonds slow down diffusion in polyethylenes (McCall et al., 1984) and in epoxies (Tcharkhtchi et al., 2000).

- Diffusion is thermally activated and apparent activation energies are generally in the $20-60 \mathrm{~kJ}^{\mathrm{mol}}{ }^{-1}$ interval. Equilibrium water concentrations depend only slightly on temperature, which can be explained by considerations on heat of solubility (Merdas et al., 2002).

Let us consider now the term representing the chemical reactant consumption in the reaction-diffusion equation (Equation [12.33]). In the simplest case of hydrolysis, $r(C)$ is a simple first-order equation:

$$
r(C)=k E_{0} C
$$

where $k$ is the second-order rate constant of the water-polymer reaction, and $E_{0}$ is the concentration of hydrolysable groups, considered constant at reasonably low conversions.

A more complex equation is needed when hydrolysis is equilibrated by the reverse condensation reaction (see next paragraph). When Equation [12.34] is an acceptable approximation, the integration of Equation [12.33], for a symmetric sheet of thickness $L$, gives: 


$$
C=C_{\mathrm{S}} \frac{\cosh J\left(z-\frac{L}{2}\right)}{\cosh \frac{J L}{2}}
$$

where $J=k E_{0} / D$. The origin of $z$ has been taken at one sample edge.

The water concentration and then the hydrolysis rate decrease in a pseudo-exponential way from the sample edges, where $C=C_{\mathrm{S}}$ (maximum value), to the middle of the sample, where $C=C_{\mathrm{m}}$ (minimum value). Note that, when $L=6 J^{-1}, C_{\mathrm{m}} / C_{\mathrm{S}} \approx 0.1$. Thus, for $L>6 \mathrm{~J}^{-1}$, the sample behaves as a sandwich made of an undegraded core surrounded by two degraded superficial layers. In the case of an equilibrated hydrolysis, e.g. for PA11 (Jacques et al., 2002) or PA6-6 (El Mazry et al., 2012), a degradation gradient appears at the beginning of exposure, but the sample tends to homogenize as the hydrolysis rate slows down.

The case of oxidation is more complex because the mechanism is a branched radical chain of which the kinetic modelling was considered out of reach for a long time. The first attempts were made at the beginning of the 1980s by Seguchi et al. $(1981,1982)$ and Cunliffe and Davis (1982) by applying a series of simplifying assumptions: constant initiation rate, existence of a steady state for radical concentration, long kinetic chain, and low conversion of the oxidation process. All these assumptions are more or less valid in some cases of photochemical and radiochemical oxidation, but they are questionable in the case of thermal oxidation. Assuming their validity, the rate of oxygen consumption can be expressed by a hyperbolic function of oxygen concentration:

$$
r(C)=\frac{a C}{1+b C}
$$

where $a$ and $b$ can be expressed in terms of rate constants of the elementary reactions involved in the oxidation mechanistic scheme.

There is no analytical solution for Equation [12.33], but approximations can be obtained for extreme cases:

- When $C>b^{-1}$ :

$$
r(C)=\frac{a}{b}=r_{\mathrm{S}}
$$

- In contrast, when $C<<b^{-1}$ :

$$
r(C)=a C
$$

In the second case, the same solution as for hydrolysis is obtained (Equations [12.34] and [12.35]). However, in the first case, integration of Equation 
[12.33] for a symmetric sheet of thickness $L$ leads to a parabolic shape of the oxygen concentration profile:

$$
C=C_{\mathrm{S}}+\frac{r_{\mathrm{S}}}{2 D}(z-L) z
$$

The concentration in the middle of the sample is:

$$
C=C_{\mathrm{S}}-\frac{r_{\mathrm{S}} L^{2}}{8 D}
$$

\subsubsection{Reaction-diffusion coupling in composite laminates}

In the case of composite laminates, new problems linked to the anisotropy of diffusion paths, the eventual role of interfacial diffusion and the role of pre-existing or swelling-induced damage appeared in the mid-1970s. The interest was mainly focused on the effect of humidity on carbon fibre/amine crosslinked epoxy composites of aeronautical interest. For the pioneers of this research (Shen and Springer, 1976), the determination of diffusion kinetic laws appeared as the key objective. Various studies revealed that, in certain cases, diffusion in composites cannot be modelled by a simple Fick's law and that Langmuir's equation is more appropriate. Carter and Kibler (1978) proposed a method for the parameter identification. At the end of the 1970s, the kinetic analysis of water diffusion into composites became a worldwide research objective. Related experimental results can be summarized as follows.

Concerning the effect of fibre anisotropy on diffusion, a model for unidirectional composites was proposed by Kondo and Taki (1982). This model takes full account of the fact that water diffusivity is more privileged in the fibre direction than in the transverse one:

$$
D_{/ /}=\frac{1-V_{\mathrm{f}}}{1-a \sqrt{V_{\mathrm{f}}}} D_{\perp}
$$

where $D_{/ /}$and $D_{\perp}$ are the respective diffusion coefficients in the longitudinal and transverse fibre directions, $V_{\mathrm{f}}$ is the volume fraction of fibres, and $a$ is a parameter depending on the fibre arrangement:

- For a cubic stacking (Kondo and Taki, 1982; Hahn, 1987):

$$
a=\frac{2}{\sqrt{\pi}}
$$

- For a compact hexagonal stacking (Woo and Piggot, 1988): 


$$
a=\sqrt{\frac{2 \sqrt{3}}{\pi}}
$$

Examples of values of water and oxygen diffusivity determined in unidirectional composites are reported in Tables 12.4 and 12.5 respectively. Colin et al. (2005) showed that such models can also be used to predict oxygen diffusivity in composites. More recently, Roy and Singh (2009) showed that these models can be improved to take into account physical discontinuities such as highly permeable fibre/matrix interface or fibre/matrix debonding due to oxidative shrinkage and erosion.

Concerning Langmuir's mechanisms, it was assumed, for a long time, that water was trapped in 'defects' resulting from damage or pre-existing, eventually located at the interface. Tcharkhtchi et al. (2000) found that unreacted epoxide groups undergo a reversible hydrolysis:<smiles>CCC1CO1</smiles>

Epoxide groups appear thus as 'water traps' and are responsible for a Langmuir component in diffusion kinetic curves. Since industrial composites are rarely fully cured, it can be assumed that epoxide hydrolysis was often the cause of Langmuir's behaviour in previous studies. Recently, however, Derrien and Gilormini (2006) found that Langmuir's behaviour could be simply linked to the stress state induced by water diffusion.

Table 12.4 Values of oxygen diffusivity for carbon fibres/epoxy matrix in the longitudinal $\left(D_{/ /}\right)$and transverse $\left(D_{\perp}\right)$ directions of fibres

\begin{tabular}{lll}
\hline $\begin{array}{l}\text { Temperature } \\
\left({ }^{\circ} \mathrm{C}\right)\end{array}$ & \multicolumn{2}{l}{ for carbon/epoxy $\left(\mathrm{m}^{2} \cdot \mathrm{s}^{-1}\right)$} \\
\cline { 2 - 3 } & $D_{/ /} \times 10^{-12}$ & $D_{\perp} \times 10^{-12}$ \\
\hline 70 & 2.24 & 1.36 \\
\hline
\end{tabular}

Note: The epoxy matrix is an aromatic diamine (DDS) cross-linked epoxy. The volume fraction of carbon fibres is $65 \%$ (Didierjean, 2004).

Table 12.5 Values of oxygen diffusivity for glass and carbon fibres/epoxy matrix in the longitudinal $\left(D_{/ /}\right)$and transverse $\left(D_{\perp}\right)$ directions of fibres

\begin{tabular}{lllll}
\hline $\begin{array}{l}\text { Temperature } \\
\left({ }^{\circ} \mathrm{C}\right)\end{array}$ & \multicolumn{2}{l}{$\mathrm{D}$ for glass/epoxy } & $\left(\mathrm{m}^{2} . \mathrm{s}^{-1}\right)$ & \multicolumn{2}{l}{$\mathrm{D}$ for carbon/epoxy $\left(\mathrm{m}^{2} . \mathrm{s}^{-1}\right)$} \\
\cline { 2 - 5 } & $\mathrm{D}_{/ /} \times 10^{-12}$ & $\mathrm{D}_{\perp} \times 10^{-12}$ & $\mathrm{D}_{/ /} \times 10^{-12}$ & $\mathrm{D}_{\perp} \times 10^{-12}$ \\
\hline 180 & 3.75 & 0.70 & 2.59 & 0.70 \\
200 & 5.36 & 1.10 & 3.70 & 1.10 \\
\hline
\end{tabular}

Note: The epoxy matrix is an anhydride cross-linked epoxy. The volume fractions of glass and carbon fibres are $64 \%$ and $69 \%$ respectively (Barjasteh et al., 2009). 
Concerning eventual interfacial processes, there is an abundance of literature. Various techniques have been used to characterize interfaces/ interphases (Schradder and Block, 1971; Di Benedetto and Scola, 1980; Ishida and Koenig, 1980; Rosen and Goddard, 1980; Ishida, 1984; Di Benedetto and Lex, 1989; Thomason, 1990; Hoh et al., 1990; Schutte et al., 1994). Round-robin tests showed that no analytical method is able to provide unquestionable results (Pitkethly et al., 1993). Even in cases where the interface response to humid ageing has been unambiguously identified from studies on model systems (Kaelble et al., 1975, 1976; Salmon et al., 1997), it seems difficult, at this stage, to build a non-empirical kinetic model of the water effects on interfaces/interphases in composites.

\subsection{Mechanisms of chemical ageing: hydrolytic processes}

Hydrolytic processes are especially important in two main polymer matrix families containing ester or amide groups in the chain. In these cases, each hydrolysis event is a chain scission:

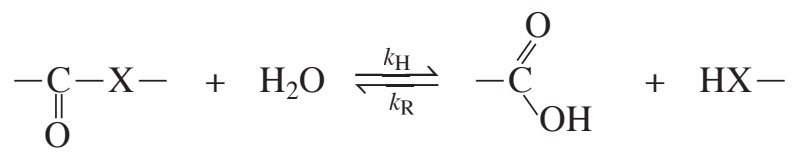

where $\mathrm{X}=-\mathrm{O}-$ (polyesters) or $-\mathrm{NH}-$ (polyamides).

Taking $[-\mathrm{CO}-\mathrm{X}-]=E,[-\mathrm{COOH}]=[\mathrm{HX}-]=b$, and $S=$ number of chain scissions (mole per mass unit), one can write:

$$
\frac{\mathrm{d} S}{\mathrm{~d} t}=k_{\mathrm{H}} C\left(E_{0}-S\right)-k_{\mathrm{R}}\left(b_{0}+S\right)^{2}
$$

where $C$ is the water concentration, and $k_{\mathrm{H}}$ and $k_{\mathrm{R}}$ are rate constants depending only on temperature.

Two cases can be distinguished:

1. Equilibrium occurs at high conversions $\left(S_{\infty} / E_{0} \approx 1\right)$. Since embrittlement occurs at low conversions, far from equilibrium, one can neglect the reverse reaction. Then, the rate of chain scissions is well approximated by:

$$
\frac{\mathrm{d} S}{\mathrm{~d} t}=-\frac{\mathrm{d} E}{\mathrm{~d} t}=k_{\mathrm{H}} E_{0} C=K
$$

where $K$ is a pseudo-zero-order rate constant of which some typical values are given in Table 12.6.

Polymers containing ester groups (linear or cross-linked polyesters, anhydride-cured epoxies, urethane cross-linked polyesters, polycarbonate, etc.) belong to this category. 
Table 12.6 Approximate value of the pseudo zero-order rate constant of hydrolysis for ester-containing polymers

\begin{tabular}{lcll}
\hline Polymer & $\begin{array}{l}\text { Temperature } \\
\left({ }^{\circ} \mathrm{C}\right)\end{array}$ & $\begin{array}{l}K \times 10^{8} \\
\left(\mathrm{~mol} . \mathrm{I}^{-1} . \mathrm{s}^{-1}\right)\end{array}$ & $\begin{array}{l}E_{\text {act }} \\
\left(\mathrm{kJ} . \mathrm{mol}^{-1}\right)\end{array}$ \\
\hline PET & 99 & 6 & 107 \\
PET & 60 & 0.08 & 107 \\
PC & 85 & 0.2 & 75 \\
PC & 100 & 0.7 & 75 \\
Unsaturated polyesters & 100 & $20-150$ & $70 \pm 10$ \\
Vinylesters & 100 & $0.2-1.0$ & - \\
\hline
\end{tabular}

Source: Bellenger et al., 1995.

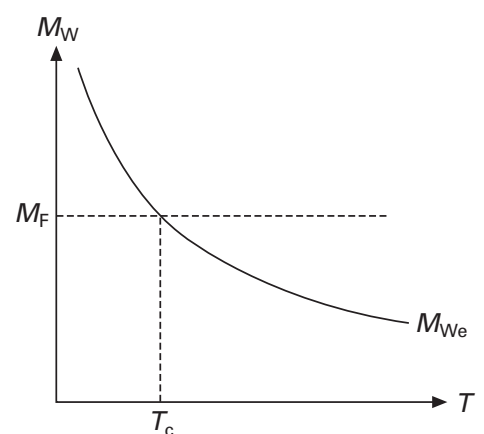

(a)

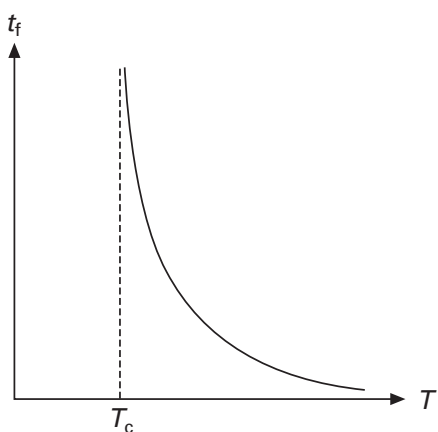

(b)

12.22 (a) Molar mass-temperature map; (b) lifetime versus temperature.

2. Equilibrium occurs at low conversions (typical case of PA11 and PA6-6). Then, the reverse reaction cannot be neglected and the kinetic model is somewhat more complicated (Jacques et al., 2002; El Mazry et al., 2012), especially when acids are present (Merdas et al., 2003). It can be easily shown that the equilibrium molar mass $M_{\mathrm{We}}$ (when $t \rightarrow \infty$ ) is given by:

$$
M_{\mathrm{We}}=2\left(\frac{k_{\mathrm{R}}}{k_{\mathrm{H}} E_{0} C}\right)^{1 / 2}
$$

The molar mass is a decreasing exponential function of temperature (Fig. 12.22). One can thus distinguish two important cases:

- If $T>T_{\mathrm{C}}$, then $M_{\mathrm{We}}<M_{\mathrm{F}}$. The material becomes brittle.

- If $T<T_{\mathrm{C}}$, then $M_{\mathrm{We}}>M_{\mathrm{F}}$. The material never becomes brittle, but reaches an equilibrium. Lifetime is theoretically infinite. In the case of PA11, $T_{\mathrm{C}} \approx 80^{\circ} \mathrm{C}$.

In composites, interphase hydrolysis can occur, e.g. in the case of silane 
coupling agents (Ishida and Koenig, 1980; Hoh et al., 1990; Salmon et al., 1997). The level of knowledge in this field remains far from what would be needed to predict lifetime from mechanical criteria.

Since hydrolysis is a chain scission process, it always induces embrittlement. In initially ductile linear polymers, such as PET or PA11, toughness falls off by two or three decades when the weight average molar mass reaches a critical value $M_{\mathrm{F}}$ of the order of $10-20 \mathrm{~mol} . \mathrm{kg}^{-1}$, corresponding to a small multiple of the entanglement molar mass (Fayolle et al., 2008). In the frame of second-order kinetics (rate constant $k_{\mathrm{H}}$ ), it is possible to determine a lifetime value corresponding to the time to embrittlement:

$$
t_{\mathrm{F}}=\left[\frac{2}{E_{0}}\left(\frac{1}{M_{\mathrm{F}}}-\frac{1}{M_{\mathrm{W} 0}}\right)\right]\left[\frac{1}{k_{\mathrm{H}}}\right]\left[\frac{1}{C}\right]
$$

This non-empirical quantity can be decomposed into three almost independent factors: the first linked to the polymer structure, the second to temperature through the Arrhenius law, and the third to water activity through the sorption isotherm equation. Note that this last factor can also slightly depend on temperature.

In thermosets, which are often initially brittle, chain scissions induce also a decrease in fracture properties, but the structure-property relationships are not yet well established in this domain.

\subsubsection{Hydrolysis-induced osmotic cracking}

In the most economically important class of hydrolysable thermosets, e.g. unsaturated polyesters (decks, swimming pools, tanks, etc.), failure comes generally from a specific consequence of hydrolysis: osmotic cracking. In laminates, subcutaneous cracks propagate preferentially parallel to the surface, giving blisters. This phenomenon was catastrophic for the composite boat industry in the 1970s and 1980s. It was later understood why cracks propagate. Indeed, they contain water in which solutes, coming from the polyester matrix, create an osmotic pressure which increases until stress concentration at crack tips induces propagation. Then, the pressure decreases until the crack stops, but new solutes are released by the polymer, the osmotic pressure increases again, etc. (Ashbee et al., 1967; Ashbee and Wyatt, 1969). The mechanism of crack initiation was elucidated by Gautier et al. (1999): it is due to the accumulation of small highly hydrophilic molecules (diacids, dialcohols) resulting from hydrolysis events near the end of dangling chains (these latter pre-existing or being formed by hydrolysis events on elastically active chains). The composite resistance to osmotic cracking would be thus linked to three factors having additive effects on the initiation rate: the initial presence of solutes linked to the polymerization catalysts; the initial presence of dangling chains (which is a decreasing function of the prepolymer molar 
mass); and the polyester hydrolysis rate. If, by a proper optimization of the above factors, the rate of small molecules release is lowered enough, then they can eventually disappear (at least partially) by diffusion, and the time to cracking increases considerably, or even becomes infinite.

In the case of glass fibre/unsaturated polyester matrix composites, the kinetic curve of weight changes can present a peculiar shape revealing the presence of osmotic cracking (see Fig. 12.23). Such behaviour can be explained as follows:

- At time $t_{1}$, sorption equilibrium is reached.

- At $t_{2}$, cracks initiate and the sorption capacity of the sample increases.

- At $t_{3}$, cracks coalesce and organic molecules, resulting from polymer hydrolysis and dissolved in water contained in the cracks, are extracted. The weight begins to decrease.

Note that the phenomena of sorption and cracking are distinguishable if the sample thickness $L$ is low enough to have $t_{\mathrm{D}}<t_{\mathrm{C}}$, where $t_{\mathrm{D}}=L^{2} / D$ is the characteristic time of diffusion, $D$ is the diffusion coefficient of water in the material, and $t_{\mathrm{C}}$ is the characteristic time of osmotic cracking, mainly linked to the hydrolysis rate and independent of thickness (Gautier et al., 1999).

\subsection{Mechanisms of chemical ageing: oxidation processes}

Oxidation processes are especially important in hydrocarbon polymer matrices. These processes result from a radical chain reaction established

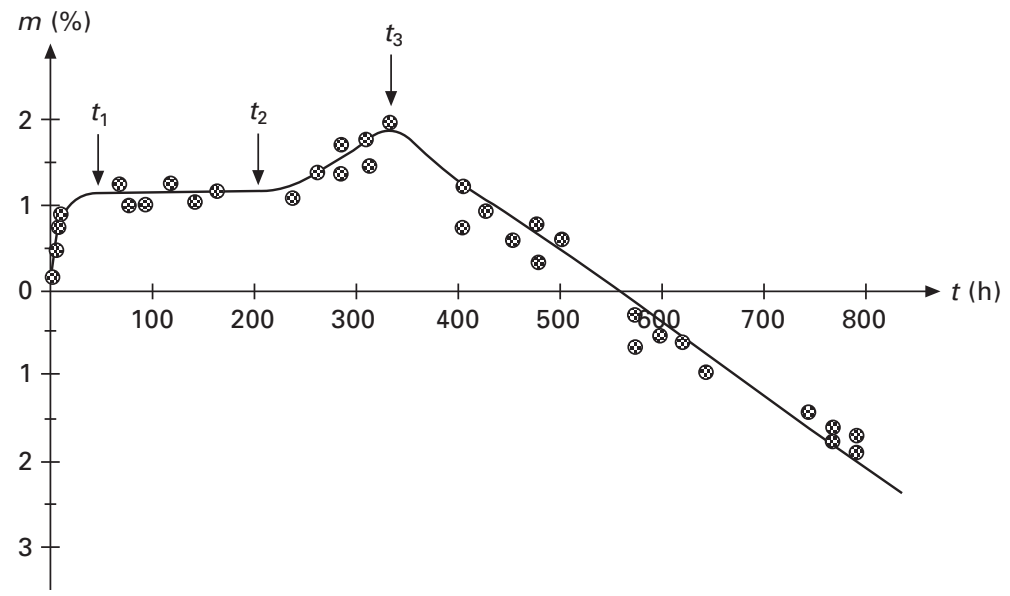

12.23 Osmotic cracking in a polyester for boat hulls, as revealed by the kinetic curve of weight changes after immersion in boiling water (according to Mortaigne et al., 1992). 
for the first time by Semenov (who was awarded a Nobel Prize in 1956) and co-workers in the 1930s (Semenov, 1935). However, in the polymer community of western countries, this mechanism remained ignored until the end of the Second World War, when it was rediscovered by a British team (Bolland and Gee, 1946) and then called the 'standard oxidation scheme'. In its general form, it involves six elementary steps:
1. Polymer
$\rightarrow \mu \mathrm{P}^{\bullet}$
$\left(r_{1}\right)$
2. $\mathrm{P}^{\bullet}+\mathrm{O}_{2}$
$\rightarrow \mathrm{PO}_{2}^{\bullet}$
3. $\mathrm{PO}_{2}^{\bullet}+$ polymer
$\rightarrow$ Per $+\mathrm{P}^{\bullet}$
$\left(k_{3}\right)$
4. $\mathrm{P}^{\bullet}+\mathrm{P}^{\bullet}$
$\rightarrow$ inactive products
$\left(k_{4}\right)$
5. $\mathrm{P}^{\bullet}+\mathrm{PO}_{2}^{\bullet}$
$\rightarrow$ inactive products
$\left(k_{5}\right)$
6. $\mathrm{PO}_{2}^{\bullet}+\mathrm{PO}_{2}^{\bullet}$
$\rightarrow$ inactive products $+\mathrm{O}_{2}$

where Per, $\mathrm{P}^{\bullet}$ and $\mathrm{PO}_{2}^{\bullet}$ refer respectively to peroxides and alkyl and peroxy radicals, $r_{1}$ is the initiation rate, $k_{i}$ are rate constants, and $\mu$ is the yield of radicals formation in initiation.

Oxidation propagates in two elementary steps:

1. Oxygen addition to alkyl radicals. This is a very fast process and thus practically structure and temperature independent. The corresponding rate constant is very high: $k_{2}=10^{8}-10^{9} 1 . \mathrm{mol}^{-1} \cdot \mathrm{s}^{-1}$ (Kamiya and Niki, 1978).

2. Peroxyl radical reaction with the polymer. This is a generally much slower process, which is structure dependent. In saturated hydrocarbon polymers, e.g. polyethylene (PE) and polypropylene (PP), it is exclusively a hydrogen atom abstraction. In this case, Per is a hydroperoxide group $(\mathrm{POOH})$. The corresponding rate constant is very low: $k_{3}=10^{-3}-10^{-1}$ 1.mol ${ }^{-1} \cdot \mathrm{s}^{-1}$ at ambient temperature (see Table 12.7). In polyenic elastomers, e.g. polybutadiene (PBD) and polyisoprene (PIP), step 3 can also be an addition to double bonds. In this case, Per is a peroxide bridge (POOP). The corresponding rate constant is also very low: typically $k_{3}=10^{-1}-10$ $1 . \mathrm{mol}^{-1} \cdot \mathrm{s}^{-1}$ at ambient temperature for an intramolecular addition (see Table 12.7).

In the absence of antioxidants, radicals terminate according to bimolecular processes (steps 4, 5 and 6). At relatively low temperature, close to ambient temperature, the corresponding termination rate constants classify in the following order (Gillen et al., 1995):

$$
k_{4}>k_{5}>k_{6}
$$

whereas the corresponding activation energies classify in the reverse order, mainly because $\mathrm{P}^{\bullet}$ radicals can propagate by hydrogen abstraction: 
Table 12.7 Propagation reactions of oxidation and corresponding value of the rate constant $\left(k_{3}\right)$ at ambient temperature in some common hydrocarbon polymers: polypropylene (PP), polyethylene (PE), polybutadiene (PBD) and polyisoprene (PIP)

\begin{tabular}{llll}
\hline Type of propagation & Polymer & $k_{3}\left({\left.\mathrm{I} . \mathrm{mol}^{-1} . \mathrm{s}^{-1} \mathrm{or} \mathrm{s}^{-1}\right)}\right.$ & Reference \\
\hline Hydrogen atom & PP & $1.0 \times 10-3$ & Korcek et al., 1972 \\
abstraction & PE & $2.4 \times 10^{-3}$ & Korcek et al., 1972 \\
& PBD & $4.9 \times 10^{-3}$ & Coquillat et al., 2007 \\
& PIP & $5.2 \times 10^{-2}$ & Colin et al., 2007 \\
Intramolecular addition & PBD & $6.1 \times 10^{-1}$ & Coquillat et al., 2007 \\
to double bonds & PIP & 2.7 & Colin et al., 2007 \\
Intermolecular addition & PBD & $5.8 \times 10^{-4}$ & Coquillat et al., 2007 \\
to double bonds & PIP & - & Colin et al., 2007 \\
\hline
\end{tabular}

$$
\mathrm{P}^{\bullet}+\mathrm{PH} \rightarrow \mathrm{PH}+\mathrm{P}^{\bullet}
$$

This transfer reaction does not influence the whole oxidation kinetics (except for polyenic elastomers), but provides a simple explanation for a relatively high mobility of alkyl radicals and thus for a high $k_{4}$ value.

However, at moderate to high temperature, elementary steps 5 and 6 lead mainly to unstable peroxide bridges (POOP). As a result, Equation [12.48] is no longer valid. As an example, when $T>200^{\circ} \mathrm{C}$, it is instead observed that (Colin and Verdu, 2003; Assadi et al., 2004; Nait-Ali et al., 2011):

$$
k_{4}>k_{5} \approx k_{6}
$$

The most debated aspect of the subject during the past half-century has been the initiation of oxidation. Initiation processes can be very varied and complex. They depend on both the polymer nature $(\mathrm{PH})$ and the way that energy is brought to organic material (by temperature or radiation). Although the intermediate steps are not always totally known and understood (mainly because of the lack of sufficiently sensitive analytical methods to elucidate the corresponding structural changes), this problem simplifies considerably because all initiation processes lead finally to the formation of $\mathrm{P}^{\bullet}$ and/or $\mathrm{PO}_{2}^{\bullet}$ radicals.

For the sake of simplicity, we will consider only the case of oxygen excess (a relatively thin polymer sample exposed to a relatively high oxygen pressure). In this case, all the $\mathrm{P}^{\bullet}$ radicals are almost instantaneously transformed into $\mathrm{PO}_{2}^{\bullet}$ ones and then, their probability of participating in reactions other than reaction 6 , in particular reactions 4 and 5 , is negligible. As a result, the 'standard oxidation scheme' reduces to four elementary steps $(1,2,3$ and 6). One can distinguish two important initiation processes according to the type of oxidative ageing under consideration. 


\subsubsection{Initiation of oxidation: initiation at a constant rate (Case 1)}

In the case of radiochemical ageing (high energy provided), the main source of radicals is the polymer radiolysis, i.e. the breakdown of lateral bonds of the monomer unit. As an example, in the case of PE, radiolysis leads to the formation of very reactive radicals $\mathrm{H}^{\bullet}$ which recombine rapidly by hydrogen atoms abstraction:

$$
\begin{aligned}
& \sim \sim \mathrm{CH}_{2}-\mathrm{CH}_{2}-\mathrm{CH}_{2} \backsim v+h v \rightarrow \sim \sim \mathrm{CH}_{2}-\mathrm{C} \mathrm{H}-\mathrm{CH}_{2} \backsim \sim+\mathrm{H}^{\bullet} \\
& \mathrm{H}^{\bullet}+\sim \sim \mathrm{CH}_{2}-\mathrm{CH}_{2}-\mathrm{CH}_{2} \backsim \sim \rightarrow \sim \sim \mathrm{CH}_{2}-\mathrm{C} \mathrm{H}-\mathrm{CH}_{2} \backsim \sim+\mathrm{H}_{2}
\end{aligned}
$$

Thus, the corresponding balance initiation can be written:

$$
\mathrm{PH} \rightarrow \mathrm{P}^{\bullet}+\frac{1}{2} \mathrm{H}_{2}\left(\mathrm{r}_{1}\right)
$$

where the initiation rate $r_{l}$ is proportional to the dose rate $I$ according to:

$$
r_{1} \approx 10^{-7} G_{1} I
$$

and $G_{1}$ is the radical yield expressed in number of radicals $\mathrm{P}^{\bullet}$ per $100 \mathrm{eV}$ absorbed, of the order of magnitude of 1-10 for saturated hydrocarbon polymers (Colin et al., 2010). In this case, the reaction rapidly reaches a steady state and oxidation products accumulate with a constant rate (Fig. 12.24).

One can easily demonstrate that initiation and termination products form with a rate proportional to $r_{1}$. As an example, if ketones are formed with a yield $\gamma_{\mathrm{K}}$ in termination:

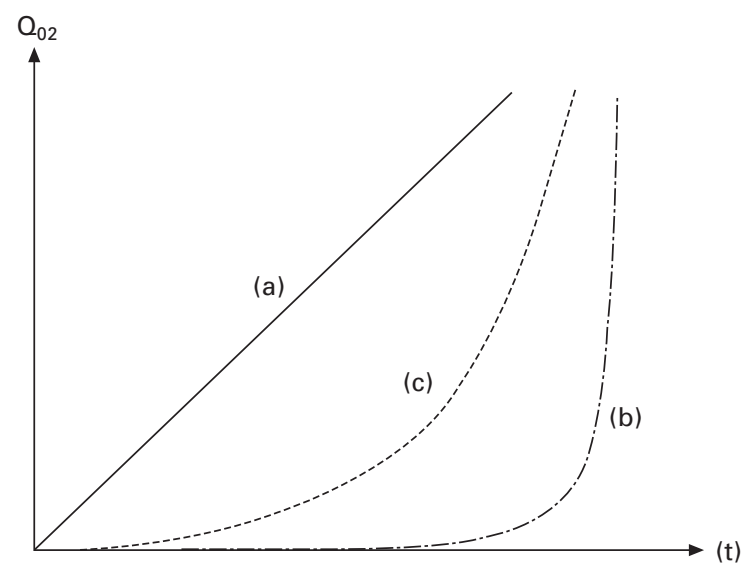

12.24 Shape of oxidation kinetic curves in the case of initiation (a) at constant rate (case of radiochemical ageing); (b) by bimolecular Per decomposition (thermal ageing); and (c) by unimolecular Per decomposition (case of many photochemical ageings). 


$$
r_{\mathrm{K}}=\gamma_{\mathrm{K}} k_{6}\left[\mathrm{PO}_{2}^{\circ}\right]^{2}=\frac{\gamma_{\mathrm{K}}}{2} r_{1}
$$

On the contrary, propagation products form with a rate proportional to the square root of $r_{1}$, e.g. for peroxides:

$$
r_{\mathrm{Per}}=k_{3}\left[\mathrm{PO}_{2}^{*}\right][\mathrm{PH}]=k_{3}[\mathrm{PH}]\left(\frac{r_{1}}{2 k_{6}}\right)^{1 / 2}
$$

Finally, oxygen is consumed with a rate:

$$
r_{\mathrm{O} 2}=k_{2}\left[\mathrm{O}_{2}\right]\left[\mathrm{P}^{\bullet}\right]-k_{6}\left[\mathrm{PO}_{2}^{*}\right]^{2}=\frac{r_{1}}{2}+k_{3}[\mathrm{PH}]\left(\frac{r_{1}}{2 k_{6}}\right)^{1 / 2}
$$

\subsubsection{Initiation of oxidation: initiation by decomposition of peroxides (Case 2)}

In the case of thermal and photochemical ageing (lower energy provided), the problem is significantly more complex. Chemical bonds of common industrial polymers rarely have a dissociation energy lower than $260 \mathrm{~kJ} \mathrm{~mol}^{-1}$ (Table 12.2) and thus decompose only at high temperatures (typically, at $T$ $>250^{\circ} \mathrm{C}$ ) or at high irradiation intensities (e.g. under gamma-irradiation in a nuclear environment). However, it has been seen, in the previous sections, that oxidation leads to the formation of two main propagation products: hydroperoxide groups $(\mathrm{POOH})$ and peroxide bridges (POOP), noted as Per, of which the activation energy of the $\mathrm{O}-\mathrm{O}$ bond is very low: $E_{\mathrm{D}} \approx 150$ $\mathrm{kJ} . \mathrm{mol}^{-1}$. Such chemical groups are thermally and photo-chemically unstable, in particular in common use conditions.

It cannot be totally excluded that 'extrinsic species' generate also primary radicals (e.g. decomposition of structural irregularities or direct oxygenpolymer reaction). But it can be easily demonstrated that their contribution to initiation is very limited: the corresponding initiation rate is initially very low and vanishes rapidly (as soon as the 'extrinsic species' concentration vanishes). As a result, in all cases, initiation by Per decomposition rapidly becomes the main source of radicals. From a kinetic modelling point of view, the following approach is usually adopted: the initially present 'extrinsic species' are replaced by a kinetically equivalent initial Per concentration: $[\text { Per }]_{0}$. Thus, initiation involves two important reactions:

$$
\delta_{\mathrm{Per}} \rightarrow \alpha \mathrm{P}^{\bullet}+\beta \mathrm{PO}_{2}^{\bullet}\left(k_{1}\right)
$$

with $\alpha=2$ and $\beta=0$ for unimolecular decomposition ( $\delta=1)$, and $\alpha=1$ and $\beta=1$ for bimolecular decomposition $(\delta=2)$.

Then, the initiation rate depends on Per concentration: 


$$
r_{1}=k_{1}[\mathrm{Per}]^{\delta}
$$

This oxidation mechanism is called a 'close-loop mechanism', as it produces its own initiator product (Per). The resulting kinetic curves present an induction period followed by a sharp auto-acceleration, preceding a steady state. The auto-acceleration step is much more progressive in its initial phase when Per decomposition is unimolecular (the case for many photochemical ageings) (see Fig. 12.23).

According to analytical models, the duration of the induction period for a unimolecular decomposition is given by:

$$
t_{\mathrm{i}} \approx \frac{5}{2 k_{1}}
$$

and for a bimolecular decomposition by:

$$
t_{\mathrm{i}} \approx \frac{1-\ln Y_{0}}{K}
$$

where $K=k_{3}[\mathrm{PH}]\left(k_{1} / k_{6}\right)^{1 / 2}$ and $Y_{0}=[\mathrm{Per}]_{0} /[\mathrm{Per}]_{\mathrm{s}}$

Moreover, in steady state, the Per concentration is:

$$
[\mathrm{Per}]_{\mathrm{s}}=-\delta k_{1}[\mathrm{Per}]^{\delta}+k_{3}\left[\mathrm{PO}_{2}^{*}\right][\mathrm{PH}]=\left[\frac{k_{3}^{2}[\mathrm{PH}]^{2}}{\delta^{2} k_{1} k_{6}}\right]^{1 / \delta}
$$

and the rate of oxygen consumption is:

$$
r_{\mathrm{O}_{2} \mathrm{~S}}=k_{2}\left[\mathrm{O}_{2}\right]\left[\mathrm{P}^{\bullet}\right]-k_{6}\left[\mathrm{PO}_{2}^{\bullet}\right]^{2}=\frac{2}{\delta^{2}} \frac{k_{3}^{2}[\mathrm{PH}]^{2}}{k_{6}}
$$

\subsubsection{Prediction of polymer oxidizability}

From the previous kinetic analysis of the 'standard oxidation scheme', it is possible to state that the oxidation kinetic behaviour of a given hydrocarbon polymer matrix depends on two main factors:

- An extrinsic factor (i.e. an external factor to the polymer structure): initiation rate $r_{1}$ or initiation rate constant $k_{1}$

- An intrinsic factor: ratio $k_{3}[\mathrm{PH}] / \sqrt{k_{6}}$.

According to some authors (Korcek et al., 1972), there is a linear relationship between $\log k_{3}$ and the dissociation energy $E_{\mathrm{D}}$ of $\mathrm{CH}$ bonds. Thus, in a first approach, the polymer oxidizability can be roughly estimated from the reactivity of the $\mathrm{CH}$ bonds involved (see Table 12.8).

The following global trends can be deduced: 


\begin{tabular}{ll}
\hline $\mathrm{CH}$ bond & $E_{\mathrm{D}}\left(\mathrm{kJ} \cdot \mathrm{mol}^{-1}\right)$ \\
\hline & 465 \\
$-\mathrm{CH}_{3}$ & 414 \\
$>\mathrm{CH}_{2}-\mathrm{CH}_{2}-$ & 393 \\
$-\mathrm{CH}-$ & 378 \\
$-\mathrm{O}-\mathrm{CH}_{2}-$ or $-\mathrm{N}-\mathrm{CH}_{2}-$ & 376 \\
$>\mathrm{C}=\mathrm{CH}-\mathrm{CH}_{2}-$ & 335 \\
\hline
\end{tabular}

- Polymers without $\mathrm{CH}$ bonds, e.g. poly(tetrafluoroethylene) (PTFE), or containing exclusively aromatic $\mathrm{CH}$ bonds, e.g. poly(ether ether ketone) (PEEK), poly(ether sulfone) (PES) and polyimides (PI), are stable to oxidation.

- Polymers containing exclusively methyl $\mathrm{CH}$ bonds, e.g. poly(dimethyl siloxane) (PdMS), or containing methyl and methylene $\mathrm{CH}$ bonds, e.g. poly(methyl methacrylate) (PMMA), polycarbonate (PC) and polyethylene (PE), are moderately stable.

- Polymers containing methyne $\mathrm{CH}$ bonds, e.g. polypropylene (PP), or methylene $\mathrm{CH}$ bonds in the $\alpha$ position of a heteroatom, e.g. poly(methylene oxide) (POM), polyamides (PA) and amine cross-linked epoxy (ACE), are relatively unstable.

- Finally, polymers containing allylic $\mathrm{CH}$ bonds, e.g. polyisoprene (PIP) and polybutadiene (PBD), are highly unstable.

The above section has treated oxidation kinetics only through polymer intrinsic stability. But there are other factors of determining importance to take into account, for instance:

- Oxygen diffusivity allows oxygen transport into deeper layers of the material. It is about three orders of magnitude higher in elastomers than in glassy polymers. Thus, at equal reactivity, glassy polymers appear much more stable than elastomers, because their superficial oxidized layer is considerably thinner.

- Polymer sensitivity to macromolecular changes resulting from oxidation is a key factor from the mechanical point of view. As an example, mechanical embrittlement occurs in polypropylene (PP) for a number of chain scissions 10 times lower than in an amorphous polymer. Thus, at equal reactivity, according to this mechanical endlife criterion, PP will be 10 times less stable than an amorphous polymer. 


\subsubsection{Oxidation-induced spontaneous cracking}

Oxidation is kinetically controlled by oxygen diffusion in FRP composites. In other words, in relatively thick FRP structures (typically $2 \mathrm{~mm}$ thick), oxidation is restricted to a superficial layer of thickness $\ell_{\mathrm{ox}}$. As shown previously in this chapter, $\ell_{\mathrm{ox}}$ can be determined from Equation [12.33]. But it can also be estimated from a simple scaling law (Audouin et al., 1994):

$$
\ell_{\mathrm{ox}}=\left(\frac{D C_{\mathrm{S}}}{r_{\mathrm{S}}}\right)^{1 / 2}
$$

where $D$ is the coefficient of oxygen diffusion in the polymer matrix, and $C_{\mathrm{S}}$ and $r_{\mathrm{S}}$ are respectively the equilibrium concentration and consumption rate of oxygen in the superficial layer of the material.

As shown previously, $C_{\mathrm{S}}$ is generally temperature independent, whereas the diffusion coefficient $D$ obeys an Arrhenius law:

$$
D=D_{0} \exp \left(-\frac{E_{\mathrm{D}}}{R T}\right)
$$

where $D_{0}$ and $E_{\mathrm{D}}$ are respectively the pre-exponential factor and activation energy of oxygen diffusion.

Moreover, the temperature effect on $r_{\mathrm{S}}$ can be satisfyingly approximated by an Arrhenius law:

$$
r_{\mathrm{S}}=r_{\mathrm{S} 0} \exp \left(-\frac{E_{\mathrm{r}}}{R T}\right)
$$

where $r_{\mathrm{S} 0}$ and $E_{r}$ are respectively the pre-exponential factor and activation energy of reactant consumption.

Finally, one can see that $\ell_{\mathrm{ox}}$ also obeys an Arrhenius law:

$$
\ell_{\mathrm{ox}}=\ell_{0} \exp \left(-\frac{E_{\ell}}{R T}\right)
$$

where $\ell_{0}=\left(D_{0} C / r_{\mathrm{S} 0}\right)^{1 / 2}$ and $E_{\ell}=\frac{1}{2}\left(E_{\mathrm{D}}-E_{\mathrm{r}}\right)$.

In most cases of thermal oxidation and hydrolysis, $E_{\mathrm{D}}<E_{\mathrm{r}}$ so that $E_{\ell}$ is negative. Thus, $\ell_{o x}$ is a decreasing function of temperature.

In the case of irradiation-induced chemical ageing, e.g. radio- and photooxidation, $C_{\mathrm{S}}$ and $D$ are light intensity independent (Equation [12.60] remains valid). At the opposite, it can be demonstrated that the effect of light intensity $I$ on $r_{S}$ can be satisfyingly approximated by a simple power law:

$$
r_{\mathrm{S}} \propto I^{\alpha}
$$

with $\alpha=\frac{1}{2}$ in the simplest models.

Thus, $\ell_{\mathrm{ox}}$ is a slowly decreasing function of dose rate given by: 


$$
\ell_{\mathrm{ox}} \propto I^{-\alpha / 2}
$$

The fact that the thickness of the degraded layer is, in general, a decreasing function of the 'severity' of ageing conditions has been systematically observed by many authors.

Degradation gradients, resulting from diffusion control of chemical reaction kinetics, play an important role from a mechanical point of view. Schematically, an initially ductile/tough and homogeneous polymer sample is progressively transformed into a binary structure, the sample core remaining ductile/tough, whereas the superficial layer becomes brittle and thus highly sensitive to cracking (Colin et al., 2005). A superficial crack can rapidly cross the whole superficial layer thickness and reach the skin-core interface. At this stage, two scenarios can take place (Fig. 12.25):

1. The crack tip blunts and remains restricted to the sample superficial layers.

2. The crack crosses the interface and propagates in the core. Since cracks are a preferred path for penetration of small reactive molecules, the degradation front moves towards deeper layers. A secondary degraded layer, of the same thickness as the primary one, forms beyond the crack tip, and so on. Following this scheme, failure will ultimately occur, even without external loading.

In a first approach, one can consider that the brittle superficial layer is equivalent to a 'natural' notch with the same depth. Fracture mechanics

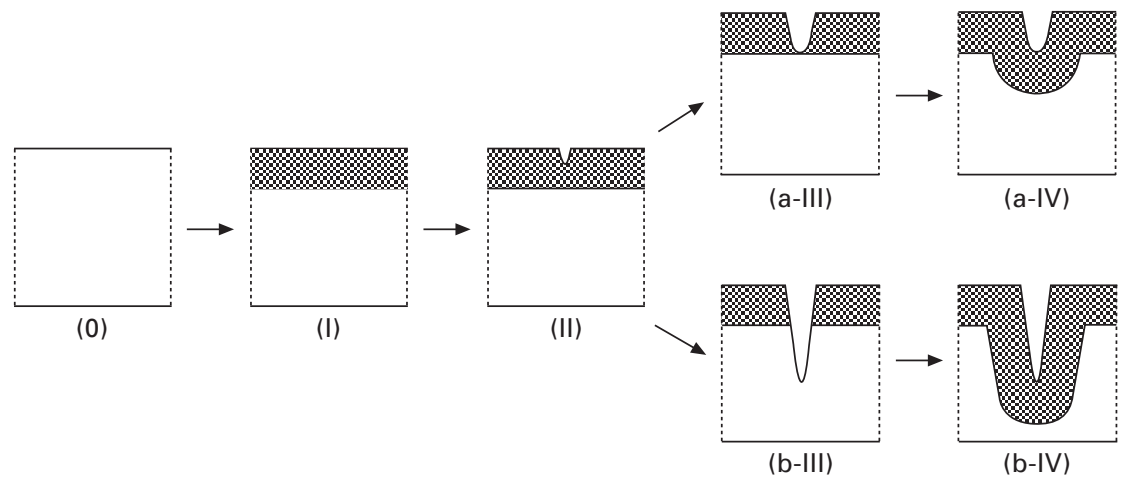

12.25 Schematization of chemical ageing-induced cracking. Sample zones where the polymer chemical structure has been changed are represented in grey. (0) Initial (virgin) sample; (I) superficial degraded layer below its embrittlement threshold; (II) superficial degraded layer close to its embrittlement threshold; (a-III) crack having reached the skin-core interface and having blunted; (b-III) crack having crossed the interface; (a-IV) and (b-IV) propagation of oxidation front towards deeper layers. 
(Griffith, 1921) predicts that there is a critical notch depth below which the notch does not initiate the material failure. This depth depends on the material toughness, this latter depending, in turn, on the rate of crack propagation. As an example, in the case of PE oxidation, this depth is of the order of magnitude of $100 \mu \mathrm{m}$ (Audouin and Verdu, 1991). It is thus expected that rapid chemical ageing, leading to very small thicknesses of degraded layer, will have less effect on the material fracture behaviour than slower ones. This general trend has also been observed by many authors.

\subsection{Chemical ageing: stabilization techniques}

One can envisage two possible ways of stabilization of the polymer matrix against chemical ageing:

- Internal stabilization will consist in modifying the polymer chemical structure by copolymerization, grafting or substitution, in order to reduce significantly the concentration of unstable groups (ester or amide groups in the case of hydrolysis, aliphatic $\mathrm{CH}$ groups in the case of oxidation).

- External stabilization will consist in adding appropriate additives into the polymer matrix either to restrict access by the chemical reactant or to inhibit the chemical reaction.

During the past three decades, many research works have shown a significant improvement in the gas barrier properties of nanofiller reinforced polymer membranes (Espuche, 2011). It was demonstrated that the adding of nanofillers (layered clays, carbon blacks or nanotubes, etc.) into a polymer matrix increases significantly the tortuosity of diffusion paths. Unfortunately, this physical way of external stabilization is still often ignored by practitioners.

In contrast, chemical ways of external stabilization, in particular for inhibiting the chain reaction such as by thermal or photo-oxidation, have long been well known by practitioners. They have been the subject of an abundant literature and reviews (Reich and Stivala, 1969; Hawkins, 1971; Kamiya and Niki, 1978; Zweifel, 2001). There are two main families of antioxidants which can be combined in a polymer matrix in order to constitute efficient synergistic blends of antioxidants:

- F1: Organic sulphides and phosphites decompose hydroperoxides (POOH) into non-radical species and thus reduce significantly the initiation rate of oxidation.

- F2: Hindered phosphites or secondary aromatic amines transform peroxy radicals $\left(\mathrm{PO}_{2}{ }^{\circ}\right)$ into hydroperoxides and thus interrupt efficiently the propagation of oxidation.

Except for carbon black, antioxidants are synthetic products. They are relatively expensive and moderately soluble into polymers. Therefore, their 
use makes sense only if they are efficient stabilizers at low concentration. The existence of such a property can be attributed to the 'auto-accelerated' character of thermal oxidation kinetics. Indeed, in the induction period, thermal oxidation involves very low concentrations of reactive species $\left(\mathrm{POOH}, \mathrm{PO}_{2}^{\circ}\right.$ ) which can thus be efficiently scavenged by low concentrations of antioxidants (Verdu et al., 2003).

\subsection{Fibre and interfacial degradation}

Although the reinforcing fibres are protected from direct exterior aggression by the embedding polymer matrix, they may experience substantial chemical and physical attack due to the ingress of moisture, alkaline or salt solutions in the FRP composite. In addition, these effects may be emphasized if additional sustained loads are applied to the composite materials. In this section, the various degradation mechanisms are briefly recalled for the main types of fibres used in construction.

\subsubsection{Corrosion of glass fibres}

Glass fibres are very sensitive to corrosion induced by moisture and aqueous environments (acidic, basic or neutral). The degradation mechanisms are well known and have been extensively reported by various authors (Charles, 1958; Metcalfe et al., 1971; Michalske and Frieman, 1983; Smets, 1985). When a glass fibre is exposed to an aqueous solution, the water first wets the surface and then diffuses into the glass network. Several chemical reactions may then occur between the glass and reactive species from the aqueous solution $\left(\mathrm{H}_{2} \mathrm{O}, \mathrm{H}_{3} \mathrm{O}^{+}, \mathrm{OH}^{-}\right.$and metal ions produced by dissolving metal hydroxides in water), depending on both the $\mathrm{pH}$ of the solution and the composition of the glass:

- A leaching process, i.e. an ion exchange process or the selective removal of soluble constituents, is the predominant phenomenon in acidic media.

- An etching process involving a dissolution of the glass is a common feature in alkaline media.

\section{Corrosion of glass fibres in acidic environments}

The degradation of glass in contact with an acidic solution is characterized by an exchange of ions between the surface of the glass and the solution, and is known as a desalkalinization or leaching process. The accepted mechanism involves the replacement of metal ions associated with the glass surface by $\mathrm{H}^{+}$from the acid medium, according to the following reaction (Metcalfe and Schmitz, 1972): 


$$
\overline{\mathrm{M}^{n+}}+n \mathrm{H}^{+} \rightleftarrows \overline{n \mathrm{H}^{+}}+\mathrm{M}^{n+}
$$

where the bars indicate the species associates with glass. Since protons are smaller in size than the replaced cations, tensile stresses are induced in the surface of the glass and can become large enough to promote cracking. As a result, the composite material may fracture under relatively low mechanical stress, or even spontaneously in the absence of mechanical stress (Jones and Chandler, 1984).

It was originally presumed that the corrosion effect was mainly related to the acidic strength of the solution $\left(\mathrm{H}^{+}\right.$concentration), but later studies showed that the associated anion can also play a significant role if it can form complex or insoluble species with the cations of the glass (Jones and Chandler, 1984). Such complex formation will consume leached cations and drive Equation [12.65] to the right, hence emphasizing the leaching process. This particular phenomenon may explain the severe corrosion effects observed with relatively weak acids such as oxalic acid.

In addition, the tendency of an ion to deplete would be related to the characteristics of this ion (bond energy in the glass network, valence state, hydrated volume). More generally, the extent of corrosion depends on the nature and concentration of the acid, on the glass composition and on the manufacturing process of the glass fibres (Kumosa, 2001).

\section{Corrosion of glass fibres in neutral aqueous solutions}

The diffusion of chemical species is the predominant mechanism driving corrosion in neutral solutions. After water diffusion into the glass network, hydration of alkaline oxides present in all glass formulations (even the most resistant) leads to the diffusion of $\mathrm{Na}^{+}$and $\mathrm{OH}^{-}$ions towards the surface and the aqueous medium (Equation [12.66]). Hydroxide ions may then lead to the hydrolysis of siloxane bonds (etching) without being consumed, as shown in Equations [12.67] and [12.68] (Ishai, 1975). This is an autocatalytic process, as the rate of dissolution of the glass increases with time.

$$
\begin{aligned}
& \mathrm{Si}-\mathrm{O}-\mathrm{Na}+\mathrm{H}_{2} \mathrm{O} \rightarrow \mathrm{SiOH}+\left(\mathrm{Na}^{+}, \mathrm{OH}^{-}\right) \\
& \mathrm{Si}-\mathrm{O}-\mathrm{Si}+\mathrm{OH}^{-} \rightarrow \mathrm{SiOH}+\mathrm{SiO}^{-} \\
& \mathrm{SiO}^{-}+\mathrm{H}_{2} \mathrm{O} \rightarrow \mathrm{SiOH}+\mathrm{OH}^{-}
\end{aligned}
$$

\section{Corrosion of glass fibres in alkaline media}

The predominant mechanism over $\mathrm{pH} 10$ is the degradation of the silica network (etching). In this case, hydroxide ions of the alkaline solution lead directly to the break-up of Si-O-Si linkages (Equation [12.67]). This effect 
is exacerbated by elevated temperatures and prolonged exposures. In the case of civil engineering applications, FRP materials may be embedded in concrete (internal rebars) or in contact with concrete (external strengthening of concrete structures). The concrete pore solution has a $\mathrm{pH}$ value in the range 12-13.5, depending on cement formulation. It can severely affect the glass fibres (loss in strength, embrittlement), due to combination of the chemical attack and the growth of hydration products between the glass filaments. Hydroxylation can cause fibre surface pitting, which acts as flaws and degrades the overall mechanical properties (Benmokrane et al., 2006). Several solutions are available for improving the chemical resistance of glass fibres in concrete:

- Alkali resistant (AR) glass fibres have been developed with a specific formulation that includes a substantial amount of zirconia $\left(\mathrm{ZrO}_{2}\right)$. The higher the zirconia content, the better the resistance to alkali attack of the fibres.

- The application of a surface coating (styrene acrylic copolymer emulsions, for instance) on individual glass filaments may also protect the glass surface and enhance its alkali resistance.

\subsubsection{Corrosion of aramid and carbon fibres}

Aramid fibres are also known to be affected by moisture and alkaline environments. Due to the presence of amide functions on the polymer chain, Twaron or Kevlar fibres based on poly (p-phenylene terephthalamide) or PPTA, and Technora fibres based on copoly(paraphenylene/3,4'-oxydiphenylene terephthalamide) can all be subjected to hydrolysis. For instance, the hydrolysis mechanism of PPTA fibres involves a scission of the amide $\mathrm{N}-\mathrm{C}$ linkage and yields acid and amine end-functions, as shown below by Equation [12.69] (Morgan et al., 1984). These chain scissions are responsible for the deterioration of the mechanical strength of the fibres, and such an effect is emphasized by both temperature and exposure time. The $\mathrm{pH}$ of the environment is also a crucial parameter: the higher the deviation from neutrality (towards the acid or basic domains), the higher the rate of degradation. Under alkaline conditions, Technora fibres are usually considered more stable than PPTAbased fibres. For instance, following immersion in $\mathrm{NaOH}$ solution at $95^{\circ} \mathrm{C}$ for 100 hours, Technora fibres retain $75 \%$ of their tensile strength while PPTA fibres retain only 20\% (Imuro and Yoshida, 1986).

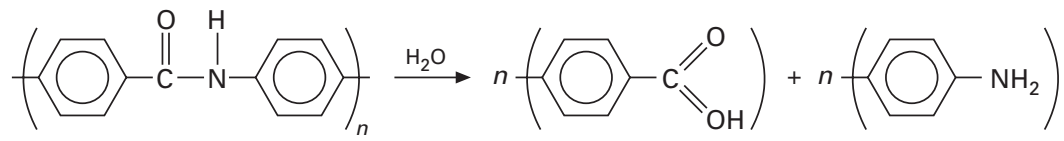


In contrast, carbon fibres are inert under normal service temperatures: they are usually considered insensitive to moisture and only little affected by alkaline environments. Therefore, apparent degradations of carbon fibre-reinforced composite are in general exclusively due to the interaction between the matrix and the environment. Besides, it is of note that galvanic corrosion may occur if CFRP composites are adventitiously placed in contact with metal elements, which usually contributes to accelerated corrosion of the metal components (Tavakkolizadeh and Saadatmanesh, 2001).

\subsubsection{Interfacial degradation}

The fibre-matrix interphase may be considered the most susceptible component of FRP composites in terms of degradation. First, it must be underlined that this interphase is the locus of many pre-existing defects that were created during the manufacturing process, such as air bubbles or local disbonds related to imperfect wetting of the reinforcing fibres by the polymer, or micro-cracks caused by residual stresses. These defects may grow and coalesce under the action of external loading (for instance, temperature or fatigue cycles), ultimately leading to transverse cracking and fibre-matrix debonding. In the case of hydrothermal ageing, the interphase is a privileged path for the penetration of the water and solutes by capillary action (the contribution of the interphase to the diffusion process in polymer composites has been discussed previously in Section 12.6). Water molecules may then break chemical and physical bonds between the fibres and the matrix by reacting, for instance, with the sizing or coupling agents, hence favouring interfacial debonding. In the case of alkali attacks on the reinforcing fibres, chemical reactions are also initiated from the fibre-matrix interface.

\subsection{Flammability of FRP composites}

The polymer phase of composite materials used in construction contains large amounts of carbon, hydrogen and nitrogen, which are all flammable to various extents if conditions of ignition are met (arson, vehicle accident, fire caused by cigarettes, adventitious ignition of spilt oil, etc.). In a fire situation, the main health hazard is caused by the release of smoke and toxic gases produced by the combustion of organic compounds; another crucial issue is also the structural integrity of the burning composite structure, as this may prematurely collapse, causing severe injuries to the occupants. Consequently, the problem of fire is a major concern for civil engineers who are planning to use composite materials, and the fire properties should be taken into account in the early design process, while choosing the material constituents (matrix and fibres).

After recalling the basic mechanisms involved in the combustion of 
polymer composites, the following sections will describe the main fire reaction properties of these materials and the different fireproofing solutions which can be implemented to enhance their flame resistance. The last part briefly discusses the degradation of the load-bearing capacity of composite-containing structures exposed to fire in the framework of various civil engineering applications (full-composite structures, FRP strengthening/retrofitting, and concrete structures reinforced by FRP rebars).

\subsubsection{Combustion principles}

A general scheme which summarizes the necessary conditions for combustion to occur is represented by the fire triangle (Fig. 12.26). This scheme involves three factors: the fuel materials (polymer matrix, and in some cases organic fibres), the combustive element (oxygen) and an additional heat source. If one of these factors is removed, the combustion phenomenon will not take place.

Combustion of polymer composites is a complex phenomenon (Fig. 12.27) which is largely governed by the chemical processes involved in the thermal decomposition of the organic phases, i.e., the polymer matrix and the organic fibres (if the latter are used as reinforcing materials). These chemical reactions may occur in three interdependent regions: within the condensed phase, at the interface between the condensed and the gas phase, or in the gas phase. It is generally admitted that combustion involves four main stages, which are heating, thermal decomposition, ignition and propagation (Cullis and Hirschler, 1981; Troitzsch, 2004; Mouritz and Gibson, 2006):

1. The initial phase consists in the heating of the FRP composite under the effect of an external heat flux produced by a pre-existing fire or a radiant source. The resulting temperature increase leads to the softening or even the melting of the polymer matrix in the case of thermoplastic systems. Thermosetting systems are less affected, due to their cross-

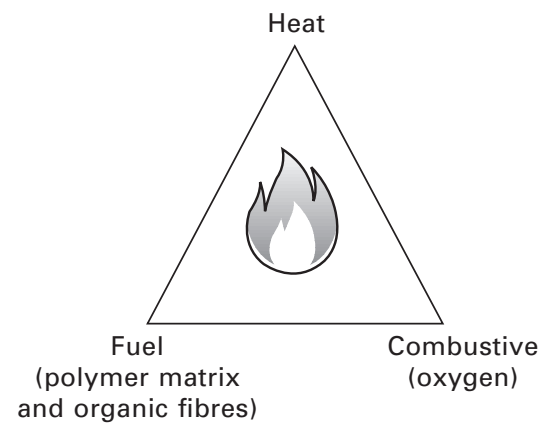

12.26 Representation of the fire triangle. 


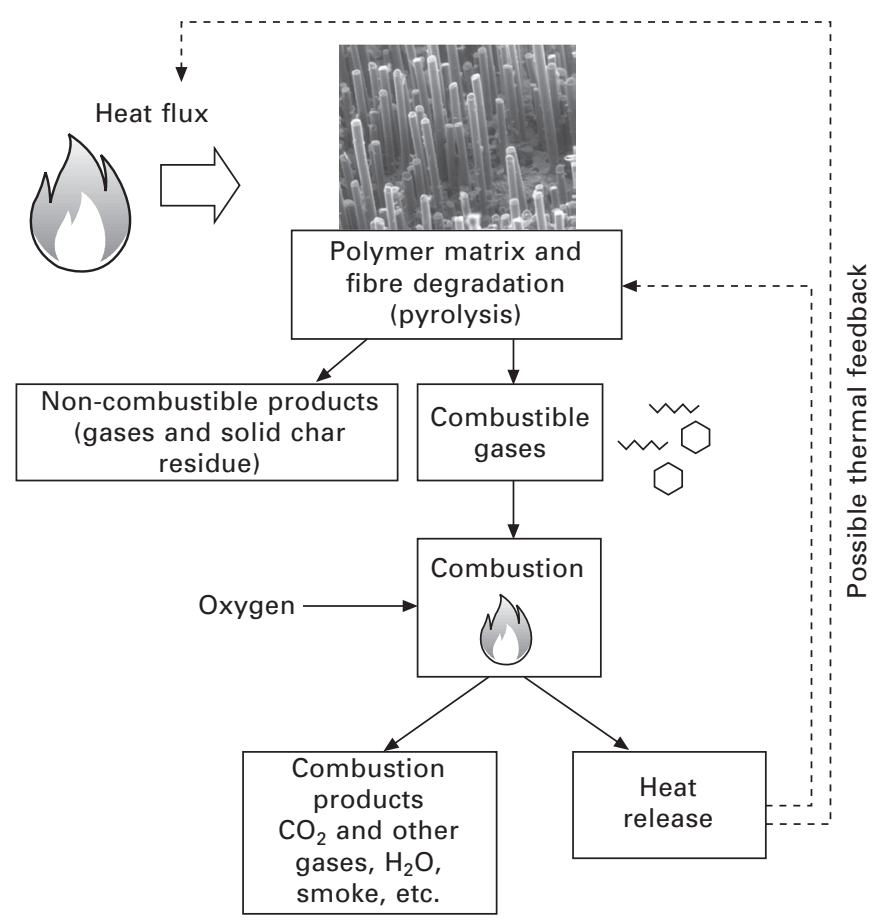

12.27 Schematic diagram of polymer composite combustion.

linked molecular structure, but they experience a substantial drop in mechanical properties over the glass transition temperature (typically in the range $70-180^{\circ} \mathrm{C}$ for composites used in construction). Globally, the evolution of the polymer composite depends on thermal properties of both polymer matrix and fibres (heat conductivities, thermal diffusivities, heat capacities, etc.).

2. Over a critical temperature (usually between 250 and $400^{\circ} \mathrm{C}$ ), the degradation of the polymer composite begins and different types of chemical reactions enter into competition: chain-end scission or depolymerization, random chain scission and degradation of side groups. The weakest chemical bonds are the first to break, followed by bonds of higher dissociation energies as the temperature increases. These degradations generate fragments of low molecular weight, such as monomer, oligomers and other species. This thermal decomposition yields non-flammable products on the one hand (solid carbonaceous char and soot particles), and flammable volatiles on the other hand, including a large amount of hydrocarbon gases. Those volatiles then diffuse across the degraded polymer matrix into the fire environment.

3. The third step involves the ignition of the combustible gases, provided 
the release rate of the volatile products is high enough to produce a favourable gas mixture with air. This combustion produces highly reactive $\mathrm{H}^{\bullet}$ radicals which may combine with oxygen to form $\mathrm{OH}^{\bullet}$ radicals, finally leading to the formation of combustion products $\left(\mathrm{CO}, \mathrm{CO}_{2}\right.$, water and soot particles).

4. The heat released at this level and the subsequent heat transfers (by convection, conduction and radiation) maintain the decomposition process of the polymer composite and may also feed the main fire source. The combustion process is therefore self-sustained.

This cycle stops when one of the parameters involved in the 'fire triangle' is suppressed, usually when the polymer composite has been completely decomposed or when the oxygen content in the fire atmosphere becomes too low.

It is of note that the respective amounts of char and flammable volatiles produced by the thermal decomposition of the composite are highly dependent on the chemical nature of the organic phases, i.e., the polymer matrix and synthetic fibres, if present (Levchnick and Wilkie, 2000; Mouritz, 2007). As regards the main thermosetting polymers used in construction (i.e., polyesters, vinylesters and epoxies), pyrolysis yields a large amount of volatiles but retains a small amount of char (10-20\% of the initial mass). FRP composites based on these thermoset matrices are thus highly flammable materials.

In some cases, non-flaming combustions can occur in the form of smouldering or glowing combustions, which propagate within the material by a thermal front or wave. Glowing combustion usually occurs after the initial charring and involves pale flames of carbon burning that forms carbon monoxide. Smouldering combustion generates smoke due to pyrolysis at or near the surface of the material.

\subsubsection{Flammability of polymer composites}

The fire response of a polymer composite can be described by several reaction properties which determine both the flammability and the fire hazard of the material under consideration (Mouritz and Gibson, 2006; Mouritz, 2007):

- The flammability addresses the following questions: (1) how readily the material ignites when exposed to a flame or heat source; (2) once ignited, whether it continues to burn; (3) how rapidly the fire spreads across a surface; and (4) how much heat is released by the combustion and how fast. The main reaction properties that quantify these various parameters are the time-to-ignition, the limiting oxygen index (LOI), the flame spread rate and the heat release rate (HRR).

- The fire hazard depends on the characteristics (density, composition and toxicity) of the smoke and toxic gases released during stages of a fire. 
Besides, one can also define the fire resistance of a composite material or a composite structure as its ability to restrict the spread of fire and to retain mechanical and physical integrity. Key fire resistance parameters include heat transfer, burn-through resistance and structural integrity.

Different tests and standards are available worldwide to assess the fire reaction properties and the fire resistance. They vary from small bench-scale procedures to large-scale room tests. The most popular fire reaction tests remain bench-scale tests because they are quick and inexpensive and yield generally reproducible data. However, such small-scale tests are known to be limited because they do not reproduce exactly the conditions existing in a real fire and they ignore the effects due to fire growth (Babrauskas, 2000). In the following, a brief focus is given to the main fire reaction properties and their most common determination methods.

\section{Time-to-ignition}

The time-to-ignition $\left(t_{\mathrm{ig}}\right)$ characterizes the ease of ignition of the material by defining how quickly the flaming combustion occurs when the material is exposed to a heat source at a given incident heat flux and in an oxygencontrolled environment. It reflects various phenomena, such as the time necessary for the specimen's surface to reach the pyrolysis temperature, as well as the ability of the material to produce a critical concentration of flammable volatile gases during the thermal decomposition process. It is therefore a rough indicator of the flammability resistance. The time-to-ignition can be determined using experimental methods such as the cone calorimeter (ISO 5660-1, 2002; ASTM E 1354, 1990) or the ignitibility test (ISO 11925-2, 2002). As regards composite materials used in construction, tests are usually performed at an incident heat flux of about $50 \mathrm{~kW} / \mathrm{m}^{2}$, which corresponds to the intensity commonly released by a room fire (Mouritz, 2007) and produces a maximum temperature of $700^{\circ} \mathrm{C}$ at the surface of the material. If tests are reproduced for different heat flux values, time-to-ignition is found to increase as the heat flux is reduced; a linear relationship is usually obtained between $t_{\text {ig }}$ (in the case of thermally thin materials with a uniform temperature across the specimen) or $\sqrt{t_{\mathrm{ig}}}$ (in the case of thermally thick materials with a gradient of temperature from the surface to the interior) and the external heat flux (Tewarson, 2007). As an illustration, time-to-ignition values found in the literature for several thermoset composites are given in Table 12.9.

\section{Limiting oxygen index}

The limiting oxygen index (LOI) is defined as the minimum oxygen concentration (in vol\%) that is necessary to sustain a stable combustion of the specimen after ignition; it is therefore considered a measure of the ease 


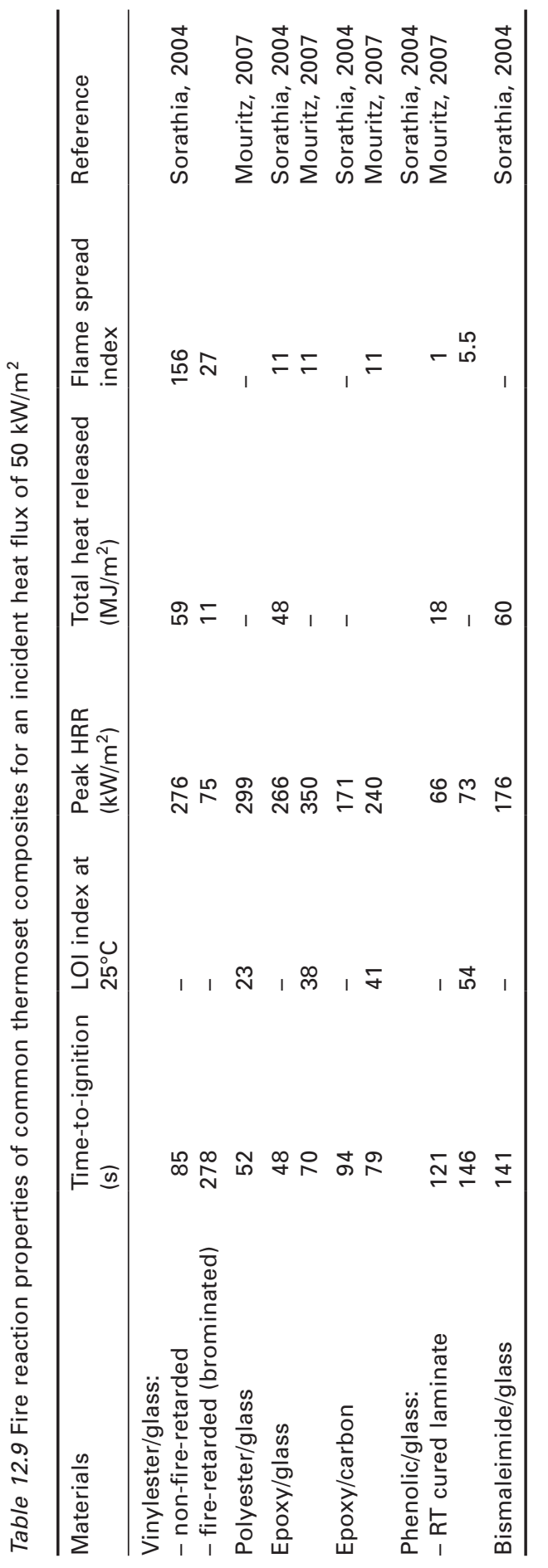


of extinguishment. LOI tests are performed under standard conditions as specified by ISO 4589 (1996) or ASTM D 2863-70 (1970), with specimens of dimension $80 \times 10 \times 4 \mathrm{~mm}^{3}$ placed vertically at the centre of a glass chimney. The test consists in subjecting the sample to a flame ignition in environments containing different oxygen concentrations, then finding the lowest concentration which just allows the specimen to burn with a candlelike flame. The higher the LOI of a polymer material, the lower the heat flux provided by its flame and the higher the flammability resistance. The LOI test is simple to carry out and shows high repeatability and reproducibility. However, it is generally performed at room temperature and does not reproduce a realistic fire environment; it is thus mainly used to compare the relative flammability and rank polymer and composite materials. Table 12.9 reports LOI values taken from the literature for common thermoset composites used in civil engineering. Most of these present LOI indexes between 20 and 40. Besides, the LOI value usually increases when using thermally stable or aromatic matrices (phenolic or bismaleimide) and high glass or carbon fibre contents (Mouritz, 2007; Tewarson, 2007).

\section{Heat released rate}

The heat released rate (HRR) is considered the most important variable in a fire, since heat release may contribute to the growth and spread of the fire (Babrauskas and Peacock, 1992). HRR mainly depends on the combustion of hydrocarbon volatiles produced during the thermal decomposition of the polymer composite, as shown in Fig. 12.28. It is therefore correlated to the amount of volatiles released by the burning material. The HRR varies continuously during the stages of the fire development (Mouritz and Gibson, 2006). An initial induction period is observed, during which no heat is generated because the surface temperature remains below the decomposition temperature. It is then followed by a sharp increase in the HRR due to the combustion of volatiles released from the sample's surface. The curve then reaches a peak HRR value and starts to decrease progressively, as the formation of char limits both heat transfers towards the underlying substrate and diffusion of combustible gases in the fire environment. Based on this HRR evolution profile, one can define several parameters (Fig. 12.28):

- The peak heat release rate (PHRR), expressed in $\mathrm{W} / \mathrm{m}^{2}$, corresponds to the maximum release rate during the combustion process. It is generally considered one of the best indicators of flammability; materials with large PHRR values are thus considered to be highly flammable.

- The total heat released (THR), expressed in $\mathrm{J} / \mathrm{m}^{2}$, is the total amount of energy released by the combustion. Materials which exhibit large THR values contribute to the temperature and the development of the fire. 


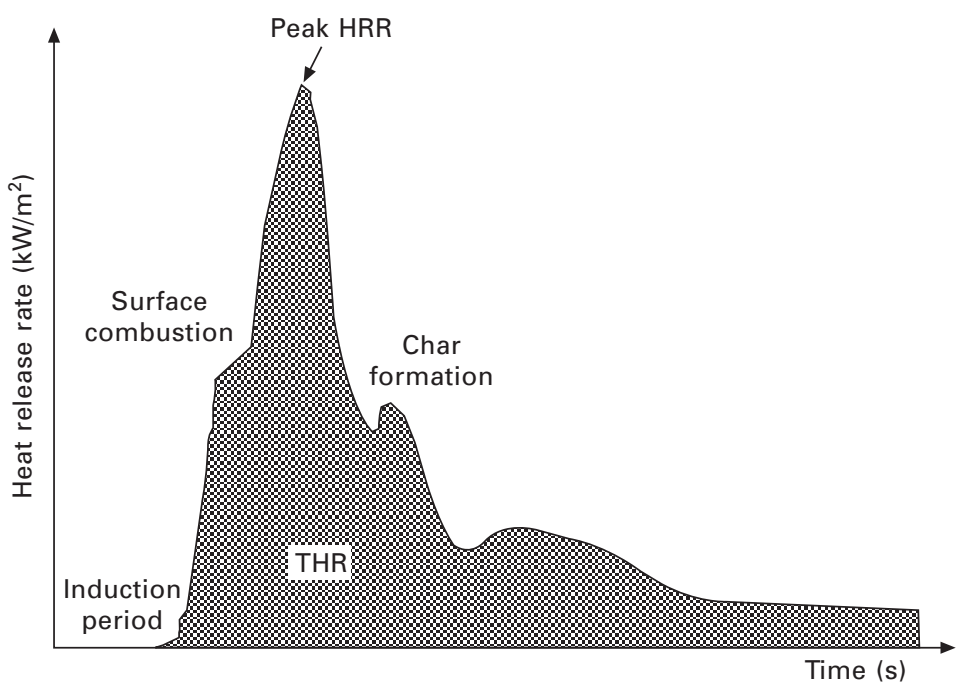

12.28 Profile of the heat release rate versus time for a polymer composite exposed to a constant incident heat flux, after Mouritz and Gibson (2006).

- The average heat release rate, expressed in $\mathrm{J} / \mathrm{m}^{2}$, corresponds to the total heat release averaged over a specific period of time (usually 5 minutes); it can be understood as a measure of the heat contribution to a sustained fire.

HRR parameters can be assessed using bench-scale methods or large fire test rooms, depending on the size of the representative specimen (small sample or large structural element). Among bench-scale tests, the cone calorimeter makes it possible to determine both the peak and average HRR, the total heat released, and the ignition properties previously mentioned. The test protocol is standardized according to ASTM E 1354 and ISO 5660-1: specimens of dimensions $100 \times 100 \times 4 \mathrm{~mm}^{3}$ are placed on a load cell and exposed to a preset radiant heat flux in the range $0-100 \mathrm{~kW} / \mathrm{m}^{2}$. An electric spark ignition source is used for piloted ignition of the pyrolysis gases. HRR is then calculated from the oxygen concentration and mass flow rate measurements, considering it is proportional to the amount of oxygen consumed. The Ohio State University (OSU) calorimeter is an alternative method used in the United States for measuring the heat release rate, which is covered by ASTM E 906 (1984). Although it generates a greater error than the cone calorimeter (Babrauskas, 2000), several regulatory authorities such as the Federal Aviation Administration have adopted this technique as a standard method.

Table 12.9 reports values of HRR parameters found by various authors for the common thermoset composites used in civil engineering. Values of 
the peak HRR and THR are usually ranked in the following order: phenolic/ glass $<<$ epoxy/glass < vinylester/glass < polyester/glass, suggesting that FRP materials based on phenolic matrices exhibit a much lower flammability and are suitable in the design of fire-safe infrastructures. In addition, it is usually admitted that increasing the amount of glass or carbon fibres leads to a decrease in the HRR properties. This feature can be ascribed to the reduced content of the organic phase, which limits the amount of flammable volatiles (Le Bras et al., 1998).

\section{Spread of flames}

The spread of flames over the burning material plays an important role in the fire growth. In fires where large surfaces of very flammable materials are involved, the increase in the heat release rate with time is mainly due to the increase in burning area. The flame spread ability of polymer composites can be assessed by several experimental methods. The radiant panel test (ASTM D 3675 for polymer material and ASTM E 162 for other building materials) is probably the most popular and involves subjecting a panel of the test material to a fixed heat flux. The panel itself is angled at $45^{\circ}$ to the heater, directed at the panel's top edge. During the test, the rate at which the flame travels down the panel along with the temperature rise are recorded. From these, a Flame Spread Index (FSI) is determined and used to compare different materials to each other; the lower the value of the FSI, the lower the flame spread ability. However, the downward direction of the flame spread is considered unrealistic of a real fire where flame spread is predominately upwards, hence more rapid. Therefore the relevance of the radiant panel test is still a matter of discussion. It can be seen from Table 12.9 that highly flammable thermoset systems such as polyester or epoxy composites present low FSI values associated with rapid flame propagation. In contrast, composites based on phenolic or bismaleimide matrices present a reduced flame spread (high FSI values), in agreement with the superior fire resistance of these polymers shown previously by ignition and heat release rate tests.

\subsection{Improving the fire retardancy of FRP composites}

As shown in the previous section, most polymer composites used in construction involve highly flammable matrices, such as polyester, vinylester or epoxy resins. Besides, if glass and carbon fibres are generally considered heat resistant, other type of fibres used for specific applications may also exhibit poor fire behaviour (aramid, polyolefins or other polymer fibres, for instance). Therefore, to meet the safety requirements specified in building codes and 
standards, it can be necessary to improve the overall fire resistance of the composite material through adequate fire-proofing solutions.

Flame-retardant systems are intended to inhibit or to stop the combustion cycle of the polymer composite. After such a treatment, the material does not become non-combustible, but it is more resistant to ignition, takes more time to burn and generates less heat compared to the original composite. As a function of their nature, flame-retardant systems act either chemically or physically (Troitzsch, 2004; Horrocks and Price, 2001; Laoutid et al., 2009). They can interfere with the various processes involved in the combustion cycle (heating, pyrolysis, ignition and propagation stages) which were previously discussed in Section 12.4.1.

Chemical action of fire retardants may involve:

- A gas phase mechanism (also called flame poisoning): flame retardants acting in the gas phase are able to react with $\mathrm{H}^{\bullet}$ and $\mathrm{OH}^{\bullet}$ radicals present in the gas phase to form inert molecules, thus leading to a marked decrease in the heat balance and a reduction in the fire development. These systems are most often based on halogenated or phosphorus chemicals.

- Condensed phase mechanisms (charring effect): at high temperatures, specific silicon- or phosphorus-containing chemicals can initiate crosslinking reactions in the polymer matrix that create a vitreous or ceramic layer with effective barrier properties against both heat transfer and diffusion of volatiles. Another condensed phase mechanism is the intumescence effect in which other additives may favour the formation of a porous carbonaceous char, which also acts as a thermal insulating layer.

Fire retardants may also operate physically, according to the following mechanism:

- Cooling effect (heat sink effect): flame retardants that decompose in endothermic reactions are able to cool the fire environment and therefore to slow down the reaction pathway. These additives are usually hydrated minerals or metal hydroxide fillers.

- Fuel dilution: by releasing inert gases $\left(\mathrm{H}_{2} \mathrm{O}, \mathrm{CO}_{2}, \mathrm{NH}_{3}\right)$ during their thermal decomposition, other flame retardants lead to a decrease in the oxygen concentration of the combustible gas mixture. This effect limits the concentration of reagents and decelerates the reaction pathway.

- Protective layer effect: some flame-retardant additives lead to the formation of a protective coating or gaseous layer between the combustion medium and the condensed phase. This barrier effect tends to decrease the rate of thermal decomposition and the diffusion of flammable volatiles.

Fire retardants can be sorted in two main categories: (1) additives which are generally incorporated during the manufacturing process and consist of 
inorganic filler particles, and (2) reactive chemicals which are introduced at the synthesis stage to modify the chemical structure and reduce the flammability of the polymer matrix. Beside these conventional methods, examples of other fire-proofing solutions receiving increasing interest include (3) the introduction of nanoparticles in the polymer matrix, (4) the application of passive fire-protection systems like insulating coatings, and (5) the use of inorganic matrices. Those various fire-retardant methods will be briefly detailed in the following sections.

\subsubsection{Fire-retardant fillers}

An efficient and easy way of reducing the flammability of polymer composites consists in dispersing flame-retardant fillers in the liquid matrix during processing. A first catergory of flame-retardant fillers involves inert mineral particles such as calcium carbonate, silica/sand or carbon black. These particles operate mainly through a fuel dilution effect, as a significant part of the flammable polymer matrix is replaced by the non-combustible fillers. The effectiveness of this method is very dependent on the quality of dispersion of the flame-retardant fillers and on their loading content (Horrocks and Price, 2001; Mouritz, 2007); the latter should be preferably higher than 50-60 wt $\%$, so as to reduce substantially the fraction of flammable polymer. On the other hand, one has to keep in mind that such a large amount of filler particles may significantly affect the ultimate mechanical properties of the composite material.

A second type of filler, called active flame-retardant fillers, is considered more effective than inert particles. Its operating mode involves not only fuel dilution, but also an additional cooling or heat sink effect. Indeed, these compounds are able to decompose at elevated temperature via endothermic reactions which absorb energy and tend to slow down thermal degradation of the composite. Besides, inert gases (water vapour, carbon dioxide) are formed by the filler decomposition and contribute to diluting the concentration of combustible volatiles in the flame-environment. Common active flame retardant fillers are:

- Metal hydroxides, in particular aluminium trihydroxide (ATH), which is a low-cost filler, and magnesium dihydroxide (MDH). The endothermic decomposition of $\mathrm{Al}(\mathrm{OH})_{3}$ occurs between 180 and $200^{\circ} \mathrm{C}$ and leads to the release of water and the formation of an insulating ceramic layer of alumina $\left(\mathrm{Al}_{2} \mathrm{O}_{3}\right)$. The use of ATH also reduces the HRR peak and the smoke production. $\operatorname{Mg}(\mathrm{OH})_{2}$ acts in a similar way but its endothermic degradation occurs at a higher temperature $\left(\right.$ over $\left.300^{\circ} \mathrm{C}\right)$ and a protective layer of $\mathrm{MgO}$ is formed at the composite surface.

- Zinc borates $\left(2 \mathrm{ZnO} .3 \mathrm{~B}_{2} \mathrm{O}_{3} \cdot 3 \cdot 5 \mathrm{H}_{2} \mathrm{O}\right)$, which decompose between 300 
and $450^{\circ} \mathrm{C}$ and release water, boric acid and boron oxide $\left(\mathrm{B}_{2} \mathrm{O}_{3}\right)$. The later flows at high temperature (over $500^{\circ} \mathrm{C}$ ) form a vitreous protective layer.

Here again, these metal hydroxides and borates must be incorporated in large quantities (around 60\%) to obtain a significant effect on the flame properties, hence the possible degradation of mechanical performance.

\subsubsection{Flame-retarded matrices}

Another fireproofing method consists in modifying the molecular structure of the polymer by introducing organohalogen compounds containing bromine or chlorine during the synthesis or polymerization stages: these compounds can be incorporated in a blend with the polymer, used as polymerization monomers, or grafted on the polymer chains. The acting principle of halogenous derivatives is the interruption of the radical chain mechanism in the gas phase, either by transfer or by recombination reactions (Papazoglou, 2004). Brominated derivatives are considered the most effective halogenous flame retardants, as they can release $\mathrm{HBr}$ hydracids very easily; some usual compounds are tetrabromobisphenol-A (TBBPA), which is mainly used with epoxy resins, and polybromodiphenyl ethers (PBDE), which are generally incorporated in polyester and polyolefin matrices (Laoutid et al., 2009). Most but not all halogenated flame retardants are used in conjunction with a synergist to enhance their efficiency. Antimony trioxide is widely used, but other forms of antimony such as the pentoxide and sodium antimonate are also used. An important feature is that fire degradation of halogenated polymer composites generates large amounts of toxic gases in the atmosphere, which is a major concern for both human health and the environment (Horrocks and Price, 2001). This has led many countries to restrict the use of halogenous flame retardants and replace them by more environmentally friendly products such as hydrated mineral fillers, for instance.

Another class of reactive chemical with effective fire-retardant properties is based on phosphorous derivatives (phosphorus, phosphates, etc.). It is mainly used with oxygen or nitrogen-rich polymers like polyesters and polyamides, as it promotes the formation of char during the decomposition of these matrices (Horrocks and Price, 2001; Mouritz, 2007; Laoutid et al., 2009).

\subsubsection{Nanoparticles}

The potential of nanoparticles for increasing the fire resistance of polymer matrices has been known since the end of the 1990s. Organoclays of the montmorillonite type were the first nanoparticles to be used as flame retardants in polymers. Introducing a low amount of these nanofillers (1 to 
$5 \mathrm{wt} \%$ ) in the matrix may improve its fire behaviour, due to the formation of a protective layer during combustion according to various mechanisms (Laoutid et al., 2009):

- Upon heating, the viscosity of the molten nanocomposite decreases, thus facilitating the migration of clay nanoparticles towards the surface of the material.

- Thermal decomposition of surfactants present at the surface of clay creates catalytic sites favouring the formation of a stable char residue.

The accumulation of clay at the surface acts thus as a barrier which limits heat transfers and reduces the release of combustible volatiles into the flame. A substantial decrease in the peak heat release rate of the nanocomposite ( 25 to 50\%) can be achieved compared to the neat polymer (Bourbigot et al., 2006). However, this effect is very dependent on the quality of dispersion of the nanoparticles within the host matrix, and a high degree of exfoliation is usually targeted in order to maximize both the mechanical and fire properties (Hackman and Hollaway, 2006). Other types of nanoparticles, such as silica $\left(\mathrm{SiO}_{2}\right)$, titanium dioxide $\left(\mathrm{TiO}_{2}\right)$, carbon nanotubes or silesquioxane, have also proven to have significant flame-retardant properties (Laoutid et al., 2009).

Nervertheless, it is admitted that nanofillers are globally less effective than conventional fire retardants (halogenous/phosphorus compounds or metal hydroxides) and nanocomposites are generally unable to meet fire performance standards. Research efforts are currently underway on the combination of nanoparticles with usual fire retardants, preferably non-halogenated, in order to promote synergistic effects (Horrocks and Price, 2001; Laoutid et al. 2009). Another promising strategy consists in the surface modification of nanoparticles with surfactants having effective flame-retardant properties instead of conventional ammonium salts.

\subsubsection{Protective coatings}

Another effective solution for protecting composites against fire involves the use of flame-resistant paints or coatings. Such coatings can be classified among the following categories (Mouritz, 2007):

- Intumescent coatings: Under the action of heat, these systems evolve gases and swell to form a voluminous foamed char. Thanks to its high porosity content, this char acts as an insulative barrier and protects the underlying substrate from heat. These coatings are very effective for delaying ignition and reducing the heat release rate properties. A typical intumescent system consists of charring agents (carbon donors such as polyalcohols) and blowing agents (whose thermal decomposition yields $\mathrm{CO}_{2}$ or $\mathrm{NH}_{3}$, such as melamine) (Papazoglou, 2004). 
- Ceramic coatings: Based on silica, zirconia, alumina, etc., they provide high heat insulation to the underlying material and are non-flammable,

- Flame-retardant films: These are based on fire-resistant polymers that contain halogenous or phosphorous flame retardants which act in the gas phase.

\subsubsection{Mineral matrices}

Over the past years, significant researches have been conducted to develop inorganic matrices as an alternative to thermosetting polymers in composite materials. For instance, fibre-reinforced cement matrix (FRCM) composites were developed for the strengthening/retrofitting of concrete or masonry structures (Triantafillou and Papanicolaou, 2006; Bournas et al., 2007; Faella et al., 2010; De Caso y Basalo et al., 2012). These mineral matrix composites exhibit very similar outstanding mechanical properties to their organic counterparts (Bournas et al., 2007). In addition, they present many advantages over polymer composites, such as improved thermal and fire resistance, no emission of toxic smoke in fire events, no release of hazardous compounds (solvents, aromatic volatiles) during the manufacturing process and the in-service period, enhanced compatibility with concrete and other mineral substrates, and lower price.

Geopolymers are another class of inorganic materials with very interesting prospects for the composite industry (Davidovits, 2008). These materials, based on the chemistry of polysialates $(-\mathrm{Si}-\mathrm{O}-\mathrm{Al}-\mathrm{O}-)_{n}$, are a particular type of alumino-silicates. In specific conditions (usually in an alkaline environment), these silicate molecules can react by polycondensation at low temperatures (room temperature to $150^{\circ} \mathrm{C}$ ) and form a mineral macromolecular network very similar to that of an organic polymer. Depending on the atomic ratio of $\mathrm{Si}: \mathrm{Al}$, one can obtain either linear molecular structures comparable to that of thermoplastic polymers (high ratios over 15), or tridimensional networks analogous to that of thermosetting polymers (low Si:Al ratios). Geopolymer matrices are compatible with various types of fibres (aramid, basalt, carbon, glass and even ceramic fibres) and can be processed to form composite laminates. This type of matrix can withstand temperatures higher than $1000^{\circ} \mathrm{C}$ without producing any smoke, and carbon fibre-reinforced geopolymer composites can retain about $63 \%$ of their original strength after long-term exposure to $800^{\circ} \mathrm{C}$ (Lyon et al., 1997).

\subsection{Structural integrity of FRP composites exposed to fire}

As previously mentioned, mechanical properties of polymer composites degrade at elevated temperatures. This degradation is more pronounced for 
resin-dominated properties (compression and shear) than for fibre-dominated properties (tension), since the polymer matrix is the first component to be affected by viscoelastic softening and pyrolysis processes.

Around the glass temperature of the polymer matrix (typically in the range $70-150^{\circ} \mathrm{C}$ for composites used in construction) FRP materials soften, creep and distort. Over $T_{\mathrm{g}}$, both stiffness and strength rapidly decrease with temperature. This drastic weakening of the mechanical properties often leads to buckling failure of load-bearing composite structures (Mouritz, 2007). At higher temperatures (in the range $300-500^{\circ} \mathrm{C}$ ), the matrix starts to decompose and fibres may also experience softening (for glass fibres) and oxidative degradation (carbon fibres).

As regards thick structural elements exposed to fire, it is to be noted that the temperature is not uniform through the composite section due to the low thermal conductivity. Only a part of the structure is over $T_{\mathrm{g}}$ and the thermal front advances gradually over time. Mechanical loads are thus supported by the part of the structure which remains below $T_{\mathrm{g}}$, so long as these loads do not exceed the capacity of the active region. A critical issue is to ensure that the mechanical functions of the structure are not compromised during the fire scenario (at least for 30 minutes), so as to permit the intervention of firefighters (Sorathia, 2004). Mouritz and Gibson (2006) have developed a simple modelling approach for evaluating the time-to-failure of such loadbearing structures in fire; however, due to the complexity and the non-linearity of the composite response, full-scale testing is usually required.

With regard to civil concrete structures externally reinforced by bonded FRP composites, the load-carrying capacity under fire conditions is primarily influenced by the thermo-mechanical behaviour of the adhesive (Ahmed and Kodur, 2011). When the temperature of the adhesive layer reaches $T_{\mathrm{g}}$, bond properties (shear and bond strength) of the glue drop considerably, which affects the load transfer in the adhesive joint and compromises the effectiveness of the reinforcing technique, ultimately leading to debonding of the FRP composite (Di Tommaso et al., 2001; Gamage et al., 2006). In this context, ACI guidelines (ACI Committee 440 2R-08, 2008) consider no contribution from the FRP reinforcements to the load-carrying capacity of reinforced concrete elements in the case of fire events. It is thus recommended to ensure a convenient thermal insulation to prevent the temperature of the FRP reinforcement from reaching $T_{\mathrm{g}}$.

For concrete structures reinforced by FRP rebars, exposure to fire also induces a progressive rise of the internal temperature. As FRP rebars are embedded in concrete, the lack of oxygen will inhibit their burning. However, if temperature within the structure exceeds $T_{\mathrm{g}}$, softening of the polymer matrix may compromise the stress transfer at the concrete/rebar interface and lead to bond failure (Saafi, 2002). This may result in increased load deflection and ultimately to the collapse of the structure. It has been demonstrated that 
the temperature of the rebars is dependent upon the concrete cover (Saafi, 2002); recommendation on minimal concrete covers may be included in future guidelines to ensure fire resistance, but further research is still needed at this stage (ACI Committee 440.1R-06, 2006).

\subsection{Conclusion and future trends}

During the last decade, there have been continuous improvements in the selection of constitutive materials, in the manufacturing processes and the field implementation of polymer composites for civil engineering applications. The use of FRP materials as externally bonded reinforcement is now an attractive solution to increase the lifespan of existing concrete infrastructures, while their use as internal reinforcing bars or as structural members is intended to prevent corrosion problems and increase the overall durability of new constructions exposed to severe environments. Nevertheless, key issues regarding the long-term durability of FRPs for infrastructure applications have been only partially addressed, and there remain considerable needs for research and development in this field:

- Durability test methods lack standardization and are not always representative of realistic service conditions; it is therefore essential to develop standard accelerated ageing tests that correspond to actual in-situ environments. In particular, significant effort should be undertaken to study the synergistic effects between environmental factors (moisture, temperature, alkalinity, chemical attacks) and mechanical loads (sustained loads, fatigue) at both the material and structural scales.

- As the durability of FRP materials is largely dependent on the environmental resistance of the polymer matrix, and as existing cold-curing polymers used in construction are more vulnerable to environmental degradation than high-temperature systems, development of appropriate cold-curing formulations or alternative polymer-based systems is an important means of improvement. Specific degradation mechanisms involved in the case of partially cured or undercured polymer matrices/adhesives should also be investigated in greater detail.

- Besides, it is necessary to improve service life models in order to accurately predict the long-term behaviour of FRP systems used in infrastructure applications. In this line, the development of theoretical approaches coupling both mechanical aspects and physico-chemical degradation processes is of primary interest. Moreover, methods for extrapolating service life predictions from short-term tests are also required. In the end, the challenge is always to determine appropriate reduction or knockdown factors that could be implemented in the design guidelines.

Another important durability-related issue is the fire behaviour of FRP 
materials used in construction, which remains partially unknown. In particular, the relationships between the fire reaction properties at the material scale and the full-scale structural performance under fire events still require further investigation. Predictive models must also be developed in order to better evaluate the fire behaviour of FRP structures.

\subsection{Sources of further information and advice}

\section{Design guidelines related to FRP composites in civil engineering}

ACI Committee 440.1R-06 (2006), Guide for the Design and Construction of Concrete Reinforced with FRP Bars, ACI, Farmington Hills, MI, USA.

ACI Committee 440.2R-08 (2008), Guide for the Design and Construction of Externally Bonded FRP Systems for Strengthening Concrete Structures, ACI, Farmington Hills, MI, USA.

AFGC (2011), Réparation et renforcement des structures en béton au moyen des matériaux composites, Technical report, Bulletin scientifique et technique de l'AFGC, in French.

CNR (2004), Guide for the Design and Construction of Externally Bonded FRP Systems for Strengthening Existing Structures - Materials, RC and PC Structures, Masonry Structures, CNR-DT 200/2004, Italian National Research Council, Rome, Italy.

CSA (2002), Design and Construction of Building Components with Fibre-reinforced Polymers, CSA-S806-02 (R2007), Canadian Standards Association (CSA) International, Toronto, Canada.

JSCE (1997), Recommendation for Design and Construction of Concrete Structures using Continuous Fibre Reinforcing Materials, Concrete Engineering Series 23, Japan Society of Civil Engineers, Tokyo, Japan. JSCE (2001), Recommendation for Upgrading of Concrete Structures with Use of Continuous Fibre Sheets, Concrete Engineering Series 41, Japan Society of Civil Engineers, Tokyo, Japan.

\section{Standard test methods}

ASTM D 2863-70 (1970), Standard Test Method for Measuring the Minimum Oxygen Concentration to Support Candle-like Combustion of Plastics (Oxygen Index), The American Society for Testing and Materials, Philadelphia, USA.

ASTM D 3675-98 (1998), Standard Test Method for Surface Flammability of Flexible Cellular Materials Using a Radiant Heat Energy Source, The American Society for Testing and Materials, Philadelphia, USA. ASTM E 1354-90 (1990), Standard Test Method for Heat and Visible Smoke 
Release Rates for Materials and Products Using an Oxygen Consumption Calorimeter, The American Society for Testing and Materials, Philadelphia, USA.

ASTM E 906-83 (1984), Standard Test Method for Heat and Visible Smoke Release Rates for Materials and Products, The American Society for Testing and Materials, Philadelphia, USA.

ISO 11925-2 (2002), Reaction to Fire Tests - Ignitability of Building Products Subjected to Direct Impingement of Flame - Part 2: Singleflame Source Test, International Organization for Standardization, Geneva, Switzerland.

ISO 4589 (1996), Plastics - Determination of Burning Behaviour by Oxygen Index, International Organization for Standardization, Geneva, Switzerland.

ISO 5660-1 (2002), Reaction to Fire Tests - Heat Release, Smoke Production and Mass Loss Rate - Part 1: Heat Release Rate (Cone Calorimeter Method), International Organization for Standardization, Geneva, Switzerland.

\subsection{References}

Ahmed, A., Kodur, V.K.R. (2011). Effect of bond degradation on fire resistance of FRP-strengthened reinforced concrete beams, Composites Part B, 42, 226-237. doi:10.1016/j.compositesb.2010.11.004

Amdouni, N. (1989). Caractérisation et role d'une interphase élastomère au sein de matériaux composites polyépoxy/renforts de verre, $\mathrm{PhD}$ thesis, University of Lyon, France.

Ashbee, K.H.G., Wyatt, R.C. (1969). Proceedings of the Royal Society, A312, 553-564. doi:10.1098/rspa.1969.0175

Ashbee, K.H.G., Frank, F.C., Wyatt, R.C. (1967). Proceedings of the Royal Society, A300, 415-419. doi:10.1098/rspa.1967.0179

Assadi, R., Colin, X., Verdu, J. (2004). Polymer, 45(13), 4403-4412. doi:10.1016/j. polymer.2004.04.029

Audouin, L., Verdu, J. (1991). In: Radiation Effects on Polymers, Clough, R.L., Shalaby, S.W. (eds), ACS Symposium Series 475, American Chemical Society, Washington DC, 473-484.

Audouin, L., Langlois, V., Verdu, J., De Bruijn, J.C.M. (1994). Journal of Materials Science, 29(3), 569-583. doi: 10.1007/BF00445968

Babrauskas, V. (2000). Fire test methods for evaluation of fire retardant efficacy in polymeric materials. In: Fire Retardancy of Polymeric Materials, Grand, A.F., Wilkie, C.A. (eds), Marcel Dekker, New York.

Babrauskas, V., Peacock, R.D. (1992). Heat release rate: the single most important variable in fire hazard, Fire Safety Journal, 18, 255-272. doi:10.1016/0379-7112(92)90019-9

Bank, L.C. (2006). Composites for Construction: Structural Design with FRP Materials, John Wiley \& Sons, Hoboken, NJ.

Barjasteh, E., Bosze, E.J., Tsai, Y.I., Nutt, S.R. (2009). Composites Part A: Applied Science and Manufacturing, 40, 2038-2045. doi:10.1016/j.compositesa.2009.09.015

Bellenger, V., Verdu, J., Ganem, M., Mortaigne, B. (1994). Polymer and Polymer Composites 2, 17-25. 
Bellenger, V., Ganem, M., Mortaigne, B., Verdu, J. (1995). Polymer Degradation and Stability, 49(1), 91-97. doi:10.1016/0141-3910(95)00049-R

Benmokrane, B., Wang, P., Pavate, T., Robert, M. (2006). Durability of FRP composites for civil infrastructure applications. In: Durability of Materials and Structures in Building and Civil Engineering, Wu, C.W., Bull, J.W. (eds), Whittles Publishing, Dunbeath, UK, 300-343.

Benzarti, K., Cangemi, L., Dal Maso, F. (2001). Transverse properties of unidirectional glass/epoxy composites: influence of fibre surface treatments, Composites Part A: Applied Science and Manufacturing, 32, 197-206. doi:10.1016/S1359-835X(00)00136-6

Benzarti, K., Chataigner, S., Quiertant, M., Marty, C., Aubagnac, C. (2011). Accelerated ageing behaviour of the adhesive bond between concrete specimens and FRP overlays, Construction and Building Materials, 25(2), 523-538. doi:10.1016/j. conbuildmat.2010.08.003

Bernier, G.A., Kambour, P. (1968). Macromolecules, 1, 393-400. doi: 10.1021/ ma60005a005

Bicerano, J. (2002). Prediction of Polymer Properties, 3rd edition, Marcel Dekker, New York.

Bolland, J.L., Gee, G. (1946). Transactions of the Faraday Society, 42, 236-252. doi: 10.1039/TF9464200236

Bourbigot, S., Duquesne, S., Jama, C. (2006). Polymer nanocomposites: how to reach low flammability? Macromolecular Symposia, 233, 180-190. doi: 10.1002/ masy.200690016

Bournas, D.A., Lontou, P.V., Papanicolaou, C.G., Triantafillou, T.C. (2007). Textilereinforced mortar versus fibre-reinforced polymer confinement in reinforced concrete columns, ACI Structural Journal, 104, 740-748.

Carter, H.G., Kibler, K.G. (1978). Journal of Composite Materials, 12, 118-131. doi: $10.1177 / 002199837801200201$

Charles, R.J. (1958). Static fatigue of glass Part I, Journal of Applied Physics, 29, 1549-1560. doi.org/10.1063/1.1722991

Charlesby, A., Pinner, S.H. (1959). Proceedings of the Royal Society, A249, 367-386. doi:10.1098/rspa.1959.0030

Chateauminois, A., Vincent, L., Chabert, B., Soulier, J.P. (1994). Study of the interfacial degradation of a glass-epoxy composite during hygrothermal ageing using water diffusion measurements and dynamic mechanical thermal analysis, Polymer, 35, 4766-4774. doi:10.1016/0032-3861(94)90730-7

Colin, X., Verdu, J. (2003). Plastics rubber and composites, Macromolecular Engineering, 32(8/9), 349-356.

Colin, X., Mavel, A., Marais, C., Verdu, J. (2005). Journal of Composite Materials, 39, 1371-1389. doi:10.1177/0021998305050430

Colin, X., Audouin, L., Verdu, J. (2007). Polymer Degradation and Stability, 92, 886-897, 898-905, 906-914. doi:10.1016/j.polymdegradstab.2007.01.017, doi.org/10.1016/j. polymdegradstab.2007.01.004, doi.org/10.1016/j.polymdegradstab.2007.01.013

Colin, X., Richaud, E., Verdu, J., Monchy-Leroy, C. (2010). Radiation Physics and Chemistry, 79, 365-370. doi.org/10.1016/j.radphyschem.2009.08.019

Coquillat, M., Verdu, J., Colin, X., Audouin, L., Nevière, R. (2007). Polymer Degradation and Stability, 92, 1326-1333, 1334-1342, 1343-1349. doi:10.1016/j. polymdegradstab.2007.03.020, doi:10.1016/j.polymdegradstab.2007.03.019, doi. org/10.1016/j.polymdegradstab.2007.03.018

Crank, J., Park, G.S. (1968). Diffusion in Polymers, Academic Press, London. 
Crawford, C.D., Lesser, A.J. (1999). Polymer Engineering and Science, 39, 385-392. doi: $10.1002 /$ pen. 11425

Cullis, C.F., Hirschler, M. (1981). The Combustion of Organic Polymers, Clarendon Press, Oxford, UK.

Cunliffe, A.V., Davis, A. (1982). Polymer Degradation and Stability, 4, 17-37. doi:10.1016/0141-3910(82)90003-9

Davidovits, J. (2008). Geopolymer Chemistry and Applications, Institut Géopolymère, Saint-Quentin, France.

De Caso y Basalo, F.B., Matta, F., Nanni, A. (2012). Fibre reinforced cement-based composite system for concrete confinement, Construction and Building Materials, 32, 55-65. doi:10.1016/j.conbuildmat.2010.12.063

De Lorenzis, L., Teng, J.G. (2007). Near-surface mounted FRP reinforcement: An emerging technique for strengthening structures, Composites Part B: Engineering, 38, 119-143. doi:10.1016/j.compositesb.2006.08.003

Derrien, K., Gilormini, P. (2006). In: Proceedings of the DSL 2006 Conference, Defect and Diffusion Forum, 258/260, 447-452.

Di Benedetto, A.T., Lex, P.J. (1989). Polymer Engineering and Science, 29, 543-555. doi: 10.1002/pen.760290809

Di Benedetto, A.T., Scola, D.A. (1980). Journal of Colloid and Interface Science, 74, 150-162. doi:10.1016/0021-9797(80)90178-2

Di Marzio, E.A. (1964). Journal of Research of the National Bureau of Standards: Section A: Physics and Chemistry, 68, 611-617.

Di Tommaso, A., Neubauer, U., Pantuso, A., Rostasy, F.S. (2001). Behaviour of adhesively bonded concrete-CFRP joints at low and high temperatures, Mechanics of Composite Materials, 37, 327-338. doi: 10.1023/A:1012392703519

Didierjean, S. (2004). Etude du comportement de matériaux composites carbone/epoxy en environnement hygrothermique, $\mathrm{PhD}$ thesis, University of Paul Sabatier, Toulouse, France.

El Mazry, C., Correc, O., Colin, X. (2012). A new kinetic model for predicting polyamide 6-6 hydrolysis and its mechanical embrittlement, Polymer Degradation and Stability, 97, 1049-1059. doi:10.1016/j.polymdegradstab.2012.03.003

Espuche, E. (2011). Gas diffusion in multiphase polymer systems. In: Handbook of Multiphase Polymer Systems, vol. 2/2, Boudenne, A., Ibos, L., Candau, Y., Thomas, S. (eds), John Wiley \& Sons, Chichester, UK, Chapter 21, 749-775.

Faella, C., Martinelli, E., Nigro, E., Paciello, S. (2010). Shear capacity of masonry walls externally strengthened by a cement-based composite material: An experimental campaign, Construction and Building Materials, 24, 84-93. doi:10.1016/j. conbuildmat.2009.08.019

Fayolle, B., Audouin, L., Verdu, J. (2002). Polymer Degradation and Stability, 75, 123-129. doi:10.1016/S0141-3910(01)00211-7

Fayolle, B., Richaud, E., Colin, X., Verdu, J. (2008). Journal of Materials Science, 43, 6999-7012. doi: 10.1007/s10853-008-3005-3

Fetters, L.J., Lohse, D.J., Graessley, W.W. (1999). Journal of Polymer Science: Part B: Polymer Physics, 37, 1023-1033. doi: 10.1002/(SICI)1099-0488(19990515)37:10<1023::AIDPOLB7>3.0.CO;2-T

Flory, P.J. (1953). Principles of Polymer Chemistry, Cornell University Press, Ithaca, NY.

Fox, T.G., Flory, P.J. (1954). Journal of Polymer Science, 14, 315-319. doi: 10.1002/ pol.1954.120147514 
Gamage, J., Al-Mahaidi, R., Wong, M.B. (2006). Bond characteristics of CFRP plated concrete members under elevated temperatures, Composite Structures, 75, 199-205. doi :10.1016/j.compstruct.2006.04.068

Gaudichet-Maurin, E., Thominette, F., Verdu, J. (2008). Journal of Applied Polymer Science, 109, 3279-3285. doi: 10.1002/app.24873

Gautier, L., Mortaigne, B., Bellenger, V., Verdu, J. (1999). Polymer, 41, 2481-2490. doi :10.1016/S0032-3861(99)00383-3

George, S., Thomas, S. (2001). Progress in Polymer Science, 26, 985-1017. doi:10.1016/ S0079-6700(00)00036-8

Gillen K.T., Wise J., Clough R.L. (1995). General solution for the basic autoxidation scheme, Polymer Degradation and Stability, 47 (1), 149-161.

Greco, R., Ragosta, G. (1987). Plastics and Rubber Processing and Applications, 7, $163-171$.

Griffith, A.A. (1921). Philosophical Transactions of the Royal Society, Series A, 221, 163-198. doi:10.1098/rsta.1921.0006

Hackman, I., Hollaway, L. (2006). Epoxy-layered silicate nanocomposites in civil engineering. Composites Part A: Applied Science and Manufacturing, 37, 1161-1170. doi:10.1016/j.compositesa.2005.05.027

Hahn, H.T. (1987). Journal of Engineering Materials and Technology, 109, 3-11. doi:10.1115/1.3225930

Hawkins, W.L. (1971). Polymer Stabilization, Wiley-Interscience, New York.

Hoh, K.-P., Ishida, H., Koenig, J.L. (1990). Polymer Composites, 11(3), 192-199. doi: $10.1002 /$ pc. 750110308

Hollaway, L.C. (2001). Part 7: Fibre composites. In: Construction Materials: Their Nature and Behaviour, Illstone, J.M., Domone, P.L.J. (eds), Spon Press, London, 369.

Hollaway, L.C. (2010). A review of the present and future utilisation of FRP composites in the civil infrastructure with reference to their important in-service properties, Construction and Building Materials, 24, 2419-2445. doi.org/10.1016/j.conbuildmat.2010.04.062

Hopfenberg, H.B. (1974). Permeability of Plastic Films and Coatings in Gases, Vapors, and Liquids, Plenum Press, New York.

Horrocks, A.R., Price, D. (2001). Fire Retardant Materials, CRC Press, Boston, MA.

Imuro, H., Yoshida, N. (1986). Differences between HM-50 and PPTA-aramides, Proceedings of the 25th International Man Made Fibres Congress, Dornbirn, Austria, $1-23$.

Ishai, O. (1975). Environmental effects on deformation, strength, and degradation of unidirectional glass-fibre reinforced plastics. I. Survey, Polymer Engineering and Science, 15, 486-490. doi: 10.1002/pen.760150703

Ishida, H. (1984). Polymer Composites, 5, 101-123. doi: 10.1002/pc.750050201

Ishida, H., Koenig, J.L. (1980). Journal of Polymer Science: Part B: Polymer Physics, 18, 1931-1943. doi: 10.1002/pol.1980.180180906

Jacques, B., Werth, M., Merdas, I., Thominette, F., Verdu, J. (2002). Polymer, 43, 6439-6447. doi:10.1016/S0032-3861(02)00583-9

Jones, R.L., Chandler, H.D. (1984). Strength loss in E-glass fibres treated in strong solutions of mineral acids, Journal of Materials Science, 19, 3849-3854. doi: 10.1007/ BF00980747

Kaelble, D.H., Dynes, P.J., Crane, L.N., Maus, L. (1975). Journal of Adhesion, 7, 25-54. doi:10.1080/00218467508078896

Kaelble, D.H., Dynes, P.J., Maus, L. (1976). Journal of Adhesion, 8, 121-144. doi:10.1080/00218467608075078 
Kamiya, Y., Niki, E. (1978). In: Aspects of Degradation and Stabilisation of Polymers, Jellinek, H.H.G. (ed.), Elsevier, New York, Chapter 3, 79-147.

Karbhari, V. (2007). Durability of Composites for Civil Structural Applications, Woodhead Publishing, Cambridge, UK.

Karbhari, V.M., Chin, J.W., Hunston, D., Benmokrane, B., Juska, T., Morgan, R. et al. (2003). Durability gap analysis for fibre-reinforced polymer composites in civil infrastructure, Journal of Composites for Construction, 7, 238-247. doi:10.1061/ (ASCE)1090-0268(2003)7:3(238)

Kausch, H.H., Heymans, N., Plummer, C.F., Decroly, P. (2001). Matériaux Polymères. Propriétés Mécaniques et Physiques, Presses Polytechniques et Universitaires Romandes, Lausanne, Switzerland.

Keller, T. (2006). Material Tailored Use of FRP Composites in Bridge and Building Construction, Swiss Federal Institute of Technology, Lausanne, Switzerland.

Kennedy, M.A., Peacock, A.J., Mandelkern, L. (1994). Macromolecules, 27, 5297-5310. doi: $10.1021 / \mathrm{ma} 00097 \mathrm{a} 009$

Kondo, K., Taki, T. (1982). Journal of Composite Materials, 16, 82-93. doi:10.1177/002199838201600201

Korcek, S., Chenier, J.H.B., Howard, J.A., Ingold, K.U. (1972). Canadian Journal of Chemistry 50, 2285-2297. doi: 10.1139/v72-365

Kumosa, M. (2001). Fracture analysis of composite high voltage insulators, Centre for Advance Materials and Structures, 67, 269.

Laoutid, F., Bonnauda, L., Alexandreb, M., Lopez-Cuestac, J.-M., Dubois, P. (2009). New prospects in flame retardant polymer materials: from fundamentals to nanocomposites, Materials Science and Engineering: R: Reports, 63, 100-125. doi:10.1016/j. mser.2008.09.002

Le Bras, M., Bourbigot, S., Mortaigne, B., Cordellier, G. (1998). Comparative study of the fire behaviour of glass fibre insaturated polyesters using a cone calorimeter, Polymers and Polymer Composites, 6, 535-539.

Le Huy, H.M., Bellenger, V., Verdu, J., Paris, M. (1993). Polymer Degradation and Stability, 41, 149-156. doi:10.1016/0141-3910(93)90037-J

Levchnick, S., Wilkie, C.A. (2000). Char formation. In: Fire Retardancy of Polymeric Materials, Grand, A.F., Wilkie, C.A. (eds), Marcel Dekker, New York, 171-215.

Lyon, R.E., Balaguru, P., Foden, A.J., Sorathia, U., Davidovits, J. (1997). Fire resistant aluminosilicate composites, Fire and Materials, 21, 67-73. doi: 10.1002/(SICI)10991018(199703)21:2<67::AID-FAM596>3.0.CO;2-N

Masaro, L., Zhu, X.X. (1999). Progress in Polymer Science, 24, 731-775. doi:10.1016/ S0079-6700(99)00016-7

Mays, G.C., Hutchinson, A.R. (1992). Adhesives in Civil Engineering, Cambridge University Press, Cambridge, UK.

McCall, D.W., Douglass, D.C., Blyler Jr, L.L., Johnson, G.E., Jelinski, L.W., Bair, H.E. (1984). Macromolecules, 17, 1644-1649. doi: 10.1021/ma00139a001

McKague, E.L., Halkias, E., Reynolds, J.D. (1975). Journal of Composite Materials, 9, 2-9. doi:10.1177/002199837500900101

Merdas, I., Thominette, F., Tcharkhtchi, A., Verdu, J. (2002). Composites Science and Technology, 62, 487-492. doi:10.1016/S0266-3538(01)00138-5

Merdas, I., Thominette, F., Verdu, J. (2003). Polymer Degradation and Stability, 79, 419-425. doi:10.1016/S0141-3910(02)00358-0

Metcalfe, A.G., Schmitz, G.K. (1972). Mechanisms of stress corrosion in E-glass filaments, Glass Technology, 13, 5-16. 
Metcalfe, A.G., Gulden, M.E., Schmitz, G.K. (1971). Spontaneous cracking of glass filaments, Glass Technology, 12, 15-23.

Michalske, T.A., Frieman, S.W. (1983). A molecular mechanism for stress corrosion in vitreous silica, Journal of the American Ceramic Society, 66, 284-288. doi: 10.1111/j.1151-2916.1983.tb15715.x

Morgan, R.J., Pruneda, C.O., Butler, N., Kong, F.-M., Caley, L., Moore, R.L. (1984). The hydrolytic degradation of Kevlar 49 fibres, Proceedings of the 29th National SAMPE Symposium, 891-900.

Mortaigne, B., Bellenger, V., Verdu, J. (1992). Polymer Networks and Blends, 2, $187-195$.

Mouritz, A.P. (2007). Durability of composites exposed to elevated temperature and fire. In: Durability of Composites for Civil Structural Applications, Karbhari, V.M. (ed.), Woodhead Publishing, Cambridge, UK, 98-125.

Mouritz, A.P., Gibson, A.G. (2006). Fire Properties of Polymer Composite Materials, Springer, Dordrecht, The Netherlands.

Müller-Plathe, F. (1994). Polymerica Acta, 45, 259-293. doi: 10.1002/ actp.1994.010450401

Nait-Ali, K.L., Colin, X., Bergeret, A. (2011). Polymer Degradation and Stability, 96, 236-246. doi : 10.1016/j.polymdegradstab.2010.11.004

Olivier, L., Baudet, C., Bertheau, D., Grandidier, J.-C., Lafarie-Frenot, M.-C. (2009). Composites: Part A: Applied Science and Manufacturing, 40, 1008-1016. doi:10.1016/j. compositesa.2008.04.015

Papazoglou, E.S. (2004). Flame retardants for plastics. In: Handbook of Building Materials for Fire Protection, Harper, C.A. (ed.), McGraw-Hill, New York Chapter 4.

Pascault, J.-P., Sautereau, H., Verdu, J., Williams, R.J.J. (2002). In: Thermosetting Polymers, Marcel Dekker, New York, Chapter 10, 282-321, and Chapter 14, 420-467.

Pitkethly, M.J., Favre, J.-P., Gaur, U., Jakubowski, J., Mudrich, S.F., Caldwell, D.L., Drzal, L.T., Nardin, M., Wagner, H.D., Di Landro, L., Hampe, A., Armistead, J.P., Desaeger, M., Verposet, I. (1993). Composites Science and Technology, 48, 205-214. doi:10.1016/0266-3538(93)90138-7

Rasoldier, N., Colin, X., Verdu, J., Bocquet, M., Olivier, L., Chocinski-Arnault, L., Lafarie-Frenot, M.-C. (2008). Composites: Part A: Applied Science and Manufacturing, 39, 1522-1529. doi:10.1016/j.compositesa.2008.05.016

Reich, L., Stivala, S.S. (1969). Autooxidation of Hydrocarbons and Polyolefins, Marcel Dekker, New York.

Richaud, E., Ferreira, P., Audouin, L., Colin, X., Verdu, J., Monchy-Leroy, C. (2010). European Polymer Journal, 46, 731-743. doi :10.1016/j.eurpolymj.2009.12.026

Robert, M., Cousin, P., Benmokrane, B. (2009). Durability of GFRP reinforcing bars embedded in moist concrete, Journal of Composites for Construction, 13, 66-73. doi: 10.1061/(ASCE)1090-0268(2009)13:2(66)

Rosen, M.R., Goddard, E.D. (1980). Polymer Engineering and Science, 20, 413-425. doi: $10.1002 /$ pen. 760200607

Roy, S., Singh, S. (2009). Composites Science and Technology, 69, 1962-1967. doi:10.1016/j.compscitech.2009.04.019

Saafi, M. (2002). Effect of fire on FRP reinforced concrete members, Composite Structures, 58, 11-20. doi:10.1016/S0263-8223(02)00045-4

Saito, O. (1958a). Journal of the Physical Society of Japan, 13, 198-206. doi: 10.1143/ JPSJ.13.198

Saito, O. (1958b). Journal of the Physical Society of Japan, 13, 1451-1464. doi: 10.1143/ JPSJ.13.1451 
Salmon, L., Thominette, F., Pays, M.-F., Verdu, J. (1997). Composites Science and Technology, 57, 1119-1127. doi:10.1016/S0266-3538(97)00038-9

Schradder, M.E., Block, A. (1971). Journal of Polymer Science: Part C: Polymer Symposia, 34, 281-291. doi: 10.1002/polc.5070340126

Schutte, L.L., McDonough, W., Shioya, M., Mcauliffe, M., Greenwood, M. (1994). Composites, 25, 617-624. doi:10.1016/0010-4361(94)90193-7

Seguchi, T., Arakawa, K., Hayakawa, W., Watanabe, Y., Kuryama, I. (1981). Radiation Physics and Chemistry, 17, 195-201. doi:10.1016/0146-5724(81)90331-9

Seguchi, T., Arakawa, K., Hayakawa, W., Watanabe, Y., Kuryama, I. (1982). Radiation Physics and Chemistry, 19, 321-327. doi:10.1016/0146-5724(82)90116-9

Semenov, N.N. (1935). Chemical Kinetics and Chain Reactions, Oxford University Press, London.

Shen, C.H., Springer, G.S. (1976). Journal of Composite Materials, 10, 2-20. doi:10.1177/002199837601000101

Smets, B.M.J. (1985). On the mechanism of the corrosion of glass by water, Philips Technical Review, 42, 59-64.

Sorathia, U. (2004). Materials in military applications. In: Handbook of Building Materials for Fire Protection, Harper, C.A. (ed.), McGraw-Hill, New York, Chapter 9.

Struik, L.C.E. (1978). Physical Ageing in Amorphous Polymers and Other Materials, Elsevier, Amsterdam.

Tavakkolizadeh, M., Saadatmanesh, H. (2001). Galvanic corrosion of carbon and steel in aggressive environments, Journal of Composites for Construction, 5, 200-210. doi:10.1061/(ASCE)1090-0268(2001)5:3(200)

Tcharkhtchi, A., Bronnec, Y., Verdu, J. (2000). Polymer, 41, 5777-5785. doi :10.1016/ S0032-3861(99)00801-0

Tewarson, A. (2007). Flammability. In: Physical Properties of Polymers Handbook, Mark, J. E. (ed.), Springer Science + Business Media, New York, 889-925.

Theocaris, P.S. (1987). The Mesophase Concept in Composites, Springer Verlag, Berlin (1987).

Thomason, J.L. (1990). Investigation of composite interphase using dynamic mechanical analysis: artifacts and reality, Polymer Composite, 11, 105-113. doi: 10.1002/ pc.750110206

Thominette, F., Gaudichet-Maurin, E., Verdu, J. (2006). In: Proceedings of the DSL 2006 Conference, Defect and Diffusion Forum, 258/260, 442-446.

Tiemblo, P., Guzman, J., Riande, E., Mijangos, C., Reinecke, H. (2001). Polymer, 42, 4817-4823. doi:10.1016/S0032-3861(00)00922-8

Triantafillou, T.C., Papanicolaou, C.G. (2006). Shear strengthening of reinforced concrete members with textile reinforced mortar (TRM) jackets, Materials and Structures, 39 , 93-103. doi: 10.1007/s11527-005-9034-3

Troitzsch, J. (2004). Plastics Flammability Handbook: Principles, Regulations, Testing and Approval (3rd edn), Carl Hanser Verlag, Munich, Germany.

Van Krevelen, D.W., Te Nijenhuis, K. (2009). Properties of Polymers. Their Estimation and Correlation with Chemical Structure (4th edn), Elsevier, Amsterdam, Chapter 18, 655-702.

Vasquez, A., Ambrustolo, M., Moschiar, S.M., Reboredo, M.M., Gerard, J.F. (1998). Interphase modification in unidirectional glass-fibre epoxy composites, Composite Science and Technology, 58, 549-558. doi:10.1016/S0266-3538(97)00172-3

Verdu, J., Rychly, J., Audouin, L. (2003). Synergism between polymer antioxidants. Kinetic modelling, Polymer Degradation and Stability, 79(3), 503-509. doi:10.1016/ S0141-3910(02)00366-X 
Whitney, J.-M., Browning, C.E. (1978). Advanced Composite Materials: Environmental Effects, ASTM STP 658, American Society for Testing and Materials, 43-60.

Woo, M., Piggot, M.R. (1988). Journal of Composites Technology and Research, 10, 20-24. doi: 10.1520/CTR10271J

Wypych, G. (2004). Handbook of Plasticizers, ChemTec Publishing, Toronto, Canada, $151-170$.

Zweifel, H. (2001). Plastics Additives Handbook (5th edn), Hanser Publishers, Munich, Germany. 